\title{
22q11.2 deletion syndrome: intelligence, psychopathology and neurochemistry at adult age
}

Citation for published version (APA):

Evers, L. J. M. (2015). 22q11.2 deletion syndrome: intelligence, psychopathology and neurochemistry at adult age. [Doctoral Thesis, Maastricht University]. Datawyse / Universitaire Pers Maastricht. https://doi.org/10.26481/dis.20151214le

Document status and date:

Published: 01/01/2015

DOI:

10.26481/dis.20151214le

Document Version:

Publisher's PDF, also known as Version of record

\section{Please check the document version of this publication:}

- A submitted manuscript is the version of the article upon submission and before peer-review. There can be important differences between the submitted version and the official published version of record.

People interested in the research are advised to contact the author for the final version of the publication, or visit the DOI to the publisher's website.

- The final author version and the galley proof are versions of the publication after peer review.

- The final published version features the final layout of the paper including the volume, issue and page numbers.

Link to publication

\footnotetext{
General rights rights.

- You may freely distribute the URL identifying the publication in the public portal. please follow below link for the End User Agreement:

www.umlib.nl/taverne-license

Take down policy

If you believe that this document breaches copyright please contact us at:

repository@maastrichtuniversity.nl

providing details and we will investigate your claim.
}

Copyright and moral rights for the publications made accessible in the public portal are retained by the authors and/or other copyright owners and it is a condition of accessing publications that users recognise and abide by the legal requirements associated with these

- Users may download and print one copy of any publication from the public portal for the purpose of private study or research.

- You may not further distribute the material or use it for any profit-making activity or commercial gain

If the publication is distributed under the terms of Article $25 \mathrm{fa}$ of the Dutch Copyright Act, indicated by the "Taverne" license above, 


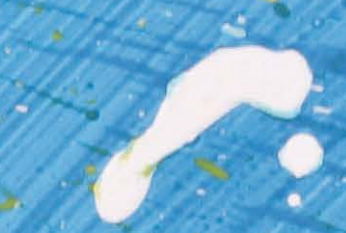

\section{2 -111.2 delefion syndrome}

intelligence, psychopathology -. and

neviochemistry at adult age

neviocher

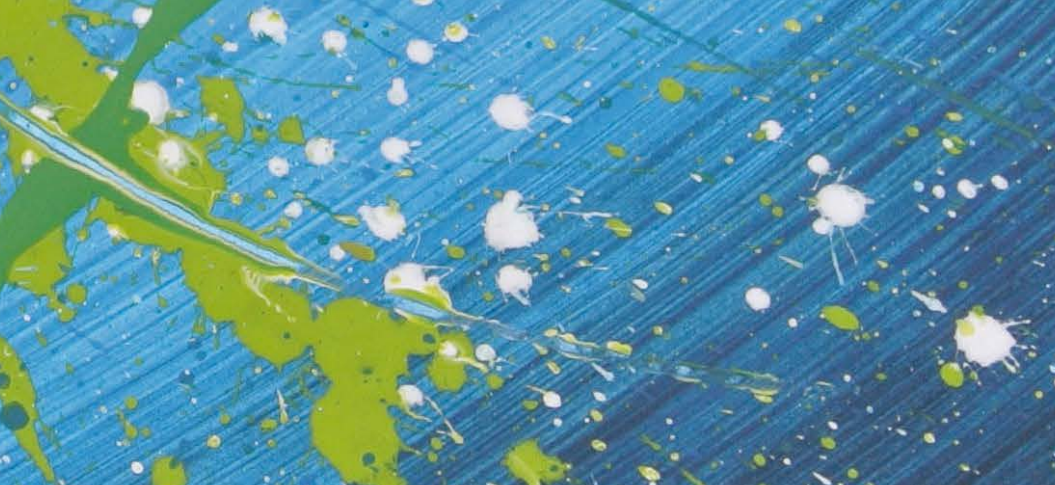

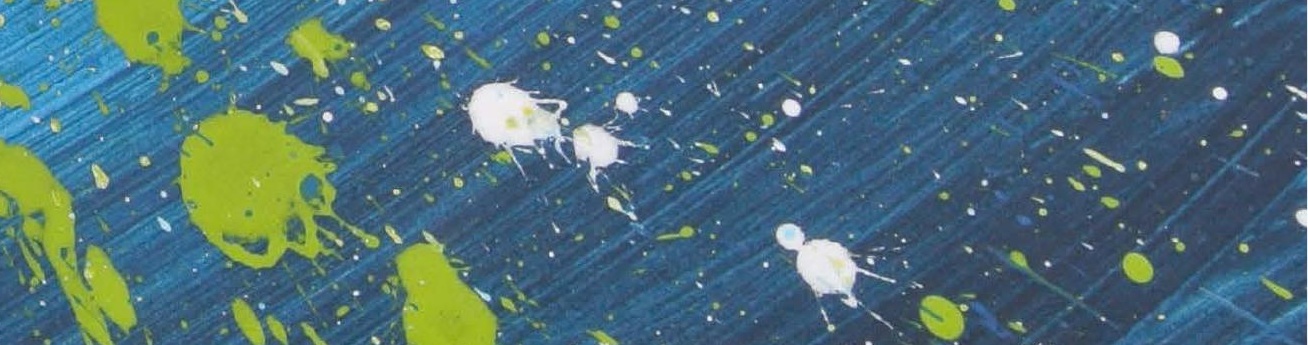

nus:

ifly 
The research presented in this thesis was conducted at the Governor Kremers Centre (GKC) and the Departments of Clinical Genetics and Psychiatry and Neuropsychology of Maastricht University Medical Centre $\left(\mathrm{MUMC}^{+}\right.$).

The studies presented in this dissertation were funded by Koraal Groep (www.koraalgroep.nl).
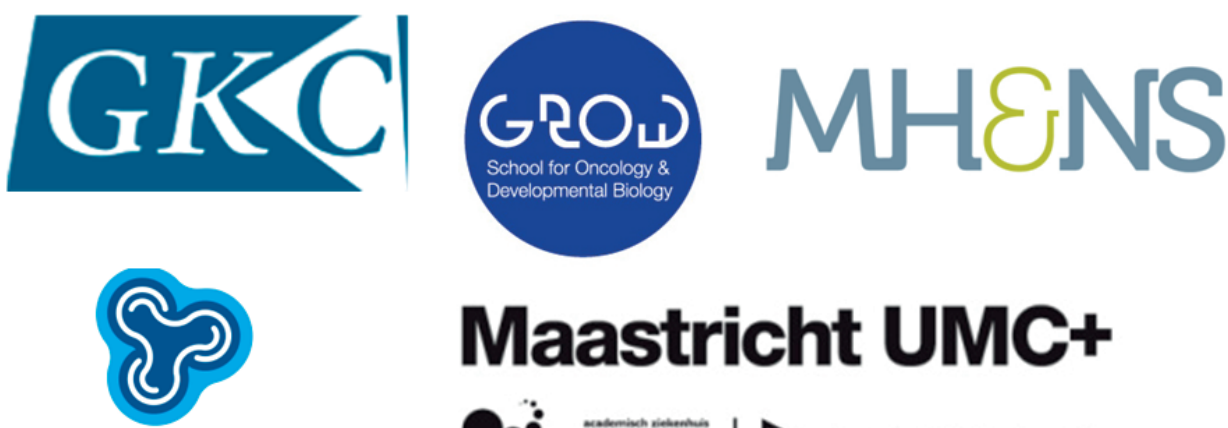

\section{Maastricht UMC+}

Koraal Groep

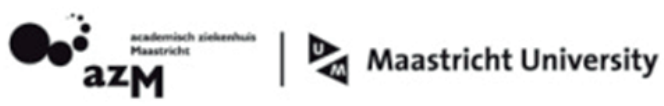

(C) Copyright Rens Evers, Heel 2015

ISBN 9789461594952

Omslagontwerp: Leanne Evers

Vormgeving omslag: Jules Evers

Production: Datawyse | Universitaire Pers Maastricht 


\title{
22q11.2 deletion syndrome Intelligence, psychopathology and neurochemistry at adult age
}

\author{
PROEFSCHRIFT \\ ter verkrijging van de graad van doctor \\ aan de universiteit Maastricht \\ op gezag van Rector Magnificus, Prof. Dr. L.L.G. Soete, \\ volgens het besluit van het College van Decanen, \\ in het openbaar te verdedigen \\ op maandag 14 december 2015 om 10:00 uur \\ door

\section{Rens Evers} \\ Geboren op 25 maart 1961 te Budel
}

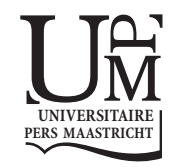




\section{Promotores}

Prof. dr. L.M.G. Curfs

Prof dr. T.A.M.J. van Amelsvoort

\section{Beoordelingscommissie}

Prof. Dr. C.T.R.M. Stumpel (voorzitter)

Prof. Dr. R.W.H.M. Ponds

Prof. Dr. A. Swillen (katholieke universiteit Leuven)

Dr. J.A.S. Vorstman (universiteit Utrecht) 
aan Toon Evers 



\section{Contents}

Chapter 1 Introduction 9

Chapter 2 Case studies in 22q11.2 deletion syndrome 27

2.1 The velocardiofacial syndrome in older age: dementia and 29 autistic features.

Genet Couns. 2006;17(3):333-40

2.2 The velo-cardio-facial syndrome: the spectrum of

psychiatric problems and cognitive deterioration at adult age.

Genet Couns. 2009;20(4):307-15.

Chapter 3 Psychopathology in adults with 22q11 deletion syndrome and moderate and severe intellectual disability.

J Intellect Disabil Res. 2014;58(10):915-25.

Chapter 4 The use of two different MLPA kits in 22q11.2 Deletion

Syndrome

Submitted

Chapter 5 Serotonergic, noradrenergic and dopaminergic markers are

related to cognitive function in adults with $22 \mathrm{q} 11$ deletion syndrome.

Int J Neuropsychopharmacol. 2014;17(8):1159-65.

Chapter 6 Glutamatergic markers, age, intellectual functioning and

psychosis in 22q11 deletion syndrome.

Psychopharmacology. 2015;232(18):3319-25.

Chapter 7 General discussion and conclusions

Summary

Samenvatting

Valorisation

Dankwoord

Curriculum Vitae

155

List of publication 

CHAPTER 1

INTRODUCTION 



\section{Introduction}

\section{Genetic disorders}

Many disorders have a genetic background. Single-gene disorders often follow Mendelian rules and are based on the absence or alteration of a single gene. An alteration of a single gene (base pair deletion, base pair insertion, or base pair substitution) can influence gene function. Besides single-gene variants, which are well known to contribute to variation in human diseases, large-scale genomic variants also make a great contribution to human health. These variants are caused by recurrent DNA rearrangements involving unstable genomic regions. Such chromosomal rearrangements are facilitated by the presence of region-specific low copy repeats (LCRs) and result in nonallelic homologous recombination (NAHR) between paralogous genomic segments (Stankiewicz \& Lupski, 2002). NAHR between directly oriented LCRs can generate microdeletions and microduplications of megabases in size. These large-scale variants are also called copy number variations (CNVs). CNVs exhibit variable copy numbers among individuals, comprising deletions, duplications, and insertions (Chen, Zhou, Zhang, \& Zhang, 2014). In recent years, there has been an increased attention to CNVs and the role they play in intellectual function, psychiatric disorders such as schizophrenia, and other neurodevelopmental disorders (Addington \& Rapoport, 2012; Schwab \& Wildenauer, 2013; Shishido, Aleksic, \& Ozaki, 2014). Overall, there is rapid progress in the development of new technologies, with microarray techniques as an example (Crotwell \& Hoyme, 2012).

\section{2q11.2 Deletion Syndrome}

One of the most common recurrent CNV disorders is $22 \mathrm{q} 11.2$ deletion syndrome (22q11DS), caused by a microdeletion on the long arm of chromosome 22 at position 11.2. It has an estimated population prevalence of 1:2000 (Fung, Butcher, Costain, Andrade, Boot, Chow,... Bassett, 2015; Shprintzen, 2008). Recently, Grati et al. (Grati, Molina Gomes, Ferreira, Dupont, Alesi, Gouas... Vialard, 2015) reported an incidence during pregnancy of more than 1:1000.

Though described as a microdeletion, the typically deleted region (in 70\%$80 \%$ of cases) is about $3 \mathrm{Mb}$ long (Hwang, Maar, Regan, Angkustsiri, Simon, \& Tassone, 2014; 1 megabase is the length for DNA fragments equal to 1 million nucleotides), and it contains at least 48 genes (Williams, 2011). The smaller, nested deletions of $1.5 \mathrm{Mb}$ (occurring in $10 \%-15 \%$ of cases) contain at least 28 genes (Williams, 2011). Atypical lengths of deletion can also occur (Shaikh, Kurahashi, \& Emanuel, 2001). Haplo-insufficiency of these genes has been thought to be partially responsible for the clinical symptoms associated with the syndrome. So far, there have been no reports that show a relation between deletion size and clinical 
phenotype (physical, cognitive, or psychiatric) (Bassett, McDonald-McGinn, Devriendt, Digilio, Goldenberg, Habel,.... Vorstman, 2011). The variability in symptomatology reflects the many names that were used in the past for the same disorder.

\section{History of 22q11.2 Deletion Syndrome}

In 1968, the immunologist DiGeorge described immunological problems together with parahypothyroidism, associated cardiovascular anomalies, and dysmorphic facies (DiGeorge, 1968; Conley, Beckwith, Mancer, \& Tenckhoff, 1979). Sedlačková, a phoniatrist, published 28 already-reported cases of patients with a short palate in 1955, which was later followed with an additional 20 cases (Sedlačková, 1967). Shprintzen introduced a multiple-anomaly syndrome with the name velo-cardiofacial syndrome (VCFS) (Shprintzen, Goldberg, Lewin, Sidoti, Berkman, Argamaso \& Young, 1978), and the syndrome was later named after him (Shprintzen's syndrome). Chromosome 22 had already been described in association with VCFS because of the discovery of chromosomal rearrangements at 22q11.2 (de la Chapelle, Herva, Koivisto, \& Aula, 1981; Greenberg, Gothelf, Glaser, Debbane, Frisch, Kotler, Weizman, \& Eliez, 1984). It became clear that there were similarities between the genetic abnormalities seen in DiGeorge syndrome and those seen in VCFS (Scambler, Kelly, Lindsay, Williamson, Goldberg, Shprintzen,... Burn, 1992). Several syndromes with different names (and described from different points of view, depending on the specialism by whom the patient was seen) were caused by the same $22 \mathrm{q} 11.2$ deletion. There is now a consensus that 22q11.2 deletion syndrome includes DiGeorge syndrome, VCFS, Shprintzen's syndrome, Sedlačková's syndrome, conotruncal anomalies face syndrome, Cayler syndrome, Takao syndrome, and CATCH22.

\section{Physical Features of 22q11DS}

The symptoms of 22q11DS are highly variable (Bassett, Chow, Husted, Weksberg, Caluseriu, Webb, \& Gatzoulis, 2005; Bassett et al., 2011; Cancrini, Puliafito, Digilio, Soresina, Martino, Rondelli,... Rossi, 2014; Fung et al., 2015; Kobrynski \& Sullivan, 2007; McDonald-McGinn \& Sullivan, 2011). The formerly used name, VCFS, is composed of the three key symptom clusters.

Palatal (velum) abnormalities are very common in 22q11DS (Bassett et al., 2011; Shprintzen, 2008). Between 71\% (McDonald-McGinn \& Sullivan, 2011) and $88 \%$ (Cohen, Chow, Weksberg, \& Bassett, 1999) of patients show velopharyngeal abnormalities, including cleft palate and velopharyngeal insufficiency.

Cardiac abnormalities affect 50\% to 75\% of patients with 22q11DS (Bassett et al., 2011; Cancrini et al., 2014; Kobrynski \& Sullivan, 2007; Matsuoka, Kimura, Scambler, Morrow, Imamura, Minoshima... Momma 1998). Cardiac abnormalities 
are the main cause of mortality (Kyburz, Bauersfeld, Schinzel, Riegel, Hug, Tomaske \& Valsangiacomo Buchel, 2008; Ryan, Goodship, Wilson, Philip, Levy, Seidel... Scambler, 1997). The most common cardiac abnormalities are Tetralogy of Fallot, pulmonary atresia, ventricular septal defect, persistent truncus arteriosus, interrupted aortic arch, ventricular septal defect, transposition of the great arteries, double-outlet right ventricle, and other cardiovascular defects (Bassett et al., 2011; Marino, Digilio, Toscano, Anaclerio, Giannotti, Feltri,... Dallapiccola., 2001; Marino, Digilio, Toscano, Giannotti, \& Dallapiccola, 1999; Matsuoka et al., 1998).

Facial features include minor dysmorphic abnormalities (Butts, 2009; McDonald-McGinn \& Sullivan, 2011). Typical appearances are pear shaped noses, flattened malar cheekbones, increased inner cantal distances, and decreased outer cantal distances resulting in small eyes. Simple-formed, rotated, and cupped ears are often seen.

In addition to the typical velo-cardio-facial symptoms, many other organ systems are affected (Fung et al., 2015). These effects can include haematological abnormalities (often thrombocytopenia; Rosa, Rosa, Dos Santos, Zen, \& Paskulin, 2011); anomalies of the urinary tract (Burtey, 2008), the vascular system (including haemorrhoids and varices), and the skeletal system (often spine deformities such as scoliosis) (Hamidi, Nabi, Husein, Mohamed, Tay, \& McKillop, 2014); and neurological problems such as seizures and early-onset Parkinson's disease (Boot, Butcher, van Amelsvoort, Lang, Marras, Pondal... Bassett, 2015; Butcher, Kiehl, Hazrati, Chow, Rogaeva, Lang, \& Bassett, 2013; Fung et al., 2015).

\section{Psychiatric Characteristics of 22q11DS}

Across the lifespan, 22q11DS is associated with a high prevalence of several psychiatric disorders (Fung et al., 2015; Schneider, Debbane, Bassett, Chow, Fung, van den Bree... Eliez, 2014). During childhood, high rates of anxiety disorders (Swillen, Devriendt, Legius, Eyskens, Dumoulin, Gewillig, \& Fryns, 1997; Swillen, Vandeputte, Cracco, Maes, Ghesquiere, Devriendt, \& Fryns, 1999), attention deficit (hyperactivity) disorders $(\mathrm{AD}(\mathrm{H}) \mathrm{D}$; (Goldberg, Motzkin, Marion, Scambler, \& Shprintzen, 1993; Niklasson, Rasmussen, Oskarsdottir, \& Gillberg, 2001; Schneider et al., 2014; Swillen et al., 1997; Swillen, Devriendt, Legius, Prinzie, Vogels, Ghesquiere \& Fryns, 1999), and autism spectrum disorders (ASD) are reported (Eliez, 2007; Niklasson, Rasmussen, Oskarsdottir, \& Gillberg, 2009; Vorstman, Morcus, Duijff, Klaassen, Heineman-de Boer, Beemer... van Engeland., 2006). In addition, a behavioural phenotype is described with social difficulties and social withdrawal (Swillen et al., 1999). Adult patients with 22q11DS are particularly prone to psychotic disorders (including schizophrenia) and mood disorders (Schneider et al., 2014; Yuen, Chow, Silversides, \& Bassett, 2013). 


\section{2q11DS as a Model for Psychotic Disorders?}

Prevalence rates of psychosis in 22q11DS are 20 to 25 times higher in 22q11DS compared to the general population, and about $1 \%$ to $2 \%$ of patients with schizophrenia are associated with 22q11DS (Squarcione, Torti, Di Fabio, \& Biondi, 2013). Because of the high prevalence rates of psychiatric disorders and the known genetic cause, 22q11DS is often seen as a unique genetic model to understand psychotic and other psychiatric disorders also more in generally (Monks, Niarchou, Davies, Walters, Williams, Owen,... Murphy 2014; Schneider et al., 2014). In no other genetic disorder is the risk for schizophrenia and psychosis as high as in 22q11DS (Squarcione et al., 2013). Several genes located at 22q11.2 have also been identified as candidate genes for schizophrenia, including COMT, PRODH, TBX1, ZDHHC8, and Gnb1L (Prasad, Howley, \& Murphy, 2008; Squarcione et al., 2013).

\section{Aetiology of Psychotic Disorders}

There are different models for the aetiology of psychotic disorders (Linscott \& van Os, 2010). These days, it is assumed that the onset of psychosis depends on two factors: 1) individual vulnerability and 2) experienced stress. This is called the stress-vulnerability model. The more vulnerable a person, the less stress is needed to elicit a psychosis. One's vulnerability is partly genetically determined. There have been many candidate genes identified, but the problem is that schizophrenia (most of the genetic research done uses schizophrenia as the prototype of psychotic disorders) as a concept is highly polygenic with a complex array of risk loci, many of which include genes that are also implicated in intellectual disability, ASD, bipolar disorder, and major depressive disorder (Escudero \& Johnstone, 2014). Other factors, such as pregnancy and nutritional deficiencies in early life, also seem to be important in determining vulnerability to psychotic disorders (Zammit, Lewis, Gunnell, \& Smith, 2007). For many years, the dopamine hypothesis of psychosis has been the dominant model (Howes \& Kapur, 2009). Dopaminergic neurotransmission plays a crucially important role in the treatment of psychosis, since all currently available antipsychotic drugs block dopamine D2 receptors and recreational drugs that enhance dopaminergic function, such as amphetamines and cocaine, can induce psychotic symptoms (Howes \& Kapur, 2009). The initial hyperdopaminergic hypothesis was adapted later on to a hypothesis in which regional differences in the human brain, specifically excessive dopamine levels in the striatum, mainly explain the positive symptoms and hypodopaminergia in the prefrontal cortex explains the negative symptomatology (Abi Dargham, 2004; Slifstein, van de Giessen, Van Snellenberg, Thompson, Narendran, Gil... Abi Dargham, 2015), even though the latter is still under debate (Kambeitz, Abi Dargham, Kapur, \& Howes, 2014). There is still insufficient in vivo evidence of altered dopaminergic function in cortical and extrastriatal regions that could explain negative or cogni- 
tive symptoms (Kambeitz et al., 2014). In favour of this doubt is the knowledge that the currently available antipsychotic drugs are not as effective as would be expected if dopamine were the only neurotransmitter involved in schizophrenia (Lally \& MacCabe, 2015). The role of glutamatergic neurotransmission in the aetiology of psychotic disorders has received an increased interest in addition to the existing dopaminergic theory. It is now hypothesised that an aberrant glutamatergic neurotransmission via hypofunctional NMDA receptors leads to increased prefrontal glutamatergic activity in schizophrenia, possibly contributing to negative of cognitive symptoms (Poels, Kegeles, Kantrowitz, Javitt, Lieberman, Abi Dargham, \& Girgis , 2014).

\section{Schizophrenia as a Cognitive Disorder}

Psychosis is a term that covers a broad spectrum of symptoms. Only a minority of those who experience psychotic symptoms develop the chronic disabling illness that we call schizophrenia (Poulton, Caspi, Moffitt, Cannon, Murray, \& Harrington, 2000). Bleuler, who introduced the term schizophrenia, mentioned cognitive defects as a fundamental symptom of schizophrenia (Parnas, 2011). Increasingly, schizophrenia is seen as a cognitive disorder characterised by relatively stable cognitive impairments (Green \& Nuechterlein, 1999; Kahn \& Keefe, 2013). Already at illness onset, there seem to be cognitive impairments (Bilder, Goldman, Robinson, Reiter, Bell, Bates,... Lieberman, 2000), and often these impairments are very disabling. Within the group of patients with schizophrenia, cognitive defects are not the same for every patient (Rund, 1998); no particular cognitive defect is unique for schizophrenia (Robbins, 2005). It is, however, questionable whether the very negative connotation that schizophrenia has is justified. There is a lively discussion about the schizophrenia concept (www.schizofreniebestaatniet.nl), and about whether schizophrenia is now a disabling disease for everyone or whether there is only a very poor prognosis for a minority of patients. Of the patients diagnosed with schizophrenia, $25 \%$ have a very poor long-term outcome, but there is evidence that cognitive functioning does not appear to deteriorate over time (Zipursky, Reilly, \& Murray, 2013). The cognitive problems patients with schizophrenia encounter are within the neurocognitive domain (processing speed, attention/vigilance, working memory, verbal learning and memory, visual learning and memory, reasoning and problem solving, and verbal comprehension are affected) and the social cognition domain (Fett, Viechtbauer, Dominguez, Penn, van Os, \& Krabbendam, 2011; Kahn \& Keefe, 2013).

\section{Intellectual Functioning in $22 q 11 D S$}

Like many genetic syndromes, 22q11DS is often accompanied with intellectual difficulties (Swillen et al., 1999). However, there are patients with 22q11DS who 
function at an average intelligence level (IQ > 85). De Smedt et al. (De Smedt, Devriendt, Fryns, Vogels, Gewillig, \& Swillen, 2007) reported a rate of $15 \%$ of children with an IQ $>85$. Most of the time, average IQ ranges from normal to moderately impaired (Moss, Batshaw, Solot, Gerdes, McDonald-McGinn, Driscoll,... Wang 1999; Swillen et al., 1997), with a mean of about 70 (Swillen et al., 1997). Although reported occasionally (Devriendt, Thienen, Swillen, \& Fryns, 1996; Iascone, Vittorini, Sacchelli, Spadoni, Simi, \& Giusti al., 2002; Kozma, 1998), moderate and severe intellectual disabilities were thought to be rare until recently (Swillen et al., 1997).

In children with 22q11DS, it is known that intelligence seems to decline with increasing age (Green, Gothelf, Glaser, Debbane, Frisch, Kotler... Eliez, 2009; Niklasson \& Gillberg, 2010), which seems to be driven by a decline in verbal IQ (VIQ) (Antshel, Shprintzen, Fremont, Higgins, Faraone, \& Kates., 2010; Gothelf, Penniman, Gu, Eliez, \& Reiss, 2007). Duijff et al. (Duijff, Klaassen, de Veye, Beemer, Sinnema, \& Vorstman, 2012;

Duijff et al. (Duijff, Klaassen, Swanenburg de Veye, Beemer, Sinnema, \& Vorstman, 2013) reported for the first time an intellectual decline in children between ages 5 and 9 (-9.7 IQ points) and ages 9.5 and 15.3 (-5.9 IQ points), with 32\% of them showing a decline of more than 10 Full Scale IQ (FSIQ) points (Duijff et al., 2013). Overall, the majority of studies have been carried out in children, and the literature on adult patients with 22q11DS is scarce. So far, a limited number of studies have been done on adults (Chow, Watson, Young, \& Bassett, 2006; Henry, van Amelsvoort, Morris, Owen, Murphy, \& Murphy, 2002; van Amelsvoort, Henry, Morris, Owen, Linszen, Murphy, \& Murphy, 2004). In these reports, 22q11DS subjects with schizophrenia did not differ significantly in FSIQ, Verbal IQ, and Performance IQ from 22q11DS patients without schizophrenia. These individuals, however, scored within several subprofiles poorer (visuoperceptual abilities, problem solving and planning and abstract and social thinking) than those without schizophrenia. Recently, the international 22q11.2 Brain Behavior Syndrome Consortium reported that in children, a cognitive decline precedes psychosis (Vorstman, Breetvelt, Duijff, Eliez, Schneider, Jalbrzikowski... Basset, 2015).

\section{Biological Markers for Psychosis and Cognitive Decline}

In a disorder with a known cause like 22q11DS, identifying biomarkers could be the beginning of understanding the underlying pathology of psychiatric disorders associated with this disorder (Williams, 2011). Potential biomarkers include indices of neurotransmitters, which can be measured in peripheral fluids such as urine and blood (Marc, Ailts, Campeau, Bull, \& Olson, 2011). Given the genetic makeup of 22q11DS with haplo-insufficiency of approximately 50 genes, some of which are closely involved in neurotransmitter metabolism, disruption of neurotransmitter systems in 22q11DS seems a plausible hypothesis (Williams, 2011). The gene for catechol-0-methyl-transferase (COMT) encodes for COMT, an enzyme responsible 
for several steps in the breakdown of the catecholamines dopamine, norepinephrine (noradrenaline), and epinephrine (adrenaline) (Armando, Papaleo, \& Vicari, 2012).

Dopamine is a catecholamine and acts as an important hormone and neurotransmitter in the human brain and body. In the brain, dopamine functions as a neurotransmitter, a molecule released by nerve cells to send signals to other neurons. Dopamine plays important roles in motor control, motivation, arousal, cognition, and reward-motivation, as well as a number of basic functions including lactation and sexual gratification (Schultz, 2007). Several important diseases of the nervous system are associated with dysfunctions of the dopaminergic system (Gardoni \& Bellone, 2015). Parkinson's disease, a degenerative condition causing tremors and motor impairment, has been related to the loss of dopamine-secreting neurons in the midbrain area called the substantia nigra (Fearnley \& Lees, 1991). Psychotic disorders are associated with disrupted dopaminergic activity, particularly in the striatum (Sumiyoshi, Kunugi, \& Nakagome, 2014). ADHD and restless legs syndrome (RLS) are also believed to be associated with abnormalities in dopaminergic neurotransmission (Schultz, 2007).

Boot et al. (Boot, Booij, Abeling, Meijer, da Silva Alves, Zinkstok... \& van Amelsvoort., 2011; Boot, Booij, Zinkstok, Abeling, de Haan, Baas,... \& van Amelsvoort, 2008; Boot, Booij, Zinkstok, Baas, Swillen, Owen... van Amelsvoort, 2011; Boot, Booij, Zinkstok, de Haan, Linszen, Baas, \& van Amelsvoort., 2010) are among the few who have investigated the dopaminergic system in 22q11DS. A disrupted peripheral dopaminergic neurotransmission was found; patients with 22q11DS had higher urinary dopamine levels and lower levels of the urinary and plasma dopamine metabolite HVA (Boot et al., 2008). In a single photon emission computed tomography (SPECT) study, it was demonstrated that 22q11DS does not affect striatal dopaminergic neurotransmission at baseline in the human brain (Boot et al., 2010); however, within the 22q11DS group, they found lower dopamine receptor binding availability in the striatum for the COMT-Met genotype compared to the COMT-Val genotype (Boot et al., 2011). In another study, a comparison was made between 22q11DS subjects with and without psychosis and the relation with COMT genotype (Boot et al., 2011). Individuals with schizophrenia were more often Val hemizygous. Norepinephrine (noradrenaline) is a catecholamine with multiple roles, including those as a hormone and a neurotransmitter. As a neurotransmitter, it is released by sympathetic nerve terminals. The effects are manifested in alertness, arousal, and influences on the reward system. Norepinephrine is released as a hormone by the adrenal glands and causes blood vessels to contract and increase the heart rate (Guyton \& Hall, 2006). In one of the aforementioned studies by Boot et al. (2008), norepinephrine and its metabolites were also a focus. In that study, no differences were found for norepinephrine or its metabolites at baseline and after dopamine depletion between 22q11DS and controls. 
The proline dehydrogenase (PRODH) gene is also located at 22q11.2 and encodes for the enzyme PRODH, which is responsible for the formation of glutamate out of proline, one of the twenty DNA-encoded amino acids. It is a nonessential amino acid (Hiramatsu, Cortiella, Marchini, Chapman, \& Young, 1994), which means the human body can synthesise it. High levels of proline (hyperprolinemia) have been associated with neuropsychiatric conditions (Wyse \& Netto, 2011), and experimental animal models of hyperprolinemic rats presented degenerative changes (Wyse \& Netto, 2011). Glutamic acid (glutamate) is also a nonessential amino acid. Glutamate is the major excitatory neurotransmitter and is probably involved in most aspects of normal brain functioning, including cognition, memory, and learning (Danbolt, 2001). Most of the glutamate is intracellular, and in this environment, it is considered to be nontoxic. However, extracellular glutamate is highly toxic, and it is therefore of importance that extracellular glutamate levels are kept low (Danbolt, 2001). Because of the proposed role of glutamate in the aetiology of psychosis and its cerebral toxicity, glutamate is an interesting biomarker in psychosis and cognition.

Another gene of potential interest at $22 \mathrm{q} 11.2$ is the SEPT5 gene, which codes for septin-5, a protein important for active membrane movement such as vesicle trafficking and exocytosis in nondividing cells as platelets and neurons (Bartsch, Sandrock, Lanza, Nurden, Hainmann, Pavlova... Zieger, 2011). Septin-5 is involved in 5-HT release in platelets (Dent, Kato, Peng, Martinez, Cattaneo, Poujol... Ware, 2002), and the majority of 5-HT in the body is transported by platelets (Anderson, Feibel, \& Cohen, 1987). Serotonin, or 5-hydroxytryptamine (5-HT), is a monoamine neurotransmitter. Biochemically derived from tryptophan, serotonin is primarily found in the gastrointestinal tract, platelets, and the central nervous system. It is thought to be a contributor to feelings of well-being and happiness and the regulation of mood, appetite, and sleep. Serotonin also modulates cognitive functions, including memory and learning, and regulates several somatic processes including cardiovascular function, bowel motility, ejaculatory latency, and bladder control (Berger, Gray, \& Roth, 2009).

\section{Aim and outline of this thesis}

The aim of this thesis is to contribute to a better understanding of 22q11DS. The first goal is to address moderate and severe intellectual disability in adults with 22q11DS, a topic that had been relatively neglected prior to the start of this study. The second goal is to explore biological factors that may be associated with intellectual function and psychopathology in 22q11DS. The factors investigated are the neurotransmitters dopamine, norepinephrine, and serotonin and the amino acids proline, glutamate, and glutamine. Finally, a study was performed to evaluate 
whether the length of the deletion was associated with the presence of psychiatric problems and intellectual functioning.

Chapter 1 gives an overview of the neurological and clinical symptoms of 22q11DS and the background of the topics studied in this thesis.

Chapter 2 consists of two case studies. The first article describes a case and was actually the inspiration for the work described in this thesis. The second article in this chapter is a case series of seven patients with moderate to severe intellectual impairment.

Chapter 3 presents the results of a study evaluating the behaviour, psychiatric symptoms, and intellectual functioning of 33 adult 22q11DS patients with FSIQ < 55.

Chapter 4 reports the use of the Multiplex Ligation-dependent Probe Amplification (MLPA) method with different MLPA kits to determine the length of the deletion and to compare the length of deletion with intellectual function and psychiatric features.

Chapter 5 presents the exploration of the relation between peripheral concentrations of the neurotransmitters dopamine, norepinephrine, and serotonin and intellectual functioning, psychiatric features, and age.

Chapter 6 shows the results of the exploration of the relation between peripheral concentrations of proline, glutamate, and glutamine and intellectual functioning, psychiatric features, and age.

Chapter 7 consists of a general discussion in which the overall results of the studies are presented in light of the present literature. Recommendations for future research as well as reflections on implications for clinical practice are addressed.

Chapter 8 contains English and Dutch summaries of the results of this thesis. 


\section{References}

Abi Dargham, A. (2004). Do we still believe in the dopamine hypothesis? New data bring new evidence. Int J Neuropsychopharmacol, 7 Suppl 1, S1-5.

Addington, A.M., \& Rapoport, J.L. (2012). Annual research review: impact of advances in genetics in understanding developmental psychopathology. J Child Psychol Psychiatry, 53(5), 510-518.

Anderson, G.M., Feibel, F.C., \& Cohen, D.J. (1987). Determination of serotonin in whole blood, plateletrich plasma, platelet-poor plasma and plasma ultrafiltrate. Life Sci, 40(11), 1063-1070.

Antshel, K.M., Shprintzen, R., Fremont, W., Higgins, A.M., Faraone, S.V., \& Kates, W.R. (2010). Cognitive and psychiatric predictors to psychosis in velocardiofacial syndrome: a 3-year follow-up study. $\mathrm{JAm}$ Acad Child Adolesc Psychiatry, 49(4), 333-344.

Armando, M., Papaleo, F., \& Vicari, S. (2012). COMT implication in cognitive and psychiatric symptoms in chromosome 22q11 microdeletion syndrome: a selective review. CNS Neurol Disord Drug Targets, 11(3), 273-281.

Bartsch, I., Sandrock, K., Lanza, F., Nurden, P., Hainmann, I., Pavlova, A., Greinacher A., Tacke U., Barth M., Busse A., Oldenburg J., Bommer M., Strahm B., Superti-Furga A.,\& Zieger, B. (2011). Deletion of human GP1BB and SEPT5 is associated with Bernard-Soulier syndrome, platelet secretion defect, polymicrogyria, and developmental delay. Thromb Haemost, 106(3), 475-483.

Bassett, A.S., Chow, E.W., Husted, J., Weksberg, R., Caluseriu, O., Webb, G.D., \& Gatzoulis, M.A. (2005). Clinical features of 78 adults with 22q11 Deletion Syndrome. Am J Med Genet A., 138(4), 307-313.

Bassett, A.S., McDonald-McGinn, D.M., Devriendt, K., Digilio, M.C., Goldenberg, P., Habel, A., Marino B, Oskarsdottir S, Philip N, Sullivan K, Swillen A, Vorstman J; International 22q11.2 Deletion Syndrome Consortium (2011). Practical guidelines for managing patients with 22q11.2 deletion syndrome. $J$ Pediatr, 159(2), 332-339 e331.

Berger, M., Gray, J.A., \& Roth, B.L. (2009). The expanded biology of serotonin. Annu Rev Med, 60, 355366.

Bilder, R.M., Goldman, R.S., Robinson, D., Reiter, G., Bell, L., Bates, J.A., Pappadopulos E, Willson D.F., Alvir J.M., Woerner M.G., Geisler S., Kane J.M., \& Lieberman, J.A. (2000). Neuropsychology of first-episode schizophrenia: initial characterization and clinical correlates. Am J Psychiatry, 157(4), 549-559.

Boot, E., Booij, J., Abeling, N., Meijer, J., da Silva Alves, F., Zinkstok, J., Baas F, Linszen D \& van Amelsvoort, T. (2011). Dopamine metabolism in adults with 22q11 deletion syndrome, with and without schizophrenia--relationship with $\operatorname{COMT} \operatorname{Val}(1)(0)(8) /(1)(5)(8) M e t$ polymorphism, gender and symptomatology. J Psychopharmacol, 25(7), 888-895.

Boot, E., Booij, J., Zinkstok, J., Abeling, N., de Haan, L., Baas, F., Linszen, D. \& van Amelsvoort, T. (2008). Disrupted dopaminergic neurotransmission in 22q11 deletion syndrome. Neuropsychopharmacology, 33(6), 1252-1258.

Boot, E., Booij, J., Zinkstok, J. R., Baas, F., Swillen, A., Owen, M. J., Murphy D.G., Murphy K.C., Linszen D.H., \& Van Amelsvoort, T. A. (2011). COMT Val(158) met genotype and striatal $\mathrm{D}(2 / 3)$ receptor binding in adults with 22q11 deletion syndrome. Synapse, 65(9), 967-970.

Boot, E., Booij, J., Zinkstok, J.R., de Haan, L., Linszen, D.H., Baas, F., \& van Amelsvoort, T.A. (2010). Striatal $\mathrm{D}(2)$ receptor binding in 22q11 deletion syndrome: an [(1)(2)(3)I]IBZM SPECT study. J Psychopharmacol, 24(10), 1525-1531.

Boot, E., Butcher, N.J., van Amelsvoort, T.A., Lang, A. E., Marras, C., Pondal, M., Andrade D.M., Fung W.L., \& Bassett, A.S. (2015). Movement disorders and other motor abnormalities in adults with 22q11.2 deletion syndrome. Am J Med Genet A, 167a(3), 639-645.

Burtey, S. (2008). 22q11.2 microdeletion syndrome is a common cause of renal tract malformations. Nature clinical practice. Nephrology, 4(8), E1.

Butcher, N.J., Kiehl, T.R., Hazrati, L.N., Chow, E.W., Rogaeva, E., Lang, A.E., \& Bassett, A.S. (2013). Association between early-onset Parkinson disease and 22q11.2 deletion syndrome: identification of a novel genetic form of Parkinson disease and its clinical implications. JAMA neurology, 70(11), 13591366.

Butts, S.C. (2009). The facial phenotype of the velo-cardio-facial syndrome. Int J Pediatr Otorhinolaryngol, 73(3), 343-350. 
Cancrini, C., Puliafito, P., Digilio, M.C., Soresina, A., Martino, S., Rondelli, R., Consolini R, Ruga, E.M., Cardinale, F., Finocchi, A., Romiti, M.L., Martire, B., Bacchetta, R., Albano, V., Carotti, A., Specchia, F., Montin, D., Cirillo, E., Cocchi, G., Trizzino, A., Bossi, G., Milanesi, O., Azzari, C., Corsello, G., Pignata, C., Aiuti, A., Pietrogrande, M.C., Marino, B., Ugazio, A.G., Plebani A., Rossi, P.; Italian Network for Primary Immunodeficiencies. (2014). Clinical features and follow-up in patients with 22q11.2 deletion syndrome. J Pediatr, 164(6), 1475-1480 e1472.

Chen, L., Zhou, W., Zhang, L., \& Zhang, F. (2014). Genome architecture and its roles in human copy number variation. Genomics Inform, 12(4), 136-144.

Chow, E.W., Watson, M., Young, D.A., \& Bassett, A.S. (2006). Neurocognitive profile in 22q11 deletion syndrome and schizophrenia. Schizophr Res, 87(1-3), 270-278.

Cohen, E., Chow, E.W., Weksberg, R., \& Bassett, A.S. (1999). Phenotype of adults with the 22q11 deletion syndrome: A review. Am J Med Genet, 86(4), 359-365.

Conley, M.E., Beckwith, J.B., Mancer, J.F., \& Tenckhoff, L. (1979). The spectrum of the DiGeorge syndrome.J Pediatr, 94(6), 883-890.

Crotwell, P.L., \& Hoyme, H.E. (2012). Advances in whole-genome genetic testing: from chromosomes to microarrays. Curr Probl Pediatr Adolesc Health Care, 42(3), 47-73.

Danbolt, N.C. (2001). Glutamate uptake. Prog Neurobiol, 65(1), 1-105.

de la Chapelle, A., Herva, R., Koivisto, M., \& Aula, P. (1981). A deletion in chromosome 22 can cause DiGeorge syndrome. Hum Genet, 57(3), 253-256.

De Smedt, B., Devriendt, K., Fryns, J.P., Vogels, A., Gewillig, M., \& Swillen, A. (2007). Intellectual abilities in a large sample of children with Velo-Cardio-Facial Syndrome: an update. J Intellect Disabil Res, 51(Pt 9), 666-670.

Dent, J., Kato, K., Peng, X.R., Martinez, C., Cattaneo, M., Poujol, C., Nurden, P., Nurden, A., Trimble, W.S. \& Ware, J. (2002). A prototypic platelet septin and its participation in secretion. Proc Natl Acad Sci US $A, 99(5), 3064-3069$.

Devriendt, K., Thienen, M.N., Swillen, A., \& Fryns, J.P. (1996). Cerebellar hypoplasia in a patient with velo-cardio-facial syndrome. Dev Med Child Neurol, 38(10), 949-953.

DiGeorge, A.M. (1968). Congenital absence of the thymus and its immunologic consequences: occurence wit congenital hypoparathyroidism. Birth Defects Original Article Series, 4(1), 116-121.

Duijff, S.N., Klaassen, P.W., de Veye, H.F., Beemer, F.A., Sinnema, G., \& Vorstman, J.A. (2012). Cognitive development in children with 22q11.2 deletion syndrome. Br J Psychiatry, 200(6), 462-468.

Duijff, S.N., Klaassen, P.W., Swanenburg de Veye, H.F., Beemer, F.A., Sinnema, G., \& Vorstman, J.A. (2013). Cognitive and behavioral trajectories in 22q11DS from childhood into adolescence: a prospective 6year follow-up study. Res Dev Disabil., 34(9), 2937-2945.

Eliez, S. (2007). Autism in children with 22q11.2 deletion syndrome. J Am Acad Child Adolesc Psychiatry, 46(4), 433-434; author reply 434-434.

Escudero, I., \& Johnstone, M. (2014). Genetics of schizophrenia. Curr Psychiatry Rep, 16(11), 502.

Fearnley, J.M., \& Lees, A.J. (1991). Ageing and Parkinson's disease: substantia nigra regional selectivity. Brain, 114 ( Pt 5), 2283-2301.

Fett, A.K., Viechtbauer, W., Dominguez, M.D., Penn, D.L., van Os, J., \& Krabbendam, L. (2011). The relationship between neurocognition and social cognition with functional outcomes in schizophrenia: a meta-analysis. Neurosci Biobehav Rev, 35(3), 573-588.

Fung, W.L., Butcher, N.J., Costain, G., Andrade, D.M., Boot, E., Chow, E.W., Chung, B., Cytrynbaum, C., Faghfoury, H., Fishman, L., García-Miñaúr, S., George, S., Lang, A.E., Repetto, G., Shugar, A., Silversides, C., Swillen, A., van Amelsvoort, T., McDonald-McGinn, D.M. \& Bassett, A.S. (2015). Practical guidelines for managing adults with 22q11.2 deletion syndrome. Genet, 17(8):599-609.

Gardoni, F., \& Bellone, C. (2015). Modulation of the glutamatergic transmission by Dopamine: a focus on Parkinson, Huntington and Addiction diseases. Front Cell Neurosci, 9, 25.

Goldberg, R., Motzkin, B., Marion, R., Scambler, P.J., \& Shprintzen, R.J. (1993). Velo-cardio-facial syndrome: a review of 120 patients. Am J Med Genet, 45(3), 313-319.

Gothelf, D., Penniman, L., Gu, E., Eliez, S., \& Reiss, A.L. (2007). Developmental trajectories of brain structure in adolescents with 22q11.2 deletion syndrome: a longitudinal study. Schizophr Res, 96(1-3), 72-81. 
Grati, F.R., Molina Gomes, D., Ferreira, J.C., Dupont, C., Alesi, V., Gouas, L., Horelli-Kuitunen, N., Choy, K.W., García-Herrero, S., de la Vega, A.G., Piotrowski, K., Genesio, R., Queipo, G., Malvestiti, B., Hervé, B., Benzacken, B., Novelli, A., Vago, P., Piippo, K., Leung, T.Y., Maggi, F., Quibel, T., Tabet, A.C., Simoni, G. \& Vialard, F. (2015). Prevalence of recurrent pathogenic microdeletions and microduplications in over 9,500 pregnancies. Prenat Diagn. 35(8):801-9

Green, M.F., \& Nuechterlein, K.H. (1999). Should schizophrenia be treated as a neurocognitive disorder? Schizophr Bull, 25(2), 309-319.

Green, T., Gothelf, D., Glaser, B., Debbane, M., Frisch, A., Kotler, M., Weizman, A. \& Eliez, S. (2009). Psychiatric disorders and intellectual functioning throughout development in velocardiofacial (22q11.2 deletion) syndrome. J Am Acad Child Adolesc Psychiatry, 48(11), 1060-1068.

Greenberg, F., Crowder, W.E., Paschall, V., Colon-Linares, J., Lubianski, B., \& Ledbetter, D.H. (1984). Familial DiGeorge syndrome and associated partial monosomy of chromosome 22. Hum Genet, 65(4), 317-319.

Guyton, A.C., \& Hall, J. (2006). Textbook of Medical Physiology (11th ed.). Philadelphia, Pennsylvania: Elsevier Inc.

Hamidi, M., Nabi, S., Husein, M., Mohamed, M.E., Tay, K.Y., \& McKillop, S. (2014). Cervical spine abnormalities in 22q11.2 deletion syndrome. Cleft Palate Craniofac J, 51(2), 230-233.

Henry, J.C., van Amelsvoort, T., Morris, R.G., Owen, M.J., Murphy, D.G., \& Murphy, K.C. (2002). An investigation of the neuropsychological profile in adults with velo-cardio-facial syndrome (VCFS). Neuropsychologia, 40(5), 471-478.

Hiramatsu, T., Cortiella, J., Marchini, J.S., Chapman, T.E., \& Young, V.R. (1994). Plasma proline and leucine kinetics: response to $4 \mathrm{wk}$ with proline-free diets in young adults. Am J Clin Nutr, 60(2), 207215.

Howes, O.D., \& Kapur, S. (2009). The dopamine hypothesis of schizophrenia: version III--the final common pathway. Schizophr Bull, 35(3), 549-562.

Hwang, V.J., Maar, D., Regan, J., Angkustsiri, K., Simon, T.J., \& Tassone, F. (2014). Mapping the deletion endpoints in individuals with 22q11.2 deletion syndrome by droplet digital PCR. BMC Med Genet, $15,106$.

Iascone, M.R., Vittorini, S., Sacchelli, M., Spadoni, I., Simi, P., \& Giusti, S. (2002). Molecular characterization of 22q11 deletion in a three-generation family with maternal transmission. Am J Med Genet, 108(4), 319-321.

Kahn, R.S., \& Keefe, R.S. (2013). Schizophrenia is a cognitive illness: time for a change in focus. JAMA Psychiatry, 70(10), 1107-1112.

Kambeitz, J., Abi Dargham, A., Kapur, S., \& Howes, O.D. (2014). Alterations in cortical and extrastriatal subcortical dopamine function in schizophrenia: systematic review and meta-analysis of imaging studies. Br J Psychiatry, 204(6), 420-429.

Kobrynski, L.J., \& Sullivan, K.E. (2007). Velocardiofacial syndrome, DiGeorge syndrome: the chromosome 22q11.2 deletion syndromes. Lancet, 370(9596), 1443-1452.

Kozma, C. (1998). On cognitive variability in velocardiofacial syndrome: profound mental retardation and autism. Am J Med Genet, 81(3), 269-270.

Kyburz, A., Bauersfeld, U., Schinzel, A., Riegel, M., Hug, M., Tomaske, M., \& Valsangiacomo Buchel, E.R. (2008). The fate of children with microdeletion 22q11.2 syndrome and congenital heart defect: clinical course and cardiac outcome. Pediatr Cardiol, 29(1), 76-83.

Lally, J., \& MacCabe, J.H. (2015). Antipsychotic medication in schizophrenia: a review. Br Med Bull, 114(1), 169-179.

Linscott, R.J., \& van Os, J. (2010). Systematic reviews of categorical versus continuum models in psychosis: evidence for discontinuous subpopulations underlying a psychometric continuum. Implications for DSM-V, DSM-VI, and DSM-VII. Annu Rev Clin Psychol, 6, 391-419.

Marc, D.T., Ailts, J.W., Campeau, D.C., Bull, M.J., \& Olson, K.L. (2011). Neurotransmitters excreted in the urine as biomarkers of nervous system activity: validity and clinical applicability. Neurosci Biobehav Rev, 35(3), 635-644. 
Marino, B., Digilio, M.C., Toscano, A., Anaclerio, S., Giannotti, A., Feltri, C., de Ioris, M.A., Angioni, A. \& Dallapiccola, B. (2001). Anatomic patterns of conotruncal defects associated with deletion $22 \mathrm{q} 11$. Genet Med, 3(1), 45-48.

Marino, B., Digilio, M.C., Toscano, A., Giannotti, A., \& Dallapiccola, B. (1999). Congenital heart defects in patients with DiGeorge/velocardiofacial syndrome and del22q11. Genet Couns, 10(1), 25-33.

Matsuoka, R., Kimura, M., Scambler, P.J., Morrow, B.E., Imamura, S., Minoshima, S., Shimizu, N., Yamagishi, H., Joh-o, K., Watanabe, S., Oyama, K., Saji, T., Ando, M., Takao, A., \& Momma, K. (1998). Molecular and clinical study of 183 patients with conotruncal anomaly face syndrome. Hum Genet, 103(1), 70-80.

McDonald-McGinn, D.M., \& Sullivan, K.E. (2011). Chromosome 22q11.2 deletion syndrome (DiGeorge syndrome/velocardiofacial syndrome). Medicine, 90(1), 1-18.

Monks, S., Niarchou, M., Davies, A.R., Walters, J.T., Williams, N., Owen, M.J., van de Bree, M.B., \& Murphy, K.C. (2014). Further evidence for high rates of schizophrenia in 22q11.2 deletion syndrome. Schizophr Res, 153(1-3), 231-236.

Moss, E.M., Batshaw, M.L., Solot, C.B., Gerdes, M., McDonald-McGinn, D.M., Driscoll, D.A., Emanuel, B.S., Zackai, E.H, \& Wang, P.P. (1999). Psychoeducational profile of the 22q11.2 microdeletion: A complex pattern. J Pediatr, 134(2), 193-198.

Niklasson, L., \& Gillberg, C. (2010). The neuropsychology of 22q11 deletion syndrome. A neuropsychiatric study of 100 individuals. Res Dev Disabil., 31(1), 185-194.

Niklasson, L., Rasmussen, P., Oskarsdottir, S., \& Gillberg, C. (2001). Neuropsychiatric disorders in the 22q11 deletion syndrome. Genet Med, 3(1), 79-84.

Niklasson, L., Rasmussen, P., Oskarsdottir, S., \& Gillberg, C. (2009). Autism, ADHD, mental retardation and behavior problems in 100 individuals with 22q11 deletion syndrome. Res Dev Disabil., 30(4), 763-773.

Parnas, J. (2011). A disappearing heritage: the clinical core of schizophrenia. Schizophr Bull, 37(6), 1121-1130.

Poels, E.M., Kegeles, L.S., Kantrowitz, J.T., Javitt, D.C., Lieberman, J.A., Abi Dargham, A., \& Girgis, R.R. (2014). Glutamatergic abnormalities in schizophrenia: a review of proton MRS findings. Schizophr Res, 152(2-3), 325-332.

Poulton, R., Caspi, A., Moffitt, T.E., Cannon, M., Murray, R., \& Harrington, H. (2000). Children's selfreported psychotic symptoms and adult schizophreniform disorder: a 15-year longitudinal study. Arch Gen Psychiatry, 57(11), 1053-1058.

Prasad, S.E., Howley, S., \& Murphy, K.C. (2008). Candidate genes and the behavioral phenotype in 22q11.2 deletion syndrome. Dev Disabil Res Rev, 14(1), 26-34.

Robbins, T.W. (2005). Synthesizing schizophrenia: a bottom-up, symptomatic approach. Schizophr Bull, 31(4), 854-864.

Rosa, R.F., Rosa, R.C., Dos Santos, P.P., Zen, P.R., \& Paskulin, G.A. (2011). Hematological abnormalities and 22q11.2 deletion syndrome. Revista brasileira de hematologia e hemoterapia, 33(2), 151-154.

Rund, B.R. (1998). A review of longitudinal studies of cognitive functions in schizophrenia patients. Schizophr Bull, 24(3), 425-435.

Ryan, A.K., Goodship, J.A., Wilson, D.I., Philip, N., Levy, A., Seidel, H., Schuffenhauer, S., Oechsler, H., Belohradsky, B., Prieur, M., Aurias, A., Raymond, F.L., Clayton-Smith, J., Hatchwell, E., McKeown, C., Beemer, F.A., Dallapiccola, B., Novelli, G., Hurst, J.A., Ignatius, J., Green, A.J., Winter, R.M., Brueton, L., Brøndum-Nielsen, K. \& Scambler, P.J.(1997). Spectrum of clinical features associated with interstitial chromosome 22q11 deletions: a European collaborative study. J Med Genet, 34(10), 798-804.

Scambler, P.J., Kelly, D., Lindsay, E., Williamson, R., Goldberg, R., Shprintzen, R., Wilson, D.I., Goodship, J.A., Cross, I.E. \& Burn, J. (1992). Velo-cardio-facial syndrome associated with chromosome 22 deletions encompassing the DiGeorge locus. Lancet, 339(8802), 1138-1139. 
Schneider, M., Debbane, M., Bassett, A.S., Chow, E.W., Fung, W.L., van den Bree, M., Owen, M., Murphy, K.C., Niarchou, M., Kates, W.R., Antshel, K.M., Fremont, W., McDonald-McGinn, D.M., Gur, R.E., Zackai, E.H., Vorstman, J., Duijff, S.N., Klaassen, P.W., Swillen, A., Gothelf, D., Green, T., Weizman, A., Van Amelsvoort, T., Evers, L., Boot, E., Shashi, V., Hooper, S.R., Bearden, C.E., Jalbrzikowski, M., Armando, M., Vicari, S., Murphy, D.G., Ousley, O., Campbell, L.E., Simon, T.J., Eliez, S.; International Consortium on Brain and Behavior in 22q11.2 Deletion Syndrome. (2014). Psychiatric disorders from childhood to adulthood in 22q11.2 deletion syndrome: results from the International Consortium on Brain and Behavior in 22q11.2 Deletion Syndrome. Am J Psychiatry, 171(6), 627-639.

Schultz, W. (2007). Multiple dopamine functions at different time courses. Annu Rev Neurosci, 30, 259288.

Schwab, S.G., \& Wildenauer, D.B. (2013). Genetics of psychiatric disorders in the GWAS era: an update on schizophrenia. Eur Arch Psychiatry Clin Neurosci, 263 Suppl 2, S147-154.

Sedlackova, E. (1967). The syndrome of the congenitally shortened velum. The dual innervation of the soft palate. Folia Phoniatr, 19(6), 441-450.

Shaikh, T.H., Kurahashi, H., \& Emanuel, B.S. (2001). Evolutionarily conserved low copy repeats (LCRs) in 22q11 mediate deletions, duplications, translocations, and genomic instability: an update and literature review. Genet Med, 3(1), 6-13.

Shishido, E., Aleksic, B., \& Ozaki, N. (2014). Copy-number variation in the pathogenesis of autism spectrum disorder. Psychiatry Clin Neurosci, 68(2), 85-95.

Shprintzen, R.J. (2008). Velo-cardio-facial syndrome: 30 Years of study. Dev Disabil Res Rev, 14(1), 3-10.

Shprintzen, R.J., Goldberg, R.B., Lewin, M.L., Sidoti, E.J., Berkman, M.D., Argamaso, R.V., \& Young, D. (1978). A new syndrome involving cleft palate, cardiac anomalies, typical facies, and learning disabilities: velo-cardio-facial syndrome. Cleft Palate J, 15(1), 56-62.

Slifstein, M., van de Giessen, E., Van Snellenberg, J., Thompson, J.L., Narendran, R., Gil, R., Hackett, E., Girgis, R., Ojeil, N., Moore, H., D'Souza, D., Malison, R.T., Huang, Y., Lim, K., Nabulsi, N., Carson, R.E., Lieberman, J.A., \& Abi Dargham, A. (2015). Deficits in Prefrontal Cortical and Extrastriatal Dopamine Release in Schizophrenia: A Positron Emission Tomographic Functional Magnetic Resonance Imaging Study. JAMA Psychiatry, 72(4):316-24.

Squarcione, C., Torti, M.C., Di Fabio, F., \& Biondi, M. (2013). 22q11 deletion syndrome: a review of the neuropsychiatric features and their neurobiological basis. Neuropsychiatr Dis Treat, 9, 1873-1884.

Stankiewicz, P., \& Lupski, J.R. (2002). Genome architecture, rearrangements and genomic disorders. Trends Genet, 18(2), 74-82.

Sumiyoshi, T., Kunugi, H., \& Nakagome, K. (2014). Serotonin and dopamine receptors in motivational and cognitive disturbances of schizophrenia. Front Neurosci, 8, 395.

Swillen, A., Devriendt, K., Legius, E., Eyskens, B., Dumoulin, M., Gewillig, M., \& Fryns, J.P. (1997). Intelligence and psychosocial adjustment in velocardiofacial syndrome: a study of 37 children and adolescents with VCFS. Journal of medical genetics, 34(6), 453-458.

Swillen, A., Devriendt, K., Legius, E., Prinzie, P., Vogels, A., Ghesquiere, P., \& Fryns, J.P. (1999). The behavioural phenotype in velo-cardio-facial syndrome (VCFS): from infancy to adolescence. Genet couns, $10(1), 79-88$.

Swillen, A., Vandeputte, L., Cracco, J., Maes, B., Ghesquiere, P., Devriendt, K., \& Fryns, J.P. (1999). Neuropsychological, learning and psychosocial profile of primary school aged children with the velocardio-facial syndrome (22q11 deletion): evidence for a nonverbal learning disability? Child Neuropsychol, 5(4), 230-241.

van Amelsvoort, T., Henry, J., Morris, R., Owen, M., Linszen, D., Murphy, K., \& Murphy, D. (2004). Cognitive deficits associated with schizophrenia in velo-cardio-facial syndrome. Schizophr Res, 70(2-3), 223-232. 
Vorstman, J.A., Breetvelt, E.J., Duijff, S.N., Eliez, S., Schneider, M., Jalbrzikowski, M., Armando, M., Vicari, S., Shashi, V., Hooper, S.R., Chow, E.W., Fung, W.L., Butcher, N.J., Young, D.A., McDonald-McGinn, D.M., Vogels, A., van Amelsvoort, T., Gothelf, D., Weinberger, R., Weizman, A., Klaassen, P.W., Koops, S., Kates, W.R., Antshel, K.M., Simon, T.J., Ousley, O.Y., Swillen, A., Gur, R.E., Bearden, C.E., Kahn, R.S., Bassett, A.S.; International Consortium on Brain and Behavior in 22q11.2 Deletion Syndrome. (2015). Cognitive Decline Preceding the Onset of Psychosis in Patients With 22q11.2 Deletion Syndrome. JAMA Psychiatry, 72(4):377-85.

Vorstman, J.A., Morcus, M.E., Duijff, S.N., Klaassen, P.W., Heineman-de Boer, J.A., Beemer, F.A., Swaab, H., Kahn, R.S. \& van Engeland, H.(2006). The 22q11.2 deletion in children: high rate of autistic disorders and early onset of psychotic symptoms. J Am Acad Child Adolesc Psychiatry, 45(9), 1104-1113.

Williams, N.M. (2011). Molecular mechanisms in 22q11 deletion syndrome. Schizophr Bull, 37(5), 882889.

Wyse, A.T., \& Netto, C.A. (2011). Behavioral and neurochemical effects of proline. Metab Brain Dis, 26(3), 159-172.

Yuen, T., Chow, E.W., Silversides, C.K., \& Bassett, A.S. (2013). Premorbid adjustment and schizophrenia in individuals with 22q11.2 deletion syndrome. Schizophr Res, 151(1-3), 221-225.

Zammit, S., Lewis, S., Gunnell, D., \& Smith, G.D. (2007). Schizophrenia and neural tube defects: comparisons from an epidemiological perspective. Schizophr Bull, 33(4), 853-858.

Zipursky, R.B., Reilly, T.J., \& Murray, R.M. (2013). The myth of schizophrenia as a progressive brain disease. Schizophr Bull, 39(6), 1363-1372. 



\section{CHAPTER 2}

\section{CASE STUDIES}

2.1 The velocardiofacial syndrome in older age: dementia and autistic features

\subsection{The velocardiofacial syndrome: the spectrum of psychiatric problems and cognitive deterioration at adult age}

Published as:

Evers LJ, Vermaak MP, Engelen JJ, Curfs LM.

Genet Couns. 2006;17(3):333-40.

Evers LJ, De Die-Smulders CE, Smeets EE, Clerkx MG, Curfs LM.

Genet Couns. 2009;20(4):307-15. 



\section{CHAPTER 2.1}

\section{The velocardiofacial syndrome in older age: Dementia and autistic features}




\section{Summary}

Velocardiofacial syndrome (VCFS) is a syndrome with a known, but variable clinical and behavioural phenotype. Most reported cases are patients of a relatively young age. The development of the behavioural phenotype and psychopathology in older patients with VCFS is less known.

We present a case of a 52 year old male patient with VCFS and a deletion in chromosome band 22q11.2. He presents with typical symptoms reported in the behavioural phenotype, autistic features and an overall deteriorating process, which fulfils the DSMIV criteria for dementia.

Key words: Velocardiofacial syndrome, Dementia, Deletion 22q11.2 


\section{Introduction}

The DiGeorge/velocardiofacial syndrome is caused by a microdeletion in chromosome band 22q11.2 (Driscoll, Spinner, Budarf, McDonald-McGinn, Zackai, Goldberg,... Emanuel, 1992; Scambler, Kelly, Lindsay, Williamson, Goldberg, Shprintzen,... Burn, 1992) and has an incidence of 1 in 4000 to 1 in 6000 (Devriendt, Mortier, Van Thienen, Keymolen \& Fryns, 1998). The clinical features of this syndrome vary from severe midline defects to almost no clinical features at all (Ryan, Goodship, Wilson, Philip, Levy, Seidel,... Scambler, 1997). There's a growing interest in the behavioural characteristics usually known as the velocardiofacial behavioural phenotype (Murphy. 2004; Shprintzen, 2000; Swillen, Devriendt, Legius, Prinzie, Vogels, Ghesquiere \& Fryns) or as the velocardiofacial psychiatric syndrome (Verhoeven, Tuinier, Engelen, Hollanders-Crombach \& Curfs, 2002).

As most reported cases are children and adolescents the behavioural phenotype is derived from relatively young patients. Case reports of older patients are less frequently published. Recently, Verhoeven et al. (2002) reported on a 70 year old patient with VCFS and psychiatric problems. No reports have been made of patients with VCFS and dementia.

In this paper we report on a male patient with an ongoing mental deterioration. The patient suffers from behavioural and psychiatric problems including brief psychotic periods, mood swings and also exhibits autistic features. Because of his behavioural problems and the presence of a cleft palate, chromosome analysis and FISH for a microdeletion in chromosome band 22q11.2 was performed.

\section{Clinical Report}

\section{Anamneses}

The patient is a 52 year old male. He has six siblings, two of whom are mentally retarded, 1 severely and 1 mildly. One of these, his 50 year old sister has also an autistic disorder diagnosed. Both parents are deceased now but were known to be were intellectually limited. The mother had a short high arched palate and some behavioural problems were reported. Family history excludes dementia and other cognitive defects. No data are available about the psychiatric functioning of other family members. The patient attended primary school, where he repeated almost every class. Due to behavioural problems and parental neglect he lived with his grandparents between the ages of five and fifteen. For the next ten years he lived with his parents. He lived in a semi-residential institute for the mentally retarded from the age of 25. At the age of 34 he was admitted to a psychiatric hospital. Aggressive outbursts were seen as psychotic reactions to him feeling threatened. Psychiatric examination at that time showed predominantly delusional thoughts 
and some evidence of hallucinations, little concern for his environment, poor orientation in time, echolalia, perseverations, affective emptiness, slowness in thinking and rigid motor control. He stayed for almost 10 years in the psychiatric hospital. Since then a slow but steady deterioration of his cognitive functions was observed. At 44 years of age the patient was moved to a residential setting for the mentally retarded. In this setting the behavioural problems returned with persistence; behaved himself disobedient, was hyperkinetic and he began throwing things. He appeared to be continually strained and became aggressive. However, he increasingly showed also withdrawal behaviour. An explanation for this change in behaviour was believed to be the illness of some close relatives. A psychological evaluation showed that he required more structure and predictability in his daily life. At 48 years of age he was moved to another group with a very structured programme. In this period his father died, this made him occasionally sad, but gave no extreme behavioural problems. Behavioural problems were treated with haloperidol decanoate, risperidone and olanzapine. None of these drugs were successful at long term. At this moment he receives no antipsychotic medication. Most successful is a regime of structure and clarity, which is an argument to believe the behaviour is reactive of origin.

\section{Cognitive measurements}

At 8 years of age and at the age of $8 \frac{1}{2}$ years the patient had an estimated IQ of 75 and 80 (methods unknown). At the age of 36 his IQ was measured at below 45 (WISC-R). At age 44 his IQ with the WPPSI was 26. At present his IQ measured with WPPSI is 21.

His independence and memory had a continual but gradual decline over time. Scoring on the DMR (Dementia Questionnaire for Mentally Retarded Persons) (Evenhuis, 1992), shows a decline in short term memory, long term memory, orientation and daily and practical abilities over the past 7 years. Also we see a developing incontinence of urine and faeces in the last year. A slight decline in speech ability is also noted. His mood and behavioural disturbances are stable (but not normal) in this period (Table I and Figure 1). According to DSM-IV-TR criteria (American Psychiatric Association, 2000) the diagnose dementia is made. 
Table 1: Scores on DMR

\begin{tabular}{lcccccccccccc}
\hline DMR items/date & $5 / 97$ & $6 / 99$ & $2 / 00$ & $5 / 00$ & $9 / 00$ & $4 / 02$ & $12 / 02$ & $2 / 04$ & $3 / 04$ & $9 / 04$ & $4 / 05$ & $8 / 05$ \\
\hline Short term memory & 3 & 5 & 6 & 7 & 5 & 3 & 5 & 11 & 11 & 11 & 10 & 12 \\
Long term memory & 0 & 0 & 2 & 2 & 8 & 6 & 5 & 7 & 9 & 2 & 8 & 3 \\
Oriëntation & 0 & 2 & 2 & 4 & 7 & 5 & 3 & 9 & 8 & 8 & 8 & 8 \\
Speech & 2 & 2 & 1 & 2 & 3 & 3 & 2 & 5 & 4 & 3 & 4 & 2 \\
Practicle skills & 4 & 4 & 4 & 4 & 3 & 7 & 5 & 8 & 11 & 10 & 11 & 8 \\
Mood & 4 & 5 & 6 & 6 & 5 & 5 & 5 & 6 & 6 & 6 & 7 & 6 \\
Activity and interest & 4 & 7 & 8 & 5 & 6 & 5 & 6 & 10 & 11 & 8 & 7 & 4 \\
Behaviour disturbance & 4 & 7 & 6 & 6 & 6 & 7 & 6 & 6 & 5 & 9 & 8 & 8 \\
Sum cognitive score & 3 & 7 & 10 & 13 & 20 & 14 & 13 & 27 & 28 & 21 & 26 & 23 \\
Sum social score & 18 & 25 & 25 & 23 & 23 & 27 & 24 & 35 & 37 & 36 & 37 & 28 \\
Total score & 21 & 32 & 35 & 36 & 43 & 41 & 37 & 62 & 65 & 57 & 63 & 51 \\
\hline
\end{tabular}

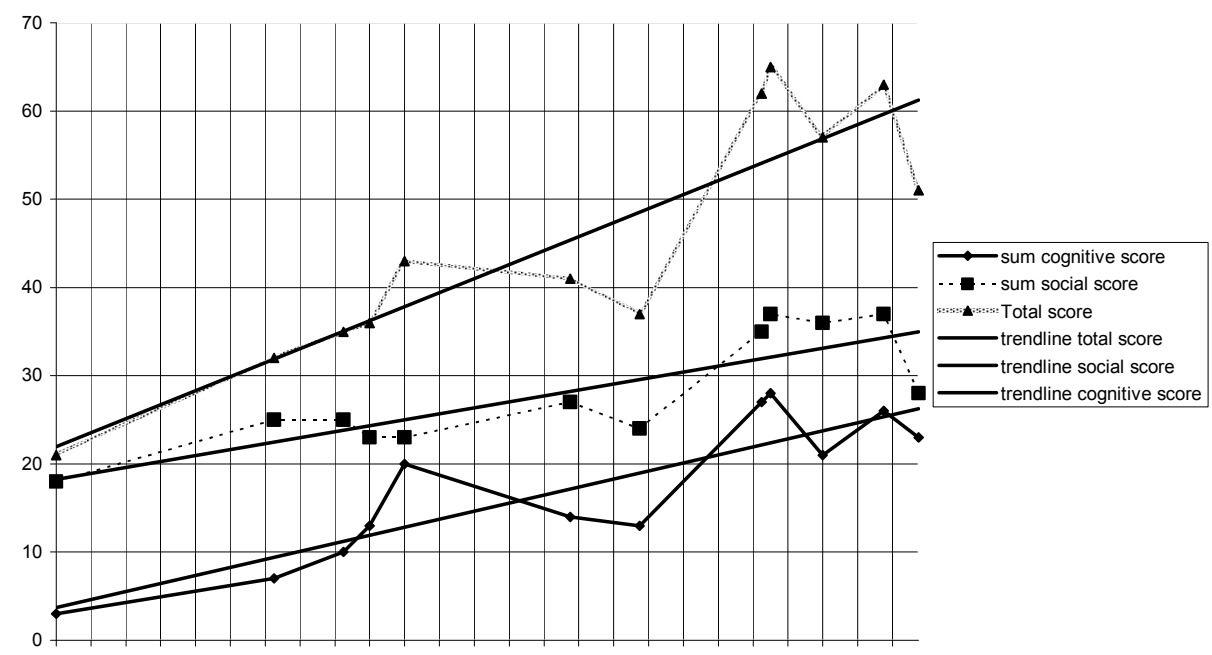

o

Figure 1. DRM scores 


\section{Clinical examination}

At clinical genetic examination we noticed slender fingers, long face, inner cantal distance of $3.5 \mathrm{~cm}(+1-2 \mathrm{SD})$, outer cantal distance $10 \mathrm{~cm}$ (-1 SD) and kyphosis. He has speech problems and was born with a cleft palate for which reconstructive surgery was performed at the age of 2 . A neurological evaluation gave, with the exception of white matter aberrations on MRI, no abnormalities.

\section{Chromosomal analysis}

Chromosomes were prepared from peripheral blood lymphocyte cultures following standard procedures and GTG-banded by treatment with trypsin and staining with Giemsa. Furthermore, FISH with probe tuple-1, specific for chromosome band 22q11.2 (Mulder, Wilke, Langeveld, Wilming, Hagemeijer, van Drunen,... Meyers, 1995), was performed as described by Lichter et al. (1990). Analysis of 10 GTGbanded metaphases showed a normal karyotype. Subsequent FISH with probe tuple-1 showed a microdeletion in chromosome band 22q11.2, the karyotype being: 46,XY.ish del(22)(q11.2q11.2)(D22S75-).

Chromosome analysis and FISH analysis of the chromosomes of his profound mentally retarded and autistic sister shows a deletion in chromosome band 22q11.2. Genetic analysis of the parents is not possible as they are both deceased. Attempts to analyse the other family members were so far not successful.

\section{Discussion}

Most VCFS patients reported in literature are descriptions of youngsters and the behavioural phenotype is mainly derived from those cases. We present the case of a 52 year old male patient with a confirmed microdeletion in chromosome band 22q11.2 that was also shown to be present in his sister. The patient meets the criteria of the behavioural phenotype of VCFS: psychotic like symptoms, which come in outbursts and subside quickly after restoring structure, and over arousal with agitated affect. Furthermore, he shows social withdrawal and reiterations. These symptoms can be explained as autistic symptoms, which are reported in literature as multiplex developmental disorder (the combination of several psychiatric symptoms with autistic features) by Klin et al. (Klin, Mayes, Volkmar \& Cohen, 1995). Pervasive development disorders in VCFS are reported by Basset et al. (Basset, Hodgkinson, Chow, Correira, Scutt \& Weksberg,1998), Chudley et al. (Chudley, Gutierre, Jocelyn \& Chodirker,1998) and Niklasson et al. (Niklasson, Rasmussen, Óskarsdóttir \& Gillberg, 2002). 
The sister fulfils the criteria of an autistic disorder. Apart from the problems in the behavioural phenotype, an ongoing deterioration with a substantial IQ decline is also noted, which fulfils the DSMIV-TR criteria of dementia (APA, 2000). An explanation for this deterioration can possibly be found in life events which he reacts upon with regression. One would expect his functioning to improve after restoring structure and security which does not happen. Another explanation may be familial factors such as familial dementia or other neurological problems, but apart from his sister (and probably his mother and brother) with del 22q11.2, neurological problems are not present in the family. The patient is not taking any antipsychotic medication at the moment so any sedating contribution can't be the reason for his cognitive decline. Another issue is the prevalence of dementia in the mentally retarded population which is, beside the group of patients with Down's syndrome, comparable to that of adults without mental retardation and not increased (Zigman, Schupf, Devenny, Miezejeski, Ryan, Urv,... Silverman, 2004).

Psychotic episodes sometimes mimic dementia like deterioration. The cognitive decline in our patient exceeds normal expectations in this regard (Russel, Munro, Jones, Hemsley \& Phil, 1997). Dementia with a start before the age of 65 is considered to be an early onset dementia (APA, 2000). The cognitive decline seen in our patient is first measured at the age of 36 and can be seen as a extreme early onset of dementia.

A predominantly female to offspring transmission of inherited del 22q11.2 was reported by McDonald-McGinn et al. (McDonald-McGinn, Tonnesen, LauferCahana, Finucane, Driscoll \& Emanuel, 2001)., Ryan et al. (1997), Desmaze et al. (Desmaze, Prieur, Amblard, Aikem, LeDeist, Demczuk \& Aurias, 1993), Adeyinka et al. (Adeyinka, Stockero, Flynn, Lorentz, Ketterling \& Jalal), with 92 transmitting female parents in 123 families. Keeping in mind the medical history of the mother, it is reasonable to assume that she is the carrier of the deletion in this family.

To the best of our knowledge, only one patient with VCFS and older age (Verhoeven et al., 2002) is reported. This 70 year old patient had no features of dementia, but meets the criteria for the behavioural phenotype of VCFS as described.

VCFS is a contiguous gene syndrome with a great variety in dysmorphology, even in familial cases. The behavioural characteristics found in VCFS can also be more varied than is thought up until now. Dementia has never been described before in VCFS, especially not at such young age. It may be a condition that can be found more often in elderly patients with a microdeletion in chromosome band 22q11.2. Its worth considering a deletion 22q11.2 in patients with autistic features and/or a decline in functioning resulting in a dementia-like condition especially in those with VCFS-linked conditions such as palatal abnormalities, cardiac defects and facial characteristics. 


\section{References}

Adeyinka A., Stockero K.J., Flynn H.C., Lorentz C.P., Ketterling R.P., Jalal S.M.: Familial 22q11.2 deletions in DiGeorge/velocardiofacial syndrome are predominantly smaller than the commonly observed 3Mb. Genet. Med., 2004, 6(6), 517-520.

American Psychiatric Association.: Diagnostic and Statistical Manual of Mental Disorder, fourth edition, Text Revision, Washington, DC, APA, 2000.

Basset A.S., Hodgkinson K., Chow E.W.C., Correira S., Scutt L.E., Weksberg R.: 22q11 deletion syndrome in adults with schizophrenia. Am. J. Med. Genet. (Neuropsychiatr. Genet.), 1998, 81, 328-337.

Chudley A.E., Gutierrez E., Jocelyn L.J., Chodirker B.N.: Outcomes of genetic evaluation in children with pervasive developmental disorder. J. Dev. Behav. Pediatr., 1998, 19(5), 321-325.

Desmaze C., Prieur M., Amblard F., Aikem M., LeDeist F., Demczuk S., Zucman J., Plougastel B., Delattre O., Croquette M.F.,Breviere G.M., Huon C., Le Merrer M., Mathieu M., Sidi D., Stephan J.L., Aurias A.A. Physical mapping by FISH of the DiGeorge critical region (DGCR): involvement of the region in familial cases. Am. J. Hum. Genet., 1993, 53(6), 1239-1249.

Devriendt K., Mortier G., Van Thienen M.N., Keymolen K., Fryns J.P.: The annual incidence of DiGeorge/velocardiofacial syndrome. J. Med. Genet., 1998, 35, 789-790.

Driscoll D.A., Spinner N.B., Budarf M.L., McDonald-McGinn D.M., Zackai E.H., Goldberg R.B., Shprintzen R.J., Saal H.M., Zonana J., Jones M.C., Mascarello J.T., Emauel B.S.: Deletions and microdeletions of 22q11.2 in velo-cardio-facial syndrome. Am. J. Med. Genet., 1992, 44 (2), 261-268.

Evenhuis HM.: Evaluation of a screening instrument for dementia in ageing mentally retarded persons. J. Intell. Disabil. Res., 1992, 36 (Pt 4), 337-347.

Klin A., Mayes L.C., Volkmar F.R., Cohen D.J..: Multiplex developmental disorder. J. Dev. Behav. Pediatr., 1995, 16 (3 Suppl), S7-11.

Lichter P., Tang C.C., Call K., Hermanson G., Evans H.J., Housman D., Ward D.C.: High resolution mapping of human chromosome 11 by in situ hybridization with cosmid clones. Science, 1990, 247, 64-69.

McDonald-McGinn D.M., Tonnesen M.K., Laufer-Cahana A., Finucane B., Driscoll D.A., Emanuel B.S., Zackai E.H.: Phenotype of the 22q11.2 deletion in individuals identified through an affected relative: cast a wide FISHing net! Genet. Med., 2001, 3(1), 23-29.

Mulder M.P., Wilke M., Langeveld A., Wilming L.G., Hagemeijer A., van Drunen E., Zwarthoff E.C., Riegman P.H., Deelen W.H., van den Ouweland A.M., Halley D.J.J, Meyers C.: Positional mapping of loci in the DiGeorge critical region at chromosome 22q11 using a new marker (D22S183). Hum Genet., 1995, 96(2), 133-141.

Murphy K.C.: The behavioural phenotype in velo-carido-facial syndrome. J. Intell. Disabil. Res., 2004, 48(6), 524-530.

Niklasson L., Rasmussen P., Óskarsdóttir S., Gillberg, C.: Chromosome 22q11 deletion syndrome (CATCH22): neuropsychiatric and neuropsychosocial aspects. Dev. Med. Child. Neurol., 2002, 44, 4450.

Russel A.J., Munro J.C., Jones P.B., Hemsley D.R., Phil M., Murray R.M.: Schizophrenia and the myth of intellectual decline. Am. J. Psychiat., 1997, 154, 635-639.

Ryan A.K., Goodship J.A., Wilson D.I., Philip N., Levy A., Seidel H., Schuffenhauer S., Oechsler H., Belohradsky B., Prieur M., Aurias A., Raymond F.L., Clayton-Smith J., Hatchwell E., McKeown C., Beemer F.A., Dallapiccola B., Novelli G., Hurst J.A., Ignatius J., Green A.J., Winter R.M., Brueton L., Brondum-Nielsen K., Scambler P.J..: Spectrum of clinical features associated with interstitial chromosome 22q11 deletions: a European collaborative study. J. Med. Genet., 1997, 34(10), 798-804.

Scambler P.J., Kelly D., Lindsay E., Williamson R., Goldberg R., Shprintzen R., Wilson D.I., Goodship J.A., Cross I.E., Burn J.: Velo-cardio-facial syndrome associated with chromosome 22 deletions encompassing the DiGeorge locus. Lancet., 1992, 339, 1138-1139.

Shprintzen R.J.: Velo-cardio-facial syndrome: a distinctive behavioral phenotype. Ment. Retard. Dev. Disabil. Res. Rev., 2000, 6(2), 142-147.

Swillen A., Devriendt K., Legius E., Prinzie P., Vogels A., Ghesquiere P., Fryns J.P.: The behavioural phenotype in velo-cardio-facial syndrome (VCFS): from infancy to adolescence. Genet. Counsel., 1999, 10(1), 79-88. 
Verhoeven W.M., Tuinier S., Engelen J.J.M., Hollanders-Crombach H.T.M., Curfs L.M.G.: Velo-Cardio-Facial Syndrome: clinical report of a 70 year old woman. Am. J. Med. Genet., 2002, 111(4), 409-411.

Zigman W.B., Schupf N., Devenny D.A., Miezejeski C., Ryan R., Urv T.K., Schubert R., Silverman W.: Incidence and prevelance of dementia in elderly adults with mental retardation without Down syndrome. Am. J. Ment. Retard,. 2004, 109(2), 126-141. 



\section{CHAPTER 2.2}

The Velo-cardio-facial Syndrome: the Spectrum of Psychiatric Problems and cognitive deterioration at Adult Age

Evers LJ, De Die-Smulders CE, Smeets EE, Clerkx MG, Curfs LM. Genet Couns. 2009;20(4):307-15. 


\section{Summary}

Deletion 22q11.2 syndrome, or the velo-cardio-facial syndrome (VCFS), is a syndrome with a known but varied clinical and behavioral phenotype. We report 7 patients with 22q11.2 deletion syndrome and an intellectual disability. Aside from the described behavioral phenotype in literature, a moderate, severe or profound intellectual disability may be present. Special attention should be given to cognitive deterioration.

Key words: VCFS-Intellectual disability-deletion 22q11.2-cognitive deterioration 


\section{Introduction}

The velo-cardio-facial syndrome (VCFS) is a clinically recognizable disorder. Its physical appearance is known to be variable (Bassett, Chow, Husted, Weksberg, Caluseriu, Webb \& Gatzoulis, 2005; Goldberg, Motzkin, Marion, Scambler \& Shprintzen, 1993; McDonald McGinn, Kirschner, Goldmuntz, Sullivan, Eicher, Gerdes,... Zackai, 1999). Recently the name 22q11.2-(micro)deletion-syndrome, which refers to its cause is used more frequently. The microdeletion, in most cases not detectable with standard cytogenetic techniques, can be detected with the fluorescence in situ hybridization (FISH) method (Lichter, Tang, Call, Hermanson, Evans, Housman \& Ward,1990) or multiple ligand dependent probe amplification (MLPA) (Stachon, Baskin, Smith, Shugar, Cytrynbaum, Fishman,... Weksberg, 2007). Microdeletion of 22q11.2 is the most common microdeletion in man, with an estimated incidence of 1:4000 (Devriendt, Fryns, Mortier, van Thienen \& Keymolen, 1998).

For VCFS, a distinctive behavioral phenotype is described in literature (Murphy, 2004; Shprintzen, 2000; Swillen, Devriendt, Legius, Prinzie, Vogels, Ghesquiere \& Fryns, 1999). The behavioral problems are social withdrawal, attention problems, somatization, poor social skills, conduct problems, and anxiety (Aneja, Fremont, Antshel, Faraone, AbdulSabur, Higgins,... Kates, 2007; GoldingKushner, Weller \& Shprintzen, 1985; Jansen, Duijff, Beemer, Vorstman, Klaassen, Morcus \& Heineman de Boer, 2007; Swillen et al, 1997). There is a high risk for the development of psychiatric problems in children and adolescents (ADHD, bipolar disorder, autism) (Aneja et al. 2007, Papolos, Faedda, Veit, Goldberg, Morrow \& Kucherlapati, 1996), and, especially in adults, psychotic disorders (Murphy, Jones \& Owen, 2001; Pulver, Nestadt, Goldberg, Shprintzen, Lamacz, Wolyniec \& Housman, 1994).

It may be difficult to recognize a VCFS phenotype because of the strong variability in the clinical picture. In addition, clinical symptoms in a particular patient can change over time.

Approximately half of the persons with this deletion have a normal to borderline intelligence. In case of an intellectual disability (ID), this is mostly a mild ID level (Swillen et al, 1997). The presence of a severe or profound ID in VCFS is considered to be rare (Swillen et a; 1997) and there are only a few casuistic reports of patients in VCFS functioning at these lower ID levels (Devriendt, Thienen, Swillen, Fryns, 1996; Isacone, Vittorini, Sacchelli, Spadoni, Simi \& Giusti, 2002, Kozma, 1998; Swillen et al, 1997).

In this study we included 7 diagnosed patients with a 22q11.2 deletion who are functioning on a low level of cognitive functioning. 


\section{Materials and methods}

The adults described in this case report were cases for which the first author was consulted as psychiatrist in our Dutch psychiatric practice working for several facilities for intellectually disabled persons. Parents or caregivers gave permission for diagnostic evaluation in all cases. The method used is based on clinical examination and study of the medical files.

For all patients FISH analysis was conducted with probe tuple-I, specific for chromosome band 22qll.2 (Mulder, Wilke, Langeveld, Wilming, Hagemeijer, van Drunen,... van den Ouweland, 1995), as described by Lichter et al (Lichter, Tang, Call, Hermanson, Evans, Housman \& Ward 1990).

\section{Results}

\section{Patient A}

Patient A is a 52-year old man. Until the age of twenty-five he lived with his parents. In the following next ten years he lived in a community care setting for mildly intellectual disabled people. At age 34 he was admitted to a psychiatric hospital because of a paranoid psychotic disorder, during which there was a deterioration in skills. At the age of 44 he was transferred to a residential care facility for people with an intellectual disability. He was constantly excited, often aggressive and there was an increase in social withdrawal. Because of psychotic complaints he was treated with haloperidol, risperidone and olanzapine in that order, and none of these medications proved to be effective. Offering structure and firmness proved to be more effective. Over the last 8 years there was even a progressive decline in functioning.

At several moments in his life, his intelligence was measured with the following results: at age 8, IQ 80 (borderline intelligence), age 36 developmental age 6 years (mild ID), age 44 developmental age 4.6 years (moderate/severe ID) and at age 52 developmental age 4.1 years (severe ID). All measurements were estimated with Wechsler intelligence scales. Scoring for dementia with the DMR (Dementia Questionnaire for Mentally Retarded Persons) (Evenhuis, 1992), showed a steady but ongoing deterioration in short term memory, long term memory, orientation and daily and practical abilities over the last 8 years. Furthermore, he developed encopresis en enuresis over the last year.

Because of his behavioral problems and the presence of a cleft palate (which was corrected in childhood) he was referred to a clinical genetic centre. By analysis with FISH, a deletion of 22q11.2 was found, which confirmed the diagnosis VCFS. 
His parents, both deceased, functioned at a subnormal intellectual level. The mother had a short, high arched palate and behavioral problems. They were never tested for any genetic disorder.

\section{Patient B}

Patient B is a 38-year old man of Portuguese origin. As a child he received normal education. At the age of 9 his family moved from Portugal to the Netherlands. Despite some language problems he attended normal primary school and subsequently had a technical and vocational training. He was unsuccessful in this and wanted to find a job. At the age of 18 years he developed his first psychosis, with predominantly paranoid delusions, from which he recovered by taking antipsychotics in short periods. A psychological assessment showed that he functioned at the level of a mild ID. In the following years he developed several psychotic episodes, which occurred more and more rapidly. They were accompanied by mood swings. Several psychiatric admissions followed. At the age of 29 his IQ was 50 (mild/moderate ID) (Wechsler Adult Intelligence Scale). His parents could not cope with his aggressive and destructive behavior. At the age of 30 he was admitted to a specialized ward for behaviorally disturbed mildly intellectual disabled people. At the age of 36 his skills were tested with the VABS (Vineland Adaptive Behavior Scale), which resulted in an estimated severe ID level. Medical interventions had been ineffective. At the moment patient receives no psychopharmaceuticals. Because of psychotic symptoms and some physical features (see Table I) there was a clinical notion of VCFS. FISH analysis revealed a deletion 22q11.2.

\section{Patient C}

Patient C is a 29-year old woman. As a child she showed little initiative and demanded a lot of attention from her parents. In later years she developed an obsession for boys. These crushes could become severely pathological. Mood swings were unpredictable and ranged from excited bursts of laughter to apathy. Gradually her behavior became more paranoid. Her work deteriorated and she could not keep up. At the age of 20 she had her first psychotic decompensation, with hallucinations and paranoid delusions. Because of her psychosis and destructive behavior, an admission to a psychiatric ward was finally unavoidable. An IQ test (WPPSI, verbal score) at age 22 resulted in a developmental age of 6.4 years (mild/moderate ID level). At the age of 25 her intellectual functioning was estimated to be mild intellectually disabled (VABS). She still experienced mood swings and the psychosis worsened. Also the aggression gradually increased as did her problematic behavior, such as smearing defecation and screaming for hours. An analysis on etiology, including FISH analysis, turned out to be positive for del22q11.2, which confirmed the diagnosis VCFS and did explain several symptoms found in 
this patient (Table I). While living in a group home she was frequently aggressive and antipsychotic drugs had little influence on her behavior. Quetiapine seemed only to have some effect on paranoid thoughts. Her cognitive functioning was difficult to assess because of her chronic psychosis. However, compared to her mild ID (estimated with VABS at age 25), her adaptive skills had considerably declined, especially in social skills. She also could no longer ride a bicycle, her writing skills worsened, and her language became more incoherent as well. At age 28 she still suffered from severe psychosis and was unresponsive to antipsychotic medication, which made testing difficult. At age 28 she was tested with the WPPSI (verbal score) and SON-R 2,5-7, which resulted in a developmental age of 4.8 years (moderate ID level). At age 30 her WPPSI (verbal score) developmental age was 2.4 years.

\section{Patient D}

Patient D is a 26-year old woman. Because of paranoid delusional thoughts and hearing voices she was seen by a social psychiatric service. At that time she had a regular job and lived on her own. She received support from an outreach team for persons with a mild ID. Her psychotic decompensation was considered to be a consequence of having demanded too much of herself. Her recovery was gradual but slow with olanzapine, and in particular giving structure to her daily life proved to be effective. Extensive personality assessment, a psychiatric examination and heteroanamnesis led to the diagnosis of autism spectrum disorder.

As a child she attended special education for children with mild ID. At the age of 19 her IQ measured with WAIS-R (Wechsler Adult Intelligence Scale, Revised) was 85. At the age of 23 her IQ measured with WAIS-III (Wechsler Adult Intelligence Scale, third edition) was 52. Because of psychiatric problems she failed to hold her job. She could not live on her own and had to move to a residential facility for intellectually disabled people. Every attempt to regain independence has failed up until now, but she did profit from a structured environment. Because of the psychiatric symptoms (psychotic symptoms with a slow response to antipsychotic drugs and autism spectrum disorder) and several physical symptoms (see Table I) we referred her for clinical genetic counseling. With a FISH analysis a microdeletion of 22q11.2 was found which confirmed the diagnosis VCFS.

At age 27 she was tested again and she had an IQ of 64 (WISC-III), but if the proper adult Wechsler scalehad been used this probably would have yielded a lower IQ level. At that moment she was psychiatrically stable and had no psychotic symptoms. She remained on antipsychotic medication (olanzapine).

\section{Patient E}

Patient E is a 24-year old man. At age 17 he was admitted to an residential care setting for intellectually disabled people because of increasing behavioral prob- 
lems, being aggressive and destructive. The most striking feature was that this abnormal behavior emerged out of the blue, and disappeared equally abruptly. Also autistic-like symptoms such as a poor "theory of mind" were seen. Intelligence testing at age 20 resulted in a developmental age of 4.10 years, and at age 24 in a developmental age of 5.2 years (Wechsler scales). Before admission he held several jobs, at all of which he failed.

Specific physical symptoms were dysplastic ears, a short stature, a nasal speech and a supernumerary nipple. FISH analysis showed a deletion 22q11.2.

\section{Patient F}

Patient F is the 50-year old sister of patient A. Starting at 11 years of age, she lived in a residential care setting for intellectually disabled people. At the age of 13 she was described as functioning on moderate ID level. At age 14, her ID level was measured to be severe. Additionally an autistic disorder was diagnosed. She is now profoundly intellectually disabled (Vineland Adaptive Behavior scale). After her brother was diagnosed with VCFS, she was tested with a FISH analysis. In her case a microdeletion $22 \mathrm{q} 11$ was also found.

Table I: Clinical features in 7 22q11.2 deletion patients

\begin{tabular}{|c|c|c|c|c|c|c|c|}
\hline & Patient A & Patient B & Patient C & Patient D & Patient E & Patient F & Patient G \\
\hline Gender/age & $\delta / 52$ & $\delta / 38$ & $+/ 29$ & $+/ 26$ & $\delta / 24$ & $+/ 50$ & $\delta / 30$ \\
\hline $\begin{array}{l}\text { Velopharyngeal } \\
\text { insufficiency/nasal } \\
\text { speech }\end{array}$ & $+/+$ & $+/+$ & $+/+$ & $+/+$ & $-/+$ & $\begin{array}{c}\text { ?/no } \\
\text { speech }\end{array}$ & $\begin{array}{c}+/ \text { no } \\
\text { speech }\end{array}$ \\
\hline Palatoschisis & + & - & - & submucus & - & - & - \\
\hline Pear shaped nose & + & + & + & + & - & + & + \\
\hline Dysplastic ears & - & & + & + & + & - & + \\
\hline Slender fingers & + & & + & + & - & + & + \\
\hline $\begin{array}{l}\text { Conotruncal cardiac } \\
\text { defects }\end{array}$ & $\begin{array}{c}\text { not } \\
\text { examined }\end{array}$ & + & $\begin{array}{c}\text { not } \\
\text { examined }\end{array}$ & $\begin{array}{c}\text { not } \\
\text { examined }\end{array}$ & $\begin{array}{c}\text { not } \\
\text { examined }\end{array}$ & $\begin{array}{c}\text { not } \\
\text { examined }\end{array}$ & + \\
\hline Varices & + & + & + & + & - & & \\
\hline $\begin{array}{l}\text { Recurrent Ear, Nose } \\
\text { and Throat } \\
\text { infections }\end{array}$ & + & + & + & - & & + & + \\
\hline $\begin{array}{l}\text { Thrombocyte count } \\
\text { (normal } 130-400 \mathrm{nl} \text { ) }\end{array}$ & $150-178$ & & $149-164$ & 262 & & 203 & \\
\hline Spine deformities & - & & kyphosis & - & - & scoliosis & \\
\hline $\begin{array}{l}\text { Documented } \\
\text { neonatal } \\
\text { hypocalcemia }\end{array}$ & & & & & & & + \\
\hline
\end{tabular}




\section{Patient G}

Patient G is a 30-year old man. He lives in a residential care setting for intellectually disabled persons. He has a profound ID (developmental age 1.11 years estimated with a Dutch developmental scale) and an autistic disorder. In earlier reports his ID level was described as severe. Patient G had several symptoms of the DiGeorge sequence, such as a right arched aorta and low serum calcium. The clinical diagnosis 22q11.2 deletion was confirmed by finding a microdeletion 22q11.2 with FISH analysis.

\section{Discussion}

The adult patients presented in this report are living in residential care settings for intellectually disabled persons. They were diagnosed with psychiatric and/or behavioral problems, sometimes combined with a heart defect or palatal abnormalities as diagnosed in their youth. It is especially remarkable that at this moment these patients are functioning on a low ID level, which is quite different from most patients described in literature (Swillen et al, 1997). Because the way they were recruited some bias for intellectual measurement is to be expected in this small group.

Focusing on the developmental course of these patients, it is remarkable to see an IQ decline in six of the seven studied patients (patient A, B, C, D, F and G). Figure I shows the IQ-decline.

Patient $G$ and F showed a decline before adolescence. Patient A, B, C and D showed a decline beginning in early adulthood accompanied with psychotic symptoms. After reaching psychiatric stability, the decline in patient D stopped. Patient A, B and C failed to react properly to antipsychotic treatment and deteriorated further in cognitive abilities as well as in daily skills.

Specific cognitive decline in childhood was observed (Golding-Kushner, 1985; Gothelf, Eliez, Thompson, Hinard, Penniman, Feinstein,... Reiss, 2005), but the decline was never more than 15 points on the verbal IQ subscales.

According to DSM-IV-TR criteria (American Psychiatric Association, 2004) dementia was diagnosed in 3 cases (A, B and C). Schizophrenia of the paranoid type is the most frequent psychiatric disorder in VCFS patients at adult age (Basset et al, 2005, Murphy \& Owen, 1990). In our case report four patients fulfilled criteria (DSM-IV-TR (APA, 2004)) for this diagnosis (A, B, C and D). In schizophrenic patients the combination of a cognitive functioning decline and daily skills decline, as we found in patients A, B and C, is very unusual (Russell, Munro, Jones, Hemsley \& Murray, 1997). The severe cognitive deterioration with dementia like features has only been described once before in a VCFS patient (Evers, Vermaak, Engelen \& Curfs, 2006). Besides the deterioration observed in this series, three patients (pa- 
tients D, F and G) had an autistic spectrum disorder. Autistic spectrum disorders are frequently diagnosed in VCFS (Fine, Weissman, Gerdes, Pinto Martin, Zackai, McDonald-McGinn \& Emanuel, 2005; Klin, Mayes, Volkmar \& Cohen, 1995; Niklasson, Rasmussen, Oskarsdottir \& Gillberg, 2001; Niklasson, Rasmussen, Oskarsdottir \& Gillberg, 2005; Vorstman, Morcus, Duijff, Klaassen, Heineman de Boer, Beemer,... van Engeland, 2006).

Figure I: IQ's in seven 22q11.2 deletion patients

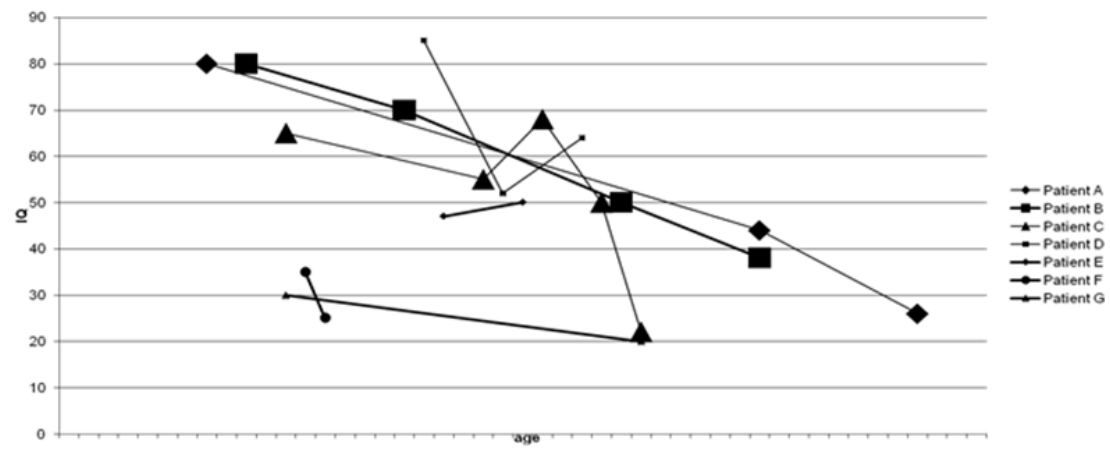

Figure 1: IQ's in seven 22q11.2 deletion patients

It is worth considering the possibility of VCFS in patients with initial mild or borderline ID levels and a psychotic disorder that causes deterioration of cognitive abilities with dementia-like proportions. 


\section{References}

American Psychiatric Association: Diagnostic and Statistical Manual of Mental Disorders, fourth edition, text revision (DSM-IV-TR). Washington (DC), American Psychiatric Association. 2004.

Aneja A., Fremont W.P., Antshel K.M., Faraone S.V., AbdulSabur N., Higgins A.M., Shprintzen R., Kates W.R.: Manic symptoms and behavioral dysregulation in youth with velocardiofacial syndrome (22q11.2 deletion syndrome). J. Child. Adolesc. Psychopharmacol., 2007, 17, 105-114.

Bassett A.S., Chow E.W., Husted J., Weksberg R., Caluseriu O., Webb G.D., Gatzoulis M.A.: Clinical features of 78 adults with 22q11 Deletion Syndrome. Am. J. Med. Genet. A, 2005,138, 307-313.

Devriend t.K., Fryns J.P., Mortier G., van Thienen M.N., Keymolen K.: The annual incidence of DiGeorge/velocardiofacial syndrome. J. Med. Genet. 1998, 35, 789-790.

Devriend t.K., Thienen M.N., Swillen A., Fryns J.P.: Cerebellar hypoplasia in a patient with velo-cardiofacial syndrome. Dev. Med. Child. Neurol., 1996, 38, 949-953.

Evenhuis H.M.: Evaluation of a screening instrument for dementia in ageing mentally retarded persons. J. Intellect. Disabil. Res., 1992, 36 ( Pt 4), 337-347.

Evers L.J.M., Vermaak M.P., Engelen J.J., Curfs L.M.: The velocardiofacial syndrome in older age: dementia and autistic features. Genet. Couns., 2006, 17, 333-340.

Fine S.E., Weissman A., Gerdes M., Pinto Martin J., Zackai E.H., McDonald-McGinn, D. M., Emanuel, B. S.: Autism spectrum disorders and symptoms in children with molecularly confirmed 22q11.2 deletion syndrome. J. Autism. Dev. Disord., 2005, 35, 461-470.

Goldberg R., Motzkin B., Marion R., Scambler P.J., Shprintzen R.J.: Velo-cardio-facial syndrome: a review of 120 patients. Am. J. Med. Genet., 1993, 45, 313-319.

Golding-Kushner K.J., Weller G., Shprintzen R.J.: Velo-cardio-facial syndrome: language and psychological profiles. J. Craniofac. Genet. Dev. Biol., 1985, 5, 259-266.

Gothelf D., Eliez S., Thompson T., Hinard C., Penniman L., Feinstein C., Kwon H., Jin S., Jo B., Antonarakis S.E., Morris M.A., Reiss A. L.: COMT genotype predicts longitudinal cognitive decline and psychosis in 22q11.2 deletion syndrome. Nat. Neurosci., 2005, 8, 1500-1502.

Iascone M.R., Vittorini S., Sacchelli M., Spadoni I., Simi P., Giusti S.: Molecular characterization of 22q11 deletion in a three-generation family with maternal transmission. Am. J. Med. Genet., 2002, 108, 319-321.

Jansen P.W., Duijff S.N., Beemer F.A., Vorstman J.A., Klaassen P.W., $\quad$ Morcus, M.E., Heineman de Boer, J.A.: Behavioral problems in relation to intelligence in children with 22q11.2 deletion syndrome: a matched control study. Am. J. Med. Genet. A, 2007, 143, 574-580.

Klin A., Mayes L.C., Volkmar F.R., Cohen D.J.: Multiplex developmental disorder. J. Dev. Behav. Pediatr., 1995, 16, S7-S11.

Kozma C.: On cognitive variability in velocardiofacial syndrome: profound mental retardation and autism. Am. J. Med. Genet., 1998, 81, 269-270.

Lichter P., Tang C.J., Call K., Hermanson G., Evans G.A., Housman D., Ward D.C.: High-resolution mapping of human chromosome 11 by in situ hybridization with cosmid clones. Science, 1990, 247, 64-69.

McDonald McGinn D.M., Kirschner R., Goldmuntz E., Sullivan K., Eicher P., Gerdes M., Moss E., Solot C., Wang P., Jacobs I., Handler S., Knightly C., Heher K., Wilson M., , ing J. E., Grace K., Driscoll D., Pasquariello P., Randall P., Larossa D., Emanuel B. S., Zackai E. H.: The Philadelphia story: the 22q11.2 deletion: report on 250 patients. Genet. Couns., 1999, 10, 11-24.

Mulder M.P., Wilke M., Langeveld A., Wilming L.G., Hagemeijer A., van Drunen E., Zwarthof E. C., Riegman P. H., Deelen W.H., van den Ouweland A.M.: Positional mapping of loci in the DiGeorge critical region at chromosome 22q11 using a new marker (D22S183). Hum. Genet., 1995, 96, 133-141.

Murphy K.C.: The behavioural phenotype in velo-cardio-facial syndrome. J Intellect. Disabil. Res., 2004, 48, 524-530.

Murphy K.C., Jones L.A., Owen M.J.: High rates of schizophrenia in adults with velo-cardio-facial syndrome. Arch. Gen. Psychiatry., 1999, 56, 940-945.

Murphy K.C., Owen M.J.: Velo-cardio-facial syndrome: a model for understanding the genetics and pathogenesis of schizophrenia. Br. J. Psychiatry, 2001, 179, 397-402. 
Niklasson L., Rasmussen P., Oskarsdottir S., Gillberg C.: Neuropsychiatric disorders in the 22q11 deletion syndrome. Genet. Med., 2001, 3, 79-84.

Niklasson L., Rasmussen P., Oskarsdottir S., Gillberg C.: Attention deficits in children with 22q.11 deletion syndrome. Dev. Med. Child. Neurol., 2005, 47, 803-807.

Papolos D.F., Faedda G.L., Veit S., Goldberg R., Morrow B., Kucherlapati R., Shprintzen R. J.: Bipolar spectrum disorders in patients diagnosed with velo-cardio-facial syndrome: does a hemizygous deletion of chromosome 22q11 result in bipolar affective disorder? Am. J. Psychiatry,1996, 153, 1541-1547.

Pulver A.E., Nestadt G., Goldberg R., Shprintzen R.J., Lamacz M., Wolyniec P. S., Morrow B., Karayiorgou M., Antonarakis S.E., Housman D.: Psychotic illness in patients diagnosed with velo-cardio-facial syndrome and their relatives. J. Nerv. Ment. Dis., 1994, 182, 476-478.

Russell A.J., Munro J.C., Jones P.B., Hemsley D.R., Murray R.M.: Schizophrenia and the myth of intellectual decline. Am. J. Psychiatry, 1997, 154, 635-639.

Shprintzen R.J.: Velo-cardio-facial syndrome: a distinctive behavioral phenotype. Ment. Retard. Dev. Disabil. Res. Rev., 2000, 6, 142-147.

Stachon A.C., Baskin B., Smith A.C., Shugar A., Cytrynbaum C., Fishman L., Mendoza-Londono R., Klatt R., Teebi A., Ray P.N., Weksberg R.: Molecular diagnosis of 22q11.2 deletion and duplication by multiplex ligation dependent probe amplification. Am. J. Med. Genet. A, 2007, 143a, 2924-2930.

Swillen A., Devriendt K., Legius E., Eyskens B., Dumoulin M., Gewillig M., Fryns J. P.: Intelligence and psychosocial adjustment in velocardiofacial syndrome: a study of 37 children and adolescents with VCFS. J. Med. Genet., 1997, 34, 453-458.

Swillen A., Devriendt K., Legius E., Prinzie P., Vogels A., Ghesquiere P., Fryns J. P.: The behavioural phenotype in velo-cardio-facial syndrome (VCFS): from infancy to adolescence. Genet. Couns., 1999, 10, 79-88.

Vorstman J.A., Morcus M.E., Duijff S.N., Klaassen P.W., Heineman de Boer J.A., Beemer F.A., Swaab H., Kahn R.S., van Engeland H.: The 22q11.2 deletion in children: high rate of autistic disorders and early onset of psychotic symptoms. J. Am. Acad. Child. Adolesc. Psychiatry, 2006, 45, 1104-1113. 



\section{CHAPTER 3}

\section{Psychopathology in adults with $22 \mathrm{q} 11$ deletion syndrome and moderate and severe intellectual disability.}

Published as:

Evers LJ, van Amelsvoort TA, Candel MJ, Boer H, Engelen JJ, Curfs LM (2014) J Intellect Disabil Res. Oct;58(10):915-25. 


\section{Abstract}

Background 22q11 deletion syndrome (22q11DS) is associated with mild or borderline intellectual disability (ID). There are hardly any reports on subjects with 22q11DS with moderate or severe ID, and therefore its behavioural and psychiatric characteristics are unknown.

Method We describe behavioural and psychiatric characteristics of 33 adults with 22q11DS and a Full Scale IQ (FSIQ) below 55. Participants were divided into two groups: one group having a FSIQ $\leq 55$ caused by intellectual decline $(n=21)$ and one group with a FSIQ $\leq 55$ who had always functioned at this level $(n=12)$.

Results High scores on psychopathology subscales were found for both subgroups. 22q11DS patients with intellectual decline showed higher rates of co-morbid psychopathology, particularly psychosis. Furthermore, psychosis and intellectual decline were positive correlated.

Conclusion This is the first report addressing adult patients with 22q11DS and moderate to severe intellectual disability. Overall we found high levels of psychopathology with higher scores of psychopathology in the intellectual decline group. Life time psychosis seems to be related to deterioration.

Keywords 22q11 deletion syndrome, intellectual decline, IQ, psychopathology, velocardiofacial syndrome 


\section{Introduction}

$22 q 11$ deletion syndrome (22q11DS), is the most common recurrent copy-number variant disorder caused by a microdeletion in chromosome band 22q11.2 occurring with an incidence of 1 in 4000 (Oskarsdottir, Vujic \& Fasth, 2004, McDonald McGinn \& Sullivan 2011). It is also known as Shprintzen's syndrome or velocardiofacial Syndrome (VCFS). Earlier reports of Conotruncal anamoly face syndrome, Cayler's syndrome, Takao's syndrome, Sedlačková-syndrome, velofacial syndrome and Di-George syndrome turned out to be caused by the same deletion (McDonald et al, 2011). Characteristic clinical features include palatal anomalies, cardiac anomalies, hypo- or aplasia of the thymus, hypoplasia of the parathyroid, and typical facial features. The physical appearance is known to be highly variable (Shprintzen 2008; McDonald-McGinn, Kirschner, Goldmuntz, Sullivan, Eicher, Gerdes,... Zackai, 1999; Shprintzen, Higgins, Antshel, Fremont, Roizen \& Kates, 2005). Approximately half of all subjects with 22q11DS have a normal to borderline intelligence (Swillen, Devriendt, Legius, Eyskens, Dumoulin, Gewillig \& Fryns, 1997, Niklasson \& Gillberg 2010, Antshel, Fremont \& Kates, 2008, Henry, van Amelsvoort, Morris, Owen, Murphy \& Murphy, 2002) and if an intellectual disability is present, this is usually mild (Swillen et al. 1997, De Smedt, Devriendt, Fryns, Vogels, Gewillig \& Swillen, 2007). The presence of a severe or profound intellectual disability is thought to be rare (Swillen et al. 1997). Patients with 22q11DS have a characteristic intelligence profile with poor visual spatial skills, planning ability and abstract reasoning (Swillen, Vandeputte, Cracco, Maes, Ghesquiere, Devriendt \& Fryns, 1999, Henry et al. 2002). Besides the physical and intellectual characteristics, several psychiatric disorders have been reported to be common in children and adolescents with 22q11DS including autism spectrum disorders (ASD) (14\%$50 \%$ ), attention-deficit/hyperactivity disorder (ADHD) (3\% to 46\%), specific and social phobias (23\%-61\%), generalized anxiety disorder (17-29\%), separation anxiety disorder (16\%-21\%), oppositional defiant disorder (16\%-21\%) obsessivecompulsive disorder (OCD) (4\%-33\%), major depressive disorder and dysthymia (10\%-20\%), and bipolar disorder (0 - 64\%) (Papolos, Faedda, Veit, Goldberg, Morrow, Kucherlapati \& Shprintzen, 1996, Arnold, Siegel Bartelt, Cytrynbaum, Teshima \& Schachar, 2001, Feinstein, Eliez, Blasey \& Reiss, 2002, Gothelf, Presburger, Zohar, Burg, Nahmani, Frydman,... Apter, 2004; Gothelf, Frisch, Michaelovsky, Weizman \& Shprintzen, 2009, Antshel, Aneja, Strunge, Peebles, Fremont, Stallone,... Kates, 2007; Vorstman, Morcus, Duijff, Klaassen, Heineman-de Boer, Beemer,... van Engeland, 2006, Niklasson, Rasmussen, Oskarsdottir \& Gillberg, 2009, McDonald et al, 2011; Philip \& Bassett 2011). Up to $30 \%$ of the patients with 22q11DS develop psychotic disorders including schizoaffective disorder and schizophrenia in late adolescence and early adulthood (Murphy, Jones \& Owen, 1999, Bassett et al. 2003, Gothelf et al. 2005, 2009, Stevens and Murphy 2005, Boot, Booij, Abeling, Meijer, da Silva Alves, Zinkstok,... van Amelsvoort, 2011b). Therefore, studying this syndrome 
offers a unique opportunity to increase our understanding of the mechanisms underlying psychiatric disorders. Only few patients with 22q11DS and moderate to severe intellectual disability [full scale intelligence (FSIQ) < 55] have been described in the literature (Gerdes, Solot, Wang, Moss, LaRossa, Randall,... Zackai, 1999, Evers, De Die Smulders, Smeets, Clerkx \& Curfs, 2009). The aim of this explorative study was to gain a better insight into the psychiatric phenotype in adults with 22q11DS who are functioning in the moderate to severe ID range. This will expand our knowledge on the cognitive and psychiatric phenotype of 22q11DS. In addition it may aid the clinician who is working with these often challenging patients.

\section{Method}

The study was approved by the Medical Ethics Committee of the University of Maastricht, Maastricht, The Netherlands.

\section{Study population}

Participants were recruited through a Dutch psychiatric 22q11DS outpatient clinic and through physicians specialized in ID. Subjects with a confirmed deletion in chromosome band 22q11.2 and a present FSIQ $\leq 55$ were included. Those aged under 18 years and over the age of 65 years were excluded, as well as participants with physical disorders affecting brain function like suspicion of major neurologic disorders like brain tumours or stroke. A number of participants gave written consent, and where participants were not able to do so (the majority), consent was obtained from caregivers.

Thirty-three participants (15 women (45.5\%), 18 men (54.5\%) with confirmed 22q11DS participated in this study. The mean age of participants was 40 years ( $S D=11$, range 19-59 years). Thirty-one (93.9\%) of the participants lived in institutions and $6.1 \%(n=2)$ lived at home with their family. Socio-demographic characteristics are presented in Table 1. All participants had a present level of functioning below FSIQ 55. Presence of psychosis during life was obtained out of data from medical files and/or positive score for psychosis on the mini PAS-ADD (Psychiatric Assessment Schedules for Adults with Developmental Disabilities). Premorbid intellectual functioning was determined preferable at young adult age by data from medical files. Based on premorbid intellectual functioning subjects were divided into two groups: an "intellectual decline group" $(n=21)$ : patients with a FSIQ>55 in the past, but who were functioning at a level of FSIQ $\leq 55$ at time of inclusion, and a "no intellectual decline group" $(n=12)$ : patients with a FSIQ $\leq 55$ who had a premorbid FSIQ $\leq 55$. 
Table 1: Sociodemographics

\begin{tabular}{|c|c|c|c|}
\hline & $\begin{array}{l}\text { Intellectual decline } \\
(n=21)\end{array}$ & $\begin{array}{l}\text { No intellectual decline } \\
(\mathrm{n}=12)\end{array}$ & P-values \\
\hline Gender & Male:10; Female:11 & Male:8; Female: 4 & .305 \\
\hline Age $($ mean \pm SD) & $41.81 \pm 7.393$ & $39.00 \pm 14.87$ & .550 \\
\hline Premorbid IQ (mean \pm SD) & $74.2 \pm 7.5$ & $43.7 \pm 8.1$ & $.000^{*}$ \\
\hline $\begin{array}{l}\text { Age at assessment of premorbid IQ } \\
\text { (mean } \pm \text { SD) Range }\end{array}$ & $\begin{array}{l}18.2 \pm 6.8 \\
6-27\end{array}$ & $\begin{array}{l}17.5 \pm 6.9 \\
7-32\end{array}$ & .769 \\
\hline $\begin{array}{l}\text { Duration between assessment of } \\
\text { premorbid functioning and present } \\
\text { assessment (mean } \pm \text { SD) Range }\end{array}$ & $\begin{array}{l}23.6 \pm 9.8 \\
8-39\end{array}$ & $\begin{array}{l}21.5 \pm 11.4 \\
14-48\end{array}$ & .585 \\
\hline V-S, communication $(\text { mean } \pm S D)^{* *}$ & $44.2 \pm 15,3$ & $35.2 \pm 15.9$ & .117 \\
\hline V-S, daily living skills (mean $\pm S D)^{* *}$ & $48.9 \pm 13.5$ & $45.8 \pm 16.8$ & .565 \\
\hline V-S, socialization $(\text { mean } \pm S D)^{* *}$ & $23.3 \pm 10.3$ & $27.3 \pm 16.6$ & .398 \\
\hline V-S, motor skills (mean $\pm S D)^{* *}$ & $38.2 \pm 13.0$ & $33.6 \pm 14.1$ & .345 \\
\hline V-S, composite score $(\text { mean } \pm S D)^{* *}$ & $39.4 \pm 12.1$ & $35.3 \pm 15.6$ & .406 \\
\hline $\begin{array}{l}\text { Estimated FSIQ (Vineland-S } \\
\text { composite scores) (mean } \pm \text { SD) }\end{array}$ & $30.2 \pm 8.0$ & $27.3 \pm 10.7$ & .383 \\
\hline FSIQ drop*** (mean \pm SD) & $43.1 \pm 14.0$ & $15.3 \pm 8.4$ & $.000 *$ \\
\hline History of Psychotic Disorder & $20(95 \%)$ & $2(15 \%)$ & $.000^{*}$ \\
\hline Use of antipsychotics & $17(81 \%)$ & $7(58 \%)$ & .171 \\
\hline Use of antidepressants & $6(29 \%)$ & $3(25 \%)$ & .831 \\
\hline Use of mood stabilizers & $11(52 \%)$ & $4(33 \%)$ & .305 \\
\hline Deletion & $\begin{array}{l}\text { De Novo: } 21 \\
\text { Familial: } 1\end{array}$ & $\begin{array}{l}\text { De Novo: } 10 \\
\text { Familial: } 1\end{array}$ & \\
\hline
\end{tabular}

${ }^{*}$ P-value $\leq 0.007$ (after Bonferroni adjustment)

**Vineland-S, in developmental age (in months)

***Drop FSIQ: premorbid FSIQ minus estimated FSIQ based on Vineland-S scores

\section{Clinical and behavioural measures}

The individuals with 22q11DS and their main caretakers were visited at home. They were interviewed by a psychiatrist with special expertise in intellectual disabilities (lead author). The following instruments were administered:

\section{Vineland-screener}

The translated version (Dutch) of the Vineland screener (Vineland-S) (Scholte, Duijn, v., Dijkxhoorn, Noens \& Berckelaer-Onnes van, 2008) was used to obtain information about adaptive functioning. It is developed for children, adolescents and adults with an developmental age up to six year. It is suitable for use in both research and clinical settings (Sparrow, Carter, Cicchetti, Scholte, vanDuijn, Dijkxhoorn,... van Berkelaer-Onnes, 2008). This instrument, completed by a prima- 
ry caregiver, provides a practical indication of the adaptive functioning related to age (van Duijn, Dijkxhoorn, Noens, Scholte \& van Berckelaer Onnes, 2009). Vineland instruments have been used in adults with a moderate to severe intellectual disability and various genetic disorders (Adams \& Oliver 2010, Wulffaert, Van Berckelaer Onnes \& Scholte, 2009). Because standard intelligence instruments are not suitable in this range of intelligence we chose for the Vineland screener. Outcomes of the Vineland-S developmental age were used to give an estimation of FSIQ (Kraijer \& Plas 2006). Comparison of intelligence measured with Wechsler scales and functioning determined with Vineland screener has been described before in 22q11DS (Antshel, AbdulSabur, Roizen, Fremont \& Kates, 2005). Internal consistency of this instrument (Cronbach's alpha) varied from 0.96 to 0.99 with a test-retest correlation varying from 0.90 and to 0.96 (van Duijn et al. 2009).

\section{Mini PAS-ADD}

The Mini PAS-ADD, a semi-structured interview for psychiatric disorders in people with an ID (Prosser, Moss, Costello, Simpson, Patel \& Rowe, 1998) was used to provide reliable information on symptoms and to obtain psychiatric diagnoses. Outcomes scores can be dichotomised applying threshold scores when indicative for diagnosis (see Table 2). All interviews were carried out by an experienced psychiatrist (lead author). Recent research into the psychometric properties showed the sensitivity to be $100 \%$ and the specificity to be $77 \%$ (Devine, Taggart \& McLornian, 2010). Cronbach's alpha varied from 0.55 for unspecified disorders to 0.95 for autism (Prosser et al. 1998).

\section{Adult Behavioral Check List (ABCL)}

The Adult Behavioral Check List (ABCL) (Achenbach \& Rescorla 2003) was administered to assess prevalence and severity of any behavioural problems. The 134items questionnaire was completed by the primary caregivers of the participants. Problematic statements were scored by a carer or family member who knew the person well, on a three-level rating scale ('not true', 'somewhat or sometimes true' and 'very true'). Following analysis, eight syndrome scales were distinguished (anxious / depressed, withdrawn, somatic complaints, thought problems, attention problems, aggressive behaviour, rule-breaking behaviour and intrusive) and six DSM-oriented scales: depressive problems, anxiety problems, somatic problems, avoidant personality problems, ADHD problems and antisocial personality problems). Internal consistency of the ABCL (Cronbach's alpha) varied from 0.70 to 0.97 with a test-retest correlation varying 0.73 and 0.92 (Achenbach \& Rescorla 2003). 


\section{Use of psychotropic drugs}

The use of psychotropic drugs was noted and classified as antipsychotics, antidepressants and mood stabilizers (Table 1).

Table 2: Mini PAS-ADD and ABCL scores

\begin{tabular}{|c|c|c|c|}
\hline Mini-PAS-ADD score $†$ & $\begin{array}{l}\text { intellectual decline } \\
\text { Mean } \pm \text { SD }\end{array}$ & $\begin{array}{l}\text { No intellectual decline } \\
\text { Mean } \pm \text { SD }\end{array}$ & P-Value \\
\hline Depression (10) & $8.38 \pm 7.24$ & $3.33 \pm 3.11$ & .010 \\
\hline Anxiety disorder (7) & $3.81 \pm 4.86$ & $0.83 \pm 2.04$ & .020 \\
\hline Mania/hypomania (8) & $2.14 \pm 2.50$ & $0.75 \pm 0.75$ & .070 \\
\hline OCD (3) & $1.29 \pm 1.95$ & $0.50 \pm 1.45$ & .234 \\
\hline Psychosis (2) & $2.00 \pm 2.15$ & $0.25 \pm 0.62$ & $.002 *$ \\
\hline Unspecified (6) & $3.29 \pm 2.43$ & $0.58 \pm 0.79$ & $.000^{*}$ \\
\hline Autism Spectrum N (4) & $5.81 \pm 1.60$ & $5.33 \pm 1.92$ & .450 \\
\hline Autism Spectrum P (1) & $1.57 \pm 0.87$ & $1.42 \pm 0.79$ & .616 \\
\hline Autism Spectrum R (3) & $1.43 \pm 0.98$ & $1.42 \pm 1.08$ & .974 \\
\hline \multicolumn{4}{|l|}{ ABCL/syndrome scale** } \\
\hline Anxious/depressed & $67.43 \pm 14.28^{\#}$ & $60.50 \pm 8.12$ & .134 \\
\hline Withdrawn & $75.38 \pm 11.05^{\# \#}$ & $70.92 \pm 6.37 \# \#$ & .151 \\
\hline somatic complaints & $59.48 \pm 6.20$ & $59.67 \pm 7.68$ & .938 \\
\hline Thought problems & $74.10 \pm 9.23^{\# \#}$ & $69.75 \pm 14.05^{\#}$ & .291 \\
\hline Attention problems & $71.52 \pm 8.52^{\# \#}$ & $65.17 \pm 6.85^{\#}$ & .035 \\
\hline Aggressive behavior & $69.33 \pm 13.26^{\#}$ & $62.75 \pm 21.02$ & .277 \\
\hline Rule breaking behavior & $64.71 \pm 6.57$ & $61.00 \pm 4.79$ & .097 \\
\hline Intrusive & $60.76 \pm 10.20$ & $59.75 \pm 7.55$ & .767 \\
\hline \multicolumn{4}{|c|}{ ABCL/DSM oriented scale $\ddagger$} \\
\hline Depressive problems & $67.86 \pm 9.99^{\#}$ & $63.33 \pm 8.86$ & .203 \\
\hline Anxiety problems & $59.10 \pm 9.46$ & $57.75 \pm 9.42$ & .697 \\
\hline Somatic problems & $58.19 \pm 6.88$ & $59.25 \pm 7.68$ & .686 \\
\hline Avoidant problems & $73.10 \pm 9.03^{\# \#}$ & $69.58 \pm 4.68^{\#}$ & .152 \\
\hline ADHD problems & $67.90 \pm 10.22^{\#}$ & $62.83 \pm 6.85$ & .136 \\
\hline Antisocial problems & $65.14 \pm 8.97 \#$ & $60.67 \pm 8.96$ & .178 \\
\hline
\end{tabular}

*P $\leq$ 0,002 (after Bonferroni adjustment)

†In brackets: threshold score when indicative for diagnosis

$\ddagger$ ABCL scores: < 65: normal; 65-70: borderline clinical range\#; >70: clinical range ${ }^{\# \#}$

Mini PAS-ADD, Mini Psychiatric Assessment Schedules for Adults with Developmental Disabilities; ABCL, Adult Behavioral Check List; DSM, Diagnostic and Statistical Manual of Mental Disorders; ADHD, attention-deficit/hyperactivity disorder. 


\section{Statistical analyses}

Socio-demographic data were examined using independent t-tests and Chi-square analysis to determine whether both groups differed with regards to age, gender and present FSIQ. Between-group comparisons were carried out to investigate differences between the deterioration group and the stable low IQ group. We used independent t-tests for all scores on the mini PAS-ADD and ABCL that met criteria for a normal distribution. Mann Whitney U-tests were used in case scores were not normally distributed. To correct for multiple comparisons (Bonferroni adjustment) the significance level for testing was set at $\alpha=0.007$ (demographics) and $\alpha=0.002$ (mini PAS-ADD and ABCL). A two-way between-group analysis of variance was conducted to explore the impact of gender on outcomes of psychopathology in both groups. For the correlation presence of psychosis during life and IQ drop and the correlation between present IQ and use of antipsychotics we performed a Spearman Rank Order correlation coefficient. Pearson product-moment correlation coefficients were performed to analyse (1) the relation between the interval between first intellectual assessment and present intellectual assessment and extend of intellectual decline, and (2) the relation of present FSIQ and Mini PAS-ADD scores for depression, psychosis, anxiety and unspecified problems.

\section{Results}

\section{Participants}

There were no significant between-group differences in gender, age and recently estimated FSIQ (Table 1). Eighteen subjects out of 21 (86\%) of the deterioration group were on antipsychotic medication; in the stable low IQ group 6 out of 12 subjects $(50 \%)$ took antipsychotic medication $(\mathrm{p}=0.027)$.

Figure 1 shows distributions of decline in individuals of the two groups showing that they are distinct groups.

\section{Previous methods of intelligence assessment}

Of eight patients (all in the "intellectual decline" group) intelligence tests were not available. Their premorbid intelligence was very conservative estimated based on their school and / or work history. Of twelve patients (five of the "intellectual decline" group and seven of the "intellectual stable" group) intelligence was assessed with a variety of test including WISC $(n=5)$, Vineland $(n=1)$, GIT $(n=1)$, WAIS $(n=$ $3)$, Peabody $(n=1)$ and WPPSI $(n=1)$. Of thirteen patients (eight of the "intellectual decline" group and five out of the "intellectual stable' group) an IQ score was found in medical files, but no method was mentioned. 


\section{Psychopathology (Table 2)}

Scores on the Mini PAS-ADD show that symptoms of depressive, psychotic and unspecified disorders were significantly more present in the deterioration group. The symptoms of anxiety disorders on the Mini PAS-ADD ( $\mathrm{P}=0.02)$ and attention problems on the ABCL $(\mathrm{P}=0.035)$ were marginally significant between the two groups, all symptoms occurring more often in the deterioration group. Those with cognitive deterioration were more likely to have a history of a psychotic disorder $(\mathrm{p}=0.000)$. The relation between life-time psychosis (yes/no) and IQ drop was investigated using Spearman Rank Order correlation coefficient. There was a strong positive correlation between the two variables, rho $=0.662, \mathrm{n}=33, \mathrm{p}=$ 0.000 , with presence of lifetime psychosis associated with a larger levels of IQ drop. The relation between present FSIQ and psychopathology was investigated using a Pearson product-moment correlation coefficient between the Mini PASSADD scores depression, anxiety, psychosis and unspecified problems (those scored in clinical ranges) with present FSIQ. None of them showed a correlation ( $\mathrm{r}=$ $0.257, \mathrm{p}=0.149 ; \mathrm{r}=0.066, \mathrm{p}=0.716 ; \mathrm{r}=0.332, \mathrm{p}=0.059 ; \mathrm{r}=0.047, \mathrm{p}=0.796$ ).

\section{Gender differences}

On the ABCL we found a significant group by gender interaction for aggressive behaviour $(p=0.015)$. In the "intellectual decline" group males showed less aggression $(p=0.04)$ compared to females, whereas in the "no intellectual decline" group there were no gender differences on ABCL scores. In the "intellectual decline" group females scored higher on psychotic symptoms compared to males $(\mathrm{p}=0.021)$, whereas in the "no intellectual decline" group there was no difference between males and females. In addition, there was a significant group by gender interaction for the ASS-N score (social interaction) $(\mathrm{p}=0.026)$, female in the intellectual decline group showed less social interaction problems compared to the female in the no intellectual decline group, and the men in the deterioration group scored showed more social interaction problems compared to the men in de "no intellectual decline" group.

\section{IQ drop}

The relation between the interval of the first assessment and present assessment and extend of decline was investigated using Pearson product-moment correlation coefficient. There was a strong positive relation $(r=0.38, p=0.027$ ) when performed in all 33 patients. When performed only on the "intellectual decline group" the correlation increases $(r=0.51, p=0.017)$. Correlation in the "no intellectual decline" group was not significant $(r=0.48, p=0.112)$ 


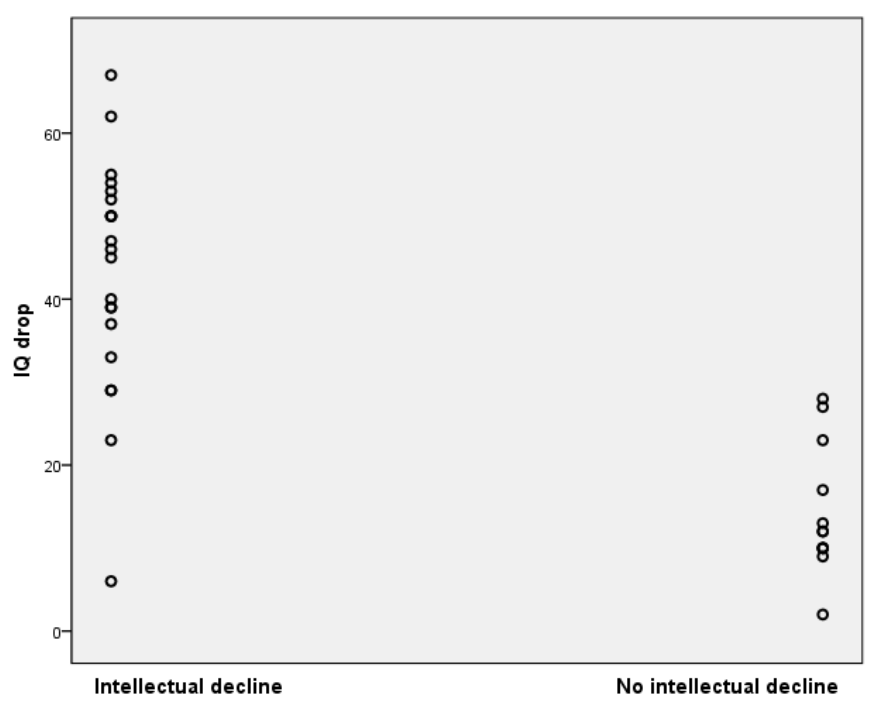

Figure 1 Scatter plot showing Full-Scale IQ (FSIQ) decline in two groups.

\section{Discussion}

This is the first study that describes psychopathology in patients with 22q11DS and a moderate to profound ID.

\section{Psychopathology}

Overall we found high levels of psychopathology. However when dividing the group in those who with premorbid IQ $<55$ and those with premorbid IQ $>70$ and subsequent cognitive decline we observed more psychopathology in the latter group. On the Mini PAS-ADD, a striking difference was observed between the two groups for symptoms of depression, psychosis and unspecified disorders (including memory and concentration problems, restlessness, sleep problems and anhedonia), with scores being significantly higher in the deterioration group. Scores on the ABCL, however, did not reach significant differences between both groups for depressive and thought problems. One of the reasons for this may be that the ABCL does not score for the same clusters as the Mini PAS-ADD. Items scoring for depression and anxiety can mimic symptoms as seen in ASD. We found high scores on the Mini PAS-ADD in domains of ASD in both groups (up to 92\%), especially on social interaction scale (scale $\mathrm{N}$ of the Mini PAS-ADD) and communication problems (scale $\mathrm{P}$ of the Mini PAS-ADD), which is higher than reported in previous studies (44\%-50\%) (Niklasson et al. 2009, Vorstman et al. 2006) which were all 
done in children with 22q11DS. High scores on scale R of the ASD domains on the Mini PAS-ADD (repetitive and stereotype behaviour) were less common than social interaction problems and communication problems. Bruining et al. (Bruining, de Sonneville, Swaab, de Jonge, Kas, van Engeland \& Vorstman, 2010) suggested that ASD in 22q11DS shows less autistic symptom variance compared to ASD not associated with 22q11DS. They suggest that the influence of a specific genetic variant (such as 22q11DS) leads to a typical ASD subtype with lower autistic symptom variance. The findings in this study give support to this lower symptom variance within 22q11DS, with high scores in the social interaction and communication scales, and low scores on ritualistic behaviour on the Mini PAS-ADD.

We found higher scores on psychopathology in the deterioration group and less psychopathology in the stable low IQ group. In a cohort of 75 children with non-specific intellectual disabilities, Koskentausta et al. (Koskentausta, Iivanainen \& Almqvist, 2007), found more psychopathology in moderately intellectually disabled children when compared to severely/profoundly intellectually disabled children. Chadwick et al. (Chadwick, Kusel \& Cuddy, 2008) also found a positive association between psychopathology and severity of intellectual disability in people with non-specific intellectual disability although the severity of the intellectual disability was also positively associated with autistic symptomatology. We did not conduct a longitudinal study, but retrospective data analysis showed fewer lifetime psychotic problems in the stable low IQ group. This is in agreement with the study of Horovitz et al. (Horovitz, Matson, Sipes, Shoemaker, Belva \& Bamburg, 2011) who found a stable pattern of psychopathology in 74 adults with a severe to profound ID (in non-specific intellectual disabled adults) over a period of one year.

\section{Low FSIQ and deterioration}

The average premorbid FSIQ of $74.2( \pm 7.5)$ in our deterioration group is within the range of intelligence normally found in children and adults with 22q11DS (Swillen, Vogels, Devriendt \& Fryns, 2000, Chow, Watson, Young \& Bassett, 2006; Vorstman et al. 2006). Cognitive deterioration in schizophrenia is a common finding (Becker, Chow, AbdelMalik, Gheorghiu, Husted \& Weksberg, 2010), however, in our study we found a more severe decline in intellectual functioning compared to cognitive deterioration typically found in schizophrenia (Russell, Munro, Jones, Hemsley \& Murray, 1997, Seidman, Buka, Goldstein \& Tsuang, 2006). Low functioning is noted on all Vineland domains demonstrating that not only verbal IQ is declined as seen in earlier research in 22q11DS (Woodin, Wang, Aleman, McDonald-McGinn, Zackai \& Moss, 2001). Our data show a strong positive correlation between psychotic problems during lifetime and deterioration in 22q11DS $(r=0.621, p=0.000)$. There was no significant correlation between deterioration and current psychotic problems according to the Mini PAS-ADD score. Therefore we presume a causal relationship between lifetime psychosis and deterioration. To the best of our 
knowledge only 2 case reports have reported the phenomenon of severe cognitive deterioration in adult 22q11DS (Evers, Vermaak, Engelen \& Curfs, 2006, Evers et al. 2009). Duijff et al. reported in children with 22q11DS between 5.5 and 9.5 years old a mean significant decline of 9.7 FSIQ points. Ten out of 29 children showed an absolute decline in cognitive raw scores between ages 7.5 and 9.5 year (Duijff, Klaassen, de Veye, Beemer, Sinnema \& Vorstman, 2012). Gothelf et al. (Gothelf, Eliez, Thompson, Hinard, Penniman, Feinstein,... Reiss, 2005) observed a cognitive deterioration in 22q11DS, during childhood. This deterioration was 10 points in verbal IQ with a strong correlation between the low activity Catechol-O-MethylTransferase (COMT) genotype, psychosis and deterioration. The relation between 22q11DS and psychosis has received attention in recent literature, where particularly COMT and Proline Dehydrogenase (PRODH) genes, both located in the deleted region, have been investigated (Raux, Bumsel, Hecketsweiler, van Amelsvoort, Zinkstok, Manouvrier-Hanu,... Camion, 2007, Boot, Booij, Zinkstok, Baas, Swillen, Owen,...Van Amelsvoort, 2011c; da Silva Alves Boot, Schmitz, Nederveen, Vorstman, Lavini,... van Amelsvoort, 2011; de Koning, Boot, Bloemen, van Duin, Abel, de Haan,... van Amelsvoort, 2012). Haplo-insufficiency of COMT and/or PRODH genes could be a factor in the process of cognitive deterioration. We found a very high prevalence of lifetime history of psychotic problems (95\%) in the deterioration group, compared to the stable low IQ group (15\%) and compared to previous findings of up to $30 \%$ in people with 22q11DS as a whole (Bassett, Chow, AbdelMalik, Gheorghiu, Husted \& Weksberg, 2003). In our study gender differences were found with the female patients in the deterioration group showing more aggression and being particularly more vulnerable to develop a psychotic disorder when compared to the stable low IQ group. Gender differences in 22q11DS have been described before. Kates et al. (Kates, Antshel, Abdulsabur, Colgan, Funke, Fremont,... Shprintzen, 2006) suggested that COMT polymorphism may have a gender modulating effect in determining the neuroanatomical phenotype. Antshel et al. (Antshel, AbdulSabur, Roizen, Fremont \& Kates, 2005) found in a cohort of children that boys may be more cognitively affected than girls and a negative association between age and cognitive functioning in girls with 22q11DS but not in boys. Also Boot et al. found indications of a slower dopamine metabolism in female patients (Boot, Booij, Abeling, Meijer, da Silva Alves, Zinkstok,... van Amelsvoort, 2011a). Oestrogens down-regulate COMT activity, resulting in a lower COMT and higher dopaminergic activity in females compared to males (Chen, Lipska, Halim, Ma, Matsumoto, Melhem,... Weinberger, 2004). Therefore, effects of COMT haploinsufficiency may differentially affect males and females in with 22q11DS (Harrison \& Tunbridge 2008).

In the analysis we looked for other possible explanations for the observed decline. Medication could be as one explanation for this decline, however we found no differences between the two groups. Also a Spearman's rho correlation coefficient showed no significant level of correlation between present IQ and use of an- 
tipsychotics. Active psychopathology can have an impact on cognitive functioning and in the intellectual decline group we observe a significant higher proportion in depressive, anxiety, psychotic and unspecified problems (the latter two still significant after Bonferroni correction). Depression, for instant, is known to have a serious impact on daily functioning and it can be expected to influence scores on the Vineland-screener. To determine if active psychopathology is correlated with the present FSIQ we performed a Pearson product-moment correlation coefficient between Mini PAS-ADD scores for depression, psychosis, anxiety and unspecified problems with present FSIQ. None of them showed a significant correlation. At this moment we presume a continuous, degenerative process having a stable and severely impairing impact on cognition and mental health.

\section{Strength and limitations}

This is the first report addressing adult patients with 22q11DS and moderate to severe ID. To date, most studies in 22q11DS concern children, adolescents and young adults. Also, subjects with moderate to severe ID are often excluded from studies therefore current literature on 22q11DS may not representative of the 22q11DS. Gaining more insight into possible prognostic outcomes is in our opinion very important. This study, however has some limitations. Although the sample size is relatively large and the first for this specific subgroup of people with 22q11DS, it is still small from a methodological point of view. Additionally, most participants were referred by psychiatric services or intellectual disability physicians, which makes the study accessible to ascertainment bias. Because of the low level of intellectual functioning we were unable to measure intelligence with standard intelligence tests. Premorbid intellectual functioning was obtained retrospectively from patient records. Therefore, premorbid functioning was established with different IQ instruments. Ideally, comparison of premorbid with present functioning is done with the same instruments. However, to our knowledge, there are no instruments that can measure mild intellectual disabilities and severe or profound disabilities making comparison possible. Establishing adaptive functioning with Vineland-Screener and afterwards making an estimation of present functioning was in our opinion the best choice.

In this study we presented a series of 33 patients who function at a low intelligence level. Some of them functioned already at young age at that low level, were others declined during adulthood. Although an IQ below 55 was thought to be relatively uncommon, but reported (Gerdes et al. 1999), we showed that it may be more common than expected. 22q11DS as a diagnosis should be considered when patients display intellectual decline, especially when accompanied by psychosis. Conditions that are relative uncommon in 22q11DS, such as polymicrogyria should not impede this (Robin, Taylor, McDonald-McGinn, Zackai, Bingham, Collins,... Dobyns, 2006). Our results suggest that those adults with 22q11DS that gradually 
deteriorate cognitively are highly likely to suffer from psychotic episodes during adult life, whereas those with a premorbid low IQ do not show the increased rates of psychosis that usually is seen in 22q11DS.

The presence of psychosis and cognitive deterioration suggests a Dementia Praecox like picture as described by Kraepelin (Kraepelin 1901). This psychotic disorder was described as a neurodegenerative process resulting in a dementialike condition. The cognitive deterioration we found in our 22q11DS sample may be more severe and suggests a neurodegenerative process involving genes located at 22q11.

More attention should be paid to psychiatric examination of 22q11DS subjects with moderate to severe intellectual disability. Longitudinal studies, including adult ages are needed to gain more insight in the behavioural, cognitive and psychiatric problems of this specific subgroup.

Acknowledgements

We thank the participating patients, their parents and their caregivers for participating in this study.

Conflict of interest

The authors declare that they have no conflict of interest. 


\section{References}

Achenbach, T. M. \& Rescorla, L. A. (2003) Manual for the ASEBA adult forms \& profiles, (Trans. Research center for children, Youth \& Families, Burlington, VT.

Adams, D. \& Oliver, C. (2010) The relationship between acquired impairments of executive function and behaviour change in adults with Down syndrome. J Intellect Disabil Res, 54, 393-405.

Antshel, K. M., AbdulSabur, N., Roizen, N., Fremont, W. \& Kates, W. R. (2005) Sex differences in cognitive functioning in velocardiofacial syndrome (VCFS). Dev Neuropsychol, 28, 849-69.

Antshel, K. M., Aneja, A., Strunge, L., Peebles, J., Fremont, W. P., Stallone, K., Abdulsabur, N., Higgins, A. M., Shprintzen, R. J. \& Kates, W. R. (2007) Autistic spectrum disorders in velo-cardio facial syndrome (22q11.2 deletion). J Autism Dev Disord, 37, 1776-86.

Antshel, K. M., Fremont, W. \& Kates, W. R. (2008) The neurocognitive phenotype in velo-cardio-facial syndrome: a developmental perspective. Dev Disabil Res Rev, 14, 43-51.

Antshel, K. M., Fremont, W., Roizen, N. J., Shprintzen, R., Higgins, A. M., Dhamoon, A. \& Kates, W. R. (2006) ADHD, major depressive disorder, and simple phobias are prevalent psychiatric conditions in youth with velocardiofacial syndrome. J Am Acad Child Adolesc Psychiatry, 45, 596-603.

Arnold, P. D., Siegel Bartelt, J., Cytrynbaum, C., Teshima, I. \& Schachar, R. (2001) Velo-cardio-facial syndrome: Implications of microdeletion 22q11 for schizophrenia and mood disorders. Am J Med Genet, 105, 354-62.

Bassett, A. S., Chow, E. W., AbdelMalik, P., Gheorghiu, M., Husted, J. \& Weksberg, R. (2003) The schizophrenia phenotype in 22q11 deletion syndrome. Am J Psychiatry, 160, 1580-6.

Becker, H. E., Nieman, D. H., Wiltink, S., Dingemans, P. M., van de Fliert, J. R., Velthorst, E., de Haan, L., van Amelsvoort, T. A. \& Linszen, D. H. (2010) Neurocognitive functioning before and after the first psychotic episode: does psychosis result in cognitive deterioration? Psychol Med, 40, 1599-606.

Boot, E., Booij, J., Abeling, N., Meijer, J., da Silva Alves, F., Zinkstok, J., Baas, F., Linszen, D. \& van Amelsvoort, T. (2011a) Dopamine metabolism in adults with 22q11 deletion syndrome, with and without schizophrenia--relationship with COMT Val108/158Met polymorphism, gender and symptomatology.J Psychopharmacol, 25, 888-95.

Boot, E., Booij, J., Abeling, N., Meijer, J., da Silva Alves, F., Zinkstok, J., Baas, F., Linszen, D. \& van Amelsvoort, T. (2011b) Dopamine metabolism in adults with 22q11 deletion syndrome, with and without schizophrenia--relationship with COMT $\operatorname{Val}(1) /(1) M e t$ polymorphism, gender and symptomatology. J Psychopharmacol, 25, 888-95.

Boot, E., Booij, J., Zinkstok, J. R., Baas, F., Swillen, A., Owen, M. J., Murphy, D. G., Murphy, K. C., Linszen, D. H. \& Van Amelsvoort, T. A. (2011c) COMT Val(158) met genotype and striatal D(2/3) receptor binding in adults with 22q11 deletion syndrome. Synapse, 65, 967-70.

Bruining, H., de Sonneville, L., Swaab, H., de Jonge, M., Kas, M., van Engeland, H. \& Vorstman, J. (2010) Dissecting the clinical heterogeneity of autism spectrum disorders through defined genotypes. PLoS One, 5, e10887.

Chadwick, O., Kusel, Y. \& Cuddy, M. (2008) Factors associated with the risk of behaviour problems in adolescents with severe intellectual disabilities. J Intellect Disabil Res, 52, 864-76.

Chen, J., Lipska, B. K., Halim, N., Ma, Q. D., Matsumoto, M., Melhem, S., Kolachana, B. S., Hyde, T. M., Herman, M. M., Apud, J., Egan, M. F., Kleinman, J. E. \& Weinberger, D. R. (2004) Functional analysis of genetic variation in catechol-0-methyltransferase (COMT): effects on mRNA, protein, and enzyme activity in postmortem human brain. Am J Hum Genet, 75, 807-21.

Chow, E. W., Watson, M., Young, D. A. \& Bassett, A. S. (2006) Neurocognitive profile in 22q11 deletion syndrome and schizophrenia. Schizophr Res, 87, 270-8.

da Silva Alves, F., Boot, E., Schmitz, N., Nederveen, A., Vorstman, J., Lavini, C., Pouwels, P. J., de Haan, L., Linszen, D. \& van Amelsvoort, T. (2011) Proton magnetic resonance spectroscopy in 22q11 deletion syndrome. PLoS One, 6, e21685.

de Koning, M. B., Boot, E., Bloemen, O. J., van Duin, E. D., Abel, K. M., de Haan, L., Linszen, D. H. \& van Amelsvoort, T. A. (2012) Startle reactivity and prepulse inhibition of the acoustic startle response are modulated by catechol-0-methyl-transferase Val(158) Met polymorphism in adults with 22q11 deletion syndrome. J Psychopharmacol, 26, 1548-60. 
De Smedt, B., Devriendt, K., Fryns, J. P., Vogels, A., Gewillig, M. \& Swillen, A. (2007) Intellectual abilities in a large sample of children with Velo-Cardio-Facial Syndrome: an update. J Intellect Disabil Res, 51, 666-70.

Devine, M., Taggart, L. \& McLornian, P. (2010) Screening for mental health problems in adults with learning disabilities using the Mini PAS-ADD Interview. British journal of learning disablities, 4, 252258.

Duijff, S. N., Klaassen, P. W., de Veye, H. F., Beemer, F. A., Sinnema, G. \& Vorstman, J. A. (2012) Cognitive development in children with 22q11.2 deletion syndrome. Br J Psychiatry, 200, 462-8.

Evers, L. J., De Die Smulders, C. E., Smeets, E. E., Clerkx, M. G. \& Curfs, L. M. (2009) The velo-cardio-facial syndrome: the spectrum of psychiatric problems and cognitive deterioration at adult age. Genet Couns, 20, 307-15.

Evers, L. J., Vermaak, M. P., Engelen, J. J. \& Curfs, L. M. (2006) The velocardiofacial syndrome in older age: dementia and autistic features. Genet Couns, 17, 333-40.

Feinstein, C., Eliez, S., Blasey, C. \& Reiss, A. L. (2002) Psychiatric disorders and behavioral problems in children with velocardiofacial syndrome: usefulness as phenotypic indicators of schizophrenia risk. Biol Psychiatry, 51, 312-8.

Gerdes, M., Solot, C., Wang, P. P., Moss, E., LaRossa, D., Randall, P., Goldmuntz, E., Clark, B. J., 3rd, Driscoll, D. A., Jawad, A., Emanuel, B. S., McDonald-McGinn, D. M., Batshaw, M. L. \& Zackai, E. H. (1999) Cognitive and behavior profile of preschool children with chromosome 22q11.2 deletion. Am J Med Genet, 85, 127-33.

Gothelf, D., Eliez, S., Thompson, T., Hinard, C., Penniman, L., Feinstein, C., Kwon, H., Jin, S., Jo, B., Antonarakis, S. E., Morris, M. A. \& Reiss, A. L. (2005) COMT genotype predicts longitudinal cognitive decline and psychosis in 22q11.2 deletion syndrome. Nat Neurosci, 8, 1500-2.

Gothelf, D., Frisch, A., Michaelovsky, E., Weizman, A. \& Shprintzen, R. J. (2009) Velo-Cardio-Facial Syndrome. J Ment Health Res Intellect Disabil, 2, 149-167.

Gothelf, D., Presburger, G., Zohar, A. H., Burg, M., Nahmani, A., Frydman, M., Shohat, M., Inbar, D., AviramGoldring, A., Yeshaya, J., Steinberg, T., Finkelstein, Y., Frisch, A., Weizman, A. \& Apter, A. (2004) Obsessive-compulsive disorder in patients with velocardiofacial (22q11 deletion) syndrome. Am J Med Genet B Neuropsychiatr Genet, 126, 99-105.

Harrison, P. J. \& Tunbridge, E. M. (2008) Catechol-O-methyltransferase (COMT): a gene contributing to sex differences in brain function, and to sexual dimorphism in the predisposition to psychiatric disorders. Neuropsychopharmacology, 33, 3037-45.

Henry, J. C., van Amelsvoort, T., Morris, R. G., Owen, M. J., Murphy, D. G. \& Murphy, K. C. (2002) An investigation of the neuropsychological profile in adults with velo-cardio-facial syndrome (VCFS). Neuropsychologia, 40, 471-8.

Horovitz, M., Matson, J. L., Sipes, M., Shoemaker, M., Belva, B. \& Bamburg, J. W. (2011) Incidence and trends in psychopathology symptoms over time in adults with severe to profound intellectual disability. Res Dev Disabil, 32, 685-92.

Kates, W. R., Antshel, K. M., Abdulsabur, N., Colgan, D., Funke, B., Fremont, W., Higgins, A. M., Kucherlapati, R. \& Shprintzen, R. J. (2006) A gender-moderated effect of a functional COMT polymorphism on prefrontal brain morphology and function in velo-cardio-facial syndrome (22q11.2 deletion syndrome). Am J Med Genet B Neuropsychiatr Genet.

Koskentausta, T., Iivanainen, M. \& Almqvist, F. (2007) Risk factors for psychiatric disturbance in children with intellectual disability. J Intellect Disabil Res, 51, 43-53.

Kraepelin, E. (1901) A general view of dementia praecox, Brownrigg AE (trans). Am J Insanity, 58, 121132.

Kraijer, D. W. \& Plas, J. J. (2006) Handboek psychodiagnostiek en beperkte begaafdheid, (Trans. Harcourt Assesment B.V., Amsterdam.

McDonald-McGinn, D. M., Kirschner, R., Goldmuntz, E., Sullivan, K., Eicher, P., Gerdes, M., Moss, E., Solot, C., Wang, P., Jacobs, I., Handler, S., Knightly, C., Heher, K., Wilson, M., Ming, J. E., Grace, K., Driscoll, D., Pasquariello, P., Randall, P., Larossa, D., Emanuel, B. S. \& Zackai, E. H. (1999) The Philadelphia story: the 22q11.2 deletion: report on 250 patients. Genet Couns, 10, 11-24. 
McDonald McGinn, D. M. \& Sullivan, K. E. (2011) Chromosome 22q11.2 deletion syndrome (DiGeorge syndrome/velocardiofacial syndrome). Medicine (Baltimore), 90, 1-18.

Murphy, K. C., Jones, L. A. \& Owen, M. J. (1999) High rates of schizophrenia in adults with velo-cardiofacial syndrome. Arch Gen Psychiatry, 56, 940-5.

Niklasson, L. \& Gillberg, C. (2010) The neuropsychology of 22q11 deletion syndrome. A neuropsychiatric study of 100 individuals. Res Dev Disabil, 31, 185-94.

Niklasson, L., Rasmussen, P., Oskarsdottir, S. \& Gillberg, C. (2009) Autism, ADHD, mental retardation and behavior problems in 100 individuals with 22q11 deletion syndrome. Res Dev Disabil, 30, 76373.

Oskarsdottir, S., Vujic, M. \& Fasth, A. (2004) Incidence and prevalence of the 22q11 deletion syndrome: a population-based study in Western Sweden. Arch Dis Child, 89, 148-51.

Papolos, D. F., Faedda, G. L., Veit, S., Goldberg, R., Morrow, B., Kucherlapati, R. \& Shprintzen, R. J. (1996) Bipolar spectrum disorders in patients diagnosed with velo-cardio-facial syndrome: does a hemizygous deletion of chromosome 22q11 result in bipolar affective disorder? Am J Psychiatry, 153, 1541-7.

Philip, N. \& Bassett, A. (2011) Cognitive, behavioural and psychiatric phenotype in 22q11.2 deletion syndrome. Behav Genet, 41, 403-12.

Prosser, H., Moss, S., Costello, H., Simpson, N., Patel, P. \& Rowe, S. (1998) Reliability and validity of the Mini PAS-ADD for assessing psychiatric disorders in adults with intellectual disability. J Intellect Disabil Res, 42 ( Pt 4), 264-72.

Raux, G., Bumsel, E., Hecketsweiler, B., van Amelsvoort, T., Zinkstok, J., Manouvrier-Hanu, S., Fantini, C., Breviere, G. M., Di Rosa, G., Pustorino, G., Vogels, A., Swillen, A., Legallic, S., Bou, J., Opolczynski, G., Drouin-Garraud, V., Lemarchand, M., Philip, N., Gerard-Desplanches, A., Carlier, M., Philippe, A., Nolen, M. C., Heron, D., Sarda, P., Lacombe, D., Coizet, C., Alembik, Y., Layet, V., Afenjar, A., Hannequin, D., Demily, C., Petit, M., Thibaut, F., Frebourg, T. \& Campion, D. (2007) Involvement of hyperprolinemia in cognitive and psychiatric features of the $22 \mathrm{q} 11$ deletion syndrome. Hum Mol Genet, 16, 83-91.

Robin, N. H., Taylor, C. J., McDonald-McGinn, D. M., Zackai, E. H., Bingham, P., Collins, K. J., Earl, D., Gill, D., Granata, T., Guerrini, R., Katz, N., Kimonis, V., Lin, J. P., Lynch, D. R., Mohammed, S. N., Massey, R. F., McDonald, M., Rogers, R. C., Splitt, M., Stevens, C. A., Tischkowitz, M. D., Stoodley, N., Leventer, R. J., Pilz, D. T. \& Dobyns, W. B. (2006) Polymicrogyria and deletion 22q11.2 syndrome: window to the etiology of a common cortical malformation. Am J Med Genet A, 140, 2416-25.

Russell, A. J., Munro, J. C., Jones, P. B., Hemsley, D. R. \& Murray, R. M. (1997) Schizophrenia and the myth of intellectual decline. Am J Psychiatry, 154, 635-9.

Scholte, E., Duijn, v. G., Dijkxhoorn, Y., Noens, I. \& Berckelaer-Onnes van, I. A. (2008) Vineland Screener 0-6 jaar, (Trans. PITS, Leiden,The Netherlands.

Seidman, L. J., Buka, S. L., Goldstein, J. M. \& Tsuang, M. T. (2006) Intellectual decline in schizophrenia: evidence from a prospective birth cohort 28 year follow-up study. J Clin Exp Neuropsychol, 28, 22542.

Shprintzen, R. J. (2008) Velo-cardio-facial syndrome: 30 Years of study. Dev Disabil Res Rev, 14, 3-10.

Shprintzen, R. J., Higgins, A. M., Antshel, K., Fremont, W., Roizen, N. \& Kates, W. (2005) Velo-cardio-facial syndrome. Curr Opin Pediatr, 17, 725-30.

Sparrow, S. S., Carter, A. C., Cicchetti, D. V., Scholte, E., vanDuijn, G., Dijkxhoorn, Y., Noens, I. \& van Berkelaer-Onnes, I. (2008) Vineland Screener 0-6 jaar, (Trans. Pits, Leiden, Netherlands.

Stevens, A. F. \& Murphy, K. C. (2005) Behavioral and psychiatric disorders in velo-cardio-facial syndrome. In: Velo-cardio-facial syndrome, a model for understanding microdeletion disorders. (eds K. C. Murphy \& P. J. Scambler). pp. 135-146. Cambridge University Press, Cambridge.

Swillen, A., Devriendt, K., Legius, E., Eyskens, B., Dumoulin, M., Gewillig, M. \& Fryns, J. P. (1997) Intelligence and psychosocial adjustment in velocardiofacial syndrome: a study of 37 children and adolescents with VCFS. J Med Genet, 34, 453-8. 
Swillen, A., Vandeputte, L., Cracco, J., Maes, B., Ghesquiere, P., Devriendt, K. \& Fryns, J. P. (1999) Neuropsychological, learning and psychosocial profile of primary school aged children with the velocardio-facial syndrome (22q11 deletion): evidence for a nonverbal learning disability? Child Neuropsychol, 5, 230-41.

Swillen, A., Vogels, A., Devriendt, K. \& Fryns, J. P. (2000) Chromosome 22q11 deletion syndrome: update and review of the clinical features, cognitive-behavioral spectrum, and psychiatric complications. Am J Med Genet, 97, 128-35.

van Duijn, G., Dijkxhoorn, Y., Noens, I., Scholte, E. \& van Berckelaer Onnes, I. (2009) Vineland Screener 012 years research version (NL). Constructing a screening instrument to assess adaptive behaviour. Int J Methods Psychiatr Res, 18, 110-7.

Vorstman, J. A., Morcus, M. E., Duijff, S. N., Klaassen, P. W., Heineman-de Boer, J. A., Beemer, F. A., Swaab, H., Kahn, R. S. \& van Engeland, H. (2006) The 22q11.2 deletion in children: high rate of autistic disorders and early onset of psychotic symptoms. J Am Acad Child Adolesc Psychiatry, 45, 1104-13.

Woodin, M., Wang, P. P., Aleman, D., McDonald-McGinn, D., Zackai, E. \& Moss, E. (2001) Neuropsychological profile of children and adolescents with the 22q11.2 microdeletion. Genet Med, 3, 34-9.

Wulffaert, J., Van Berckelaer Onnes, I. A. \& Scholte, E. M. (2009) Autistic disorder symptoms in Rett syndrome. Autism, 13, 567-81. 


\section{CHAPTER 4}

\section{The use of two different MLPA kits in 22q11.2 Deletion Syndrome}

Submitted as:

Evers LJM, Engelen JJM, Houben LMH, Curfs LMG \& van Amelsvoort TAMJ 


\section{Abstract}

$22 q 11.2$ deletion syndrome (22q11DS) is one of the most common recurrent copynumber variant disorder, caused by a microdeletion in chromosome band 22q11.2 and occurring with a population prevalence of 1 in 2000 . Until today there has been no evidence that the size of the deletion has an influence on the clinical phenotype. Most studies report that 22q11DS is associated with mild or borderline intellectual disability. There are a limited number of reports on 22q11DS subjects with moderate or severe intellectual disability.

In this study we describe 64 adult patients with 22q11DS, 33 who were functioning at an intellectual level lower than an IQ of 55 and 31 patients functioning in the average range for 22q11DS. Deletion size was established with two different Multiplex ligation-dependent probe amplification (MLPA) mixtures. We compared deletion size with intellectual functioning and presence of psychotic symptoms during life. The use of the experimental MLP kit gave extra information on deletion size: in all cases the deletion size could be delineated more precisely with the experimental MLPA kit and in two cases the deletion size was shorter than all other "typical ones".

Keywords 22q11.2 deletion syndrome, cognitive deterioration, intelligence, psychopathology, MLPA, deletion size 


\section{Introduction}

22q11.2 deletion syndrome (22q11DS) is one of the most common recurrent copynumber variant disorders caused by a microdeletion in chromosome band 22q11.2. Characteristic clinical features include palatal and cardiac anomalies, hypo- or aplasia of the thymus, hypoplasia of the parathyroid, and typical facial features. The physical appearance is known to be highly variable (McDonaldMcGinn, Kirschner, Goldmuntz, Sullivan, Eicher, Gerdes,... Zackai et al., 1999; Shprintzen, 2008; Shprintzen, Higgins, Antshel, Fremont, Roizen, \& Kates, 2005). Its prevalence and birth incidence is still under debate. Because of the strong variance in phenotype some patients with a deletions are not immediately identified or diagnosed at birth. Therefore in the literature differences in birth incidence are reported, ranging from 1 in 2000 (Shprintzen, 2008) to 1 in 6000 (Botto, May, Fernhoff, Correa, Coleman, Rasmussen,... Campbell et al., 2003). Recently Grati et al. (Grati, Molina Gomes, Ferreira, Dupont, Alesi, Gouas,... Vialard 2015) reported a birth incidence of 1:992 in a cohort of over 9.500 pregnancies, which indicates that reported prevalence rates are often underestimations of the incidence during pregnancy. As some of the physical abnormalities of 22q11DS are not compatible with life, prevalence rates will be lower, but because of the variability of penetrance of the deletion, some patient with a deletions will remain undiscovered until adulthood. The microdeletion can be diagnosed with e.g. fluorescence in situ hybridization (FISH) (Miller, 2008), multiplex ligation-dependent probe amplification (MLPA) (Jalali, Vorstman, Errami, Vijzelaar, Biegel, Shaikh, \& Emanuel, 2008) or array comparative genomic hybridization (aCGH) analysis (Bittel, Yu, Newkirk, Kibiryeva, Holt, Butler, \& Cooley, 2009). FISH testing on 22q11DS is performed with a specific probe (i.e., D22S75, N25, or TUPLE1) localized in the deletion region and a control probe. In metaphases of individuals with a 22q11.2 deletion only one fluorescent signal is present of the 22q11DS specific probe and two fluorescent signals of the control probe. In healthy individuals both probes will be visible as fluorescent spots in all metaphases (Miller, 2008). MLPA is a multiplex polymerase chain reaction (PCR) assay that utilizes up to 40 probes. Each of these probes is specific for a different DNA sequence in the 22q11DS region and is used to evaluate the relative copy number of each DNA sequence (Stuppia, Antonucci, Palka, \& Gatta, 2012). aCGH analysis arrays are constructed by attaching pieces of DNA onto a solid support and to compare a patient's DNA with a known reference DNA sample. The advantage of array analysis is that it simultaneously assays discrete loci in a high-throughput manner at a very high resolution (Shaffer, Bejjani, Torchia, Kirkpatrick, Coppinger, \& Ballif, 2007).

Approximately half of all subjects with 22q11DS have a normal to borderline intelligence (Antshel, Fremont, \& Kates, 2008; Chow, Watson, Young, \& Bassett, 2006; Henry, van Amelsvoort, Morris, Owen, Murphy, \& Murphy, 2002; Niklasson \& Gillberg, 2010; van Amelsvoort, Henry, Morris, Owen, Linszen, Murphy \& Mur- 
phy, 2004) and if an intellectual disability is present, this is usually mild (De Smedt, Devriendt, Fryns, Vogels, Gewillig \& Swillen, 2007). The presence of a profound or severe intellectual disability was thought to be rare. Patients with 22q11DS functioning at a moderate to severe intellectual disability level (full scale intelligence (FSIQ) < 55) have been described less frequently in the literature and concern mostly case reports (Devriendt, Thienen, Swillen, \& Fryns, 1996; Evers, De Die Smulders, Smeets, Clerkx, \& Curfs, 2009; Iascone, Vittorini, Sacchelli, Spadoni, Simi, \& Giusti, 2002; Kozma, 1998; Swillen, Devriendt, Legius, Eyskens, Dumoulin, Gewillig \& Fryns, 1997) but have recently received more attention (Evers, van Amelsvoort, Candel, Boer, Engelen, \& Curfs, 2014). Thus far there has been no evidence that the deletion size is related to the symptoms seen in 22q11DS, nor psychopathology or intelligence (Lindsay, 2001), but this conclusion is now under debate (Michaelovsky, Frisch, Carmel, Patya, Zarchi, Green,... Gothelf, 2012). Atypical findings in conotruncal heart defects in 22q11DS, are possibly related to atypical deletion sizes (Rauch, Zink, Zweier, Thiel, Koch, Rauch,... Hofbeck, 2005). The relation between deletion size and intellectual functioning covering the broader intellectual range has not yet been investigated in 22q11DS. Deletions in the 22q11DS region are described as LCR22-A, LCR22-B, LCR22-C, LCR22-D, LCR22-E, LCR22-F and LCR22-G corresponding to the known Low Copy Repeat (LCR) regions that are involved in the deletion. The deletions described as typical have a length of $3 \mathrm{Mb}$ and range from LCR22-A to LCR22-D (Jalali et al., 2008). MLPA analysis in 22q11DS is mostly done with the standard MLPA kit (P250, MRCHolland). In the research MLPA P324 kit (MRC-Holland) additional probes are added, including 3 Proline Dehydrogenase (PRODH) probes. PRODH is responsible for conversion of proline to glutamate and it has been suggested that it can be of importance in several psychopathological mechanisms in 22q11DS (Carmel, Zarchi, Michaelovsky, Frisch, Patya, Green,... Weizman, 2014; de Koning, Boot, Bloemen, van Duin, Bakker, Abel \& van Amelsvoort, 2015; Evers, van Amelsvoort, Bakker, de Koning, Drukker, \& Curfs, 2015; Radoeva, Coman, Salazar, Gentile, Higgins, Middleton,... Kates, 2014; Zarchi, Carmel, Avni, Attias, Frisch, Michaelovsky,... Gothelf, 2013). Also 12 additional T-Box1 (TBX1) probes are included in the P324 kit besides the two TBX1 probes in the P250 kit. TBX1 is one of the most important candidate genes at 22q11.2 concerning physical abnormalities in 22q11DS (Gao, Li, \& Amendt, 2013; Yagi, Furutani, Hamada, Sasaki, Asakawa, Minoshima,... Matsuoka, 2003), but it is also associated with psychiatric features like autism spectrum disorders (Paylor, Glaser, Mupo, Ataliotis, Spencer, Sobotka,... Lindsay, 2006) and in mouse models with social interaction problems (Hiroi, Takahashi, Hishimoto, Izumi, Boku, \& Hiramoto, 2013) and autism (Hiroi, Hiramoto, Harper, Suzuki, \& Boku, 2012).

We hypothesized that the research MLPA kit could give additional information about the deletion size compared with the standardized MLPA kit. In this study also 22q11DS subjects functioning at a level below IQ of 55 were included, cover- 
ing a broader range of this syndrome. The aim was to explore a potential relation of deletion size and intelligence, and furthermore a potential relationships between deletion size and presence of psychosis during life, as a relation between psychosis and intellectual decline has recently been described (Evers et al., 2014).

\section{Method}

The study was approved by the Medical Ethics Committee of the University of Maastricht, The Netherlands and the Academic Medical Centre, Amsterdam, The Netherlands and is part of larger research project in 22q11DS patients.

\section{Study population}

Participants were recruited through the Dutch 22q11DS family network, a specialized psychiatric 22q11DS outpatient clinic, and through several learning disability centres in The Netherlands. Patients with a confirmed deletion at chromosome 22q11.2 were included. Those aged under 18 years and over the age of 65 years were excluded. A number of participants gave written consent, and where participants were not able to do so, consent was obtained from carers. We included sixtyfour patients with 22q11DS.

\section{FSIQ measurements}

Full Scale Intelligence Quotient (FSIQ) scores were obtained in the 22q11DS group using a shortened version of the Wechsler Adult Intelligence Scale (WAIS) version III (Wechsler, 2001). Patients unable to perform a WAIS, were investigated using a Vineland-screener. The outcome of this test was converted to a FSIQ rating as described earlier (Kraijer \& Plas, 2006).

We divided the group of patients in a "low IQ group" (measured with the Vineland screener), consisting of those 22q11DS subjects that function on an IQ below 55 , and a "high IQ group" (measured with WAIS III), for those functioning at an IQ above 55 .

\section{Psychosis outcome measures}

All patients were assessed for life-time presence of a psychotic disorder, based on information obtained from medical records and/or the present score on the Mini PAS-ADD, (Psychiatric Assessment Schedules for Adults with Developmental Disabilities) (Prosser, Moss, Costello, Simpson, Patel, \& Rowe, 1998) or MINI (MiniInternational Neuropsychiatric Interview) (Sheehan, Lecrubier, Sheehan, Amorim, Janavs, Weiller,... Dunbar, 1998). 


\section{Molecular cytogenetics}

Multiplex ligation-dependent probe amplification (MLPA) was performed according to the manufacturer's specifications (MRC Holland). To determine the size of the deletion we used the P250 22q11 MLPA mix, containing primers specific for IL17RA, SLC25A18, BID, MICAL3, USP18, CLTCL1, HIRA, CDC45L, CLDN5, GP1BB, TBX1 (2 probes), TXNRD2, DGCR8, ZNF74, KLHL22, PCQAP, SNAP29, LZTR1, HIC2, PPIL2, TOP3B, RTDR1, GNAZ, RTDR1, RAB36 (2 probes), SMARCB1 (2 probes) and SNRPD3 genes. We performed also the P324 22q11 MLPA mix containing primers specific for the CECR1, BCL2L13, BID, PEX26, CGT3P, PRODH (3 probes), GSC2, TBX1 (12 probes), GNB1L, COMT (2 probes), ARVCF, DGCR8, FLJ42953, RIMBP3C, VPREB1, RAB36, BCR (2 probes), MIF, SNRPD3, and SEZ6L genes.

\section{Statistical analyses}

Coffalyser software (MLPA-Holland) was used to analyse and give an interpretation of the raw MLPA data (Coffa \& Berg van de, 2011).

The remaining data were statistical analyzed with Stata version 12.1 (StataCorp, 2011). Age and IQ are analysed with T-test analysis and displayed in means with $95 \%$ confidence interval. The relation of deletion type with dichotomised IQ and presence of psychosis during life was investigated with Pearson Chisquare analysis.

\section{Results}

\section{Participants}

Sixty-four participants [35 women (55\%), 29 men (45\%)] with confirmed 22q11DS participated in this study. The mean age of participants was 35 years (CI $32-38, \mathrm{SD}=11$, range 19-59 years). Mean age in the "low IQ group" was 41 (37.2 $44.9)$ and in the "high IQ group" $33(30.6-36.1)(\mathrm{p}=.0016)$. Mean IQ was 51 (CI 44$58, \mathrm{SD}=25)$. Mean IQ in the "low IQ group" was 28 (25 - 32) and in the "high IQ group" $76(71-80)(\mathrm{p}<.001)$. Thirty-four out of 59 patients $(58 \%)$ had a history of psychotic symptoms (23/33 in the "low IQ group" (70\%) and 11/26 in the "high IQ group" $(42 \%))(p=.062)$. Data concerning psychotic problems were not available in five patients. Pearson chi-square analysis of the relation of deletion type with dichotomised IQ and psychotic problems during life revealed no significant differences $(\mathrm{p}=.216$ and .355$)$. 


\section{Molecular cytogenetics}

MLPA analysis with the P250 kit confirmed the deletion at 22q11.2 in all the patients, with in the "low IQ group" 29 out of 33 (89\%) having the typical deletion of $3 \mathrm{Mb}$ length from CLTCL1 to LZTR1 (type A-D deletion) and in the "high IQ group" 25 out of 31 (81\%). Atypical deletions in the "low IQ group" were: A) one female patient with a deletion longer than the typical deletion ranging from CLTCL1 to HIC2 (A-D deletion including HIC2), B) one male with the common deletion but also a concomitant distal duplication (from SMARCB1 to SNRPD3, F-G duplication), C) One female with a shorter deletion from CTLC1 to DGCR8 (type A-B deletion) and D) one male with a short deletion from CTLC1 to PCQAP (type A-C deletion). In the "high IQ group" there were 25 typical (CLTCL1 - LZTR1, type A-D deletion) and six atypical deletions: One female patient had a shorter deletion ranging from CLTCL1 to PCQAP (type A-C deletion) and five patients (three male and two female) had shorter deletions ranging from CLTCL1 to DGCR8 (type A-B).

Comparing the data of the P250 kit with the data of the P324 kit showed that there were in the "low IQ group" only 27 typical deletions (82\%) and that the duplication of one patient could be delineated to end more distal (Table I). The deletion in two female patients was smaller with the P324 kit then with the P250-A1 kit when compared with the other 27 "typical" deletions. The shorter deletion extends from PRODH to FLJ42953 compared to the typical deletion that extends from GGT3P to FLJ42953. The deletion of FLJ42953 could be added in all typical deletions after assessment with the P324 kit. The deletions in the higher IQ group were the same as seen in the P250-A1 analysis: 25 typical deletions from GGT3P to FLJ42953, and six atypical: one female patient with a shorter deletion from GGT3P to PCQAP (type A-C deletion) and five patients (three male and two female) with the shorter deletions from GGT3P to DGCR8 (type A-B).The P324 MLPA analysis failed in one patient (no 64).

\section{Discussion}

In this study we included 64 patients with 22q11DS and determined the deletion size with the standard P250 MLPA kit and the experimental P324 MLPA kit. This revealed extra information about the deletion endpoints. The original A-D deletion is described as a deletion from CLTCL1 to LZTR1, but with the P324 kit, probes proximal to the A-region (GSC2, PRODH and GGT3P) and one probe distal in the Dregion (FLJ42953) were deleted in the majority of 22q11DS patients. This suggests that the description of the typical A-D deletion can be extended, including at the proximal end GGT3P, PRODH, GSC2, and at the distal end FLJ42953 and that some of the deletions described until now as typical, could be shorter, atypical. Two patients $(6 \%)$ of the "low-IQ group" with deletions characterised as "typical dele- 
tions" with P250, turned out to be shorter after analysis with P324 (from PRODH to FLJ42953) compared with the remaining 27.

12 out of 64 patients $(18,8 \%)$ had a different deletion size compared to the typical deletion of $3 \mathrm{Mb}$ length. A percentage that can be considered normal (Michaelovsky et al., 2012), especial taken into account that the use of an alternative MLPA kit delivered 2 extra patients (3\%) with atypical deletion. The atypical deletions found in this cohort $(n=11$,) had four different sizes, two extending from PRODH to FLJ42953 (both in the "low IQ group"), six from GGT3P to DGCR8 (five of them from the "low IQ group"), two from GGT3P to PCQAP (one in both IQ group) and one from GGT3P to HIC2 (from the "low IQ-group"). The duplication in one patient (combined with the typical A-D deletion) within this sample could also be located more distal by a second probe of SNRPD3 (Table I). The use of a second MLPA-kit enabled us to delineate deletion sizes more accurately. However, besides delineating the deletion size more precisely in all samples, it revealed two smaller deletions in the "low IQ group", whereas in the "high IQ group" no other deletions were found. This confirms the hypothesis that the experimental MLPA kit gives extra information about deletion endpoints in 22q11DS. In all samples one of the two PRODH and TBX1 probes were deleted. Exploring the results between the "low IQ group" and the "high IQ group" revealed that in the "low IQ group" there was one longer deletion compared to no longer deletion in the higher IQ group. In the "high IQ group" there were 6 shorter deletions (5 type A-B and one type A-C deletion) compared to 2 shorter deletions in the low IQ group (one type A-B and one type A-C deletion). Statistical analysis between deletion size and IQ and of the deletion size with presence of psychotic problems, revealed no significant difference. This suggests that deletion size is not related to psychotic problems in 22q11DS nor with intelligence.

This study confirmed that the research MLPA kit gives extra information about deletion size and in our opinion should be the preferable MLPA kit to use in scientific research. A more accurate definition of deletions can give valuable extra information on genotype-phenotype relations, but larger sample size is needed. The sample size in this cohort is too small to draw conclusions on the relation of deletion size and intelligence or psychopathology. Our finding that only in the "low IQ group" other deletion types are found, compared to those in the "high IQ group", should be further studied.

\section{Strength and limitations}

This is, to the best of our knowledge, the first study using the experimental MLPA P324 kit to establish deletion size and compared the results with the standard P250 MLPA kit. Although the sample size is relatively large for this specific group, it is still small from a methodological point of view. With the inclusion of 22q11DS patients that function at a lower intellectual level, we cover a broader range of this 
syndrome, however, it cannot be ruled out that low FSIQ is overrepresented. The use of two different methods to establish intelligence was unavoidable (IQ's below 55 cannot be established by Wechsler instruments) but is a serious limitation in this study. Another limitation is the uneven distribution of age, between the low IQ group and the high IQ group.

Acknowledgements

We thank the patients and their families for their participation in the study. 
Table1: Combined MLPA results with two Salsa kits (P250 and P324)

Blanc: two copies; X: One copy deleted (hemizygous deletion); +: duplication (three copies present)

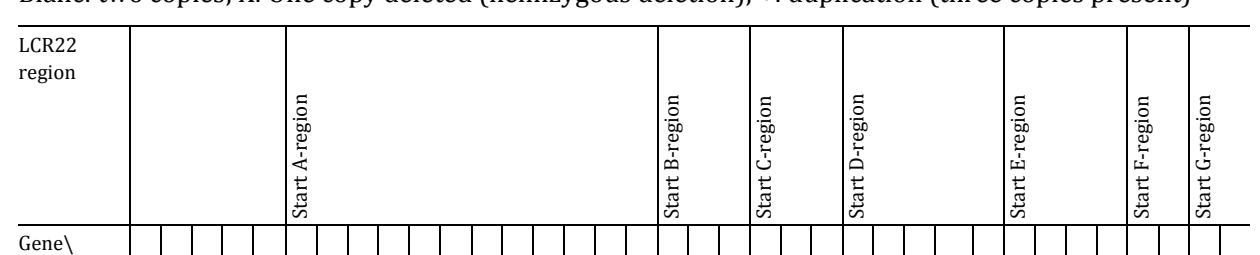

\section{patient}

(gender)/IQ

\begin{tabular}{l|}
\hline $1 \% / 24 \bullet$ \\
\hline $2 / 7 \bullet$
\end{tabular}




\begin{tabular}{|c|c|c|c|c|c|c|c|c|c|c|c|c|c|c|c|c|c|c|c|c|c|c|c|c|c|c|c|c|c|c|c|c|c|c|}
\hline $\begin{array}{l}\text { LCR22 } \\
\text { region }\end{array}$ & & & & & & 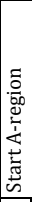 & & & & & & & & & & & & & 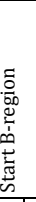 & & & 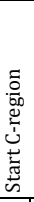 & & & 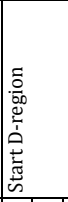 & & & 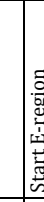 & & & & 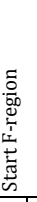 & & \\
\hline 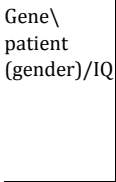 & 莱 & 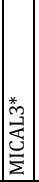 & 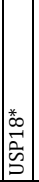 & 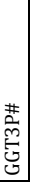 & & 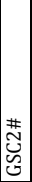 & 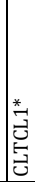 & 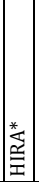 & 華 & 華 & 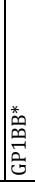 & 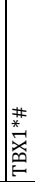 & 芦 & 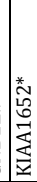 & 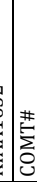 & 㟟 & 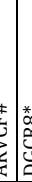 & & 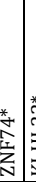 & تُ & 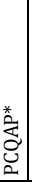 & 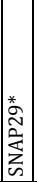 & 茎 & 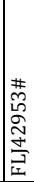 & 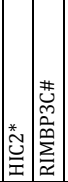 & : & 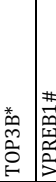 & 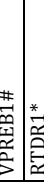 & 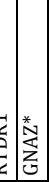 & 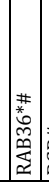 & 蘂 & & & 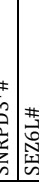 \\
\hline $38+71 \bullet$ & & & & $\mathrm{x}$ & $x$ & $\mathrm{x}$ & $\mathrm{X}$ & $\mathrm{x}$ & $\mathrm{x}$ & $x$ & $\mathrm{X}$ & $x$ & $\mathrm{X}$ & $\mathrm{X}$ & $\mathrm{X}$ & $x$ & $\bar{x}$ & $\mathrm{x}$ & \begin{tabular}{l|l}
$\mathrm{x}$ & $\mathrm{x}$ \\
\end{tabular} & $\mathrm{x}$ & $\mathrm{x}$ & $\mathrm{X}$ & $\mathrm{X}$ & $x$ & & & & & & & & & & \\
\hline $39+/ 80 \bullet$ & & & & $\mathrm{x}$ & $x$ & $\mathrm{x}$ & $x$ & $\mathrm{x}$ & $\mathrm{x}$ & $\mathrm{x}$ & $x$ & $x$ & $\mathrm{X}$ & $\mathrm{X}$ & $\mathrm{X}$ & \begin{tabular}{l|l}
$x$ \\
$X$
\end{tabular} & $\mathrm{x}$ & $\mathrm{x}$ & \begin{tabular}{l|l}
$x$ & \\
\end{tabular} & $\mathrm{X}$ & $\mathrm{x}$ & $\mathrm{x}$ & $\mathrm{X}$ & $x$ & & & & & & & & & & \\
\hline $40+/ 78$ & & & & $\mathrm{X}$ & $\mathrm{X}$ & $\mathrm{x}$ & $X$ & $\mathrm{X}$ & $\mathrm{x}$ & $\mathrm{X}$ & $\mathrm{X}$ & $X$ & $\mathrm{X}$ & $\mathrm{X}$ & $\mathrm{X}$ & $x$ & $\mathrm{x}$ & $\mathrm{x}$ & $\mathrm{x}$ & $\mathrm{x}$ & $\mathrm{x}$ & $\mathrm{x}$ & $\mathrm{X}$ & $x$ & & & & & & & & & & \\
\hline $41 \delta / 77$ & & & & $\mathrm{x}$ & $\mathrm{x}$ & $\mathrm{x}$ & $\mathrm{X}$ & $\mathrm{x}$ & $\mathrm{x}$ & $\mathrm{X}$ & $\mathrm{X}$ & $X$ & $\mathrm{X}$ & $\mathrm{X}$ & $\mathrm{X}$ & $x$ & $\mathrm{x}$ & $\mathrm{x}$ & $\mathrm{x}$ & $\mathrm{X}$ & $\mathrm{x}$ & $\mathrm{x}$ & $\mathrm{X}$ & $x$ & & & & & & & & & & \\
\hline $42+/ 62$ & & & & $\mathrm{x}$ & $x$ & $\mathrm{x}$ & $\mathrm{X}$ & $\mathrm{x}$ & $\mathrm{x}$ & $x$ & $x$ & $x$ & $\mathrm{X}$ & $\mathrm{X}$ & $\mathrm{X}$ & \begin{tabular}{l|l}
$x$ & $x$ \\
\end{tabular} & $\mathrm{x}$ & $\mathrm{x}$ & \begin{tabular}{l|l}
$x$ \\
\end{tabular} & $\mathrm{x}$ & $\mathrm{x}$ & $\mathrm{X}$ & $\mathrm{X}$ & $x$ & & & & & & & & & & \\
\hline $43 \delta / 89 \bullet$ & & & & $\mathrm{X}$ & $\mathrm{X}$ & $\mathrm{x}$ & $\mathrm{X}$ & $\mathrm{x}$ & $\mathrm{x}$ & $\mathrm{X}$ & $\mathrm{X}$ & $X$ & $\mathrm{X}$ & $\mathrm{X}$ & $\mathrm{X}$ & \begin{tabular}{l|l}
$x$ \\
\end{tabular} & $\mathrm{x}$ & $\mathrm{x}$ & & & & & & & & & & & & & & & & \\
\hline $44 / 88 \bullet$ & & & & $\mathrm{x}$ & $\mathrm{x}$ & $\mathrm{x}$ & $X$ & $\mathrm{x}$ & $\mathrm{x}$ & $\mathrm{X}$ & $\mathrm{X}$ & $\mathrm{X}$ & $\mathrm{X}$ & $\mathrm{X}$ & $\mathrm{X}$ & $x$ & $\mathrm{x}$ & $\mathrm{x}$ & $\mathrm{x}$ & $\mathrm{x}$ & $\mathrm{x}$ & $\mathrm{x}$ & $\mathrm{X}$ & $x$ & & & & & & & & & & \\
\hline $45 \% /-$ & & & & $\mathrm{x}$ & $\mathrm{x}$ & $\mathrm{x}$ & $\mathrm{X}$ & $\mathrm{x}$ & $x$ & $x$ & $x$ & $x$ & $\mathrm{X}$ & $\mathrm{X}$ & $\mathrm{X}$ & $x$ & $\mathrm{x}$ & $\mathrm{x}$ & $\mathrm{x}$ & $\mathrm{X}$ & $\mathrm{x}$ & $\mathrm{x}$ & $\mathrm{X}$ & $x$ & & & & & & & & & & \\
\hline $46+73 \bullet$ & & & & $\mathrm{x}$ & $\mathrm{X}$ & $\mathrm{X}$ & $\mathrm{X}$ & $\mathrm{x}$ & $x$ & $\mathrm{x}$ & $\mathrm{X}$ & $x$ & $x$ & $x$ & \begin{tabular}{l|l}
$x$ & $X$ \\
\end{tabular} & $x$ & $\mathrm{x} x$ & $\mathrm{X}$ & $\mathrm{X}$ & $X$ & $\mathrm{x}$ & $\mathrm{X}$ & $\mathrm{X}$ & $x$ & & & & & & & & & & \\
\hline $47 \lesssim / 66$ & & & & $\mathrm{x}$ & $\mathrm{x}$ & $\mathrm{x}$ & $\mathrm{X}$ & $\mathrm{x}$ & $x$ & $\mathrm{x}$ & $\mathrm{X}$ & $\mathrm{X}$ & $x$ & $x$ & \begin{tabular}{l|l}
$x$ & $x$ \\
\end{tabular} & $x \mid x$ & $x$ & $\mathrm{x}$ & $\mathrm{x}$ & $\mathrm{x}$ & $\mathrm{X}$ & $\mathrm{x}$ & $\mathrm{X}$ & $x$ & & & & & & & & & & \\
\hline $48 \% / 59$ & & & & $\mathrm{x}$ & $\mathrm{x}$ & $x$ & $\mathrm{X}$ & $\mathrm{x}$ & $x$ & $\mathrm{x}$ & $\mathrm{X}$ & $x$ & $x$ & $x$ & \begin{tabular}{|l|l|}
$x$ & $x$ \\
\end{tabular} & $x$ & $x$ & $\mathrm{x}$ & $\mathrm{x}$ & $\mathrm{x}$ & $\mathrm{x}$ & $\mathrm{x}$ & $\mathrm{x}$ & $x$ & & & & & & & & & & \\
\hline $49+72$ & & & & $\mathrm{x}$ & $\mathrm{X}$ & $\mathrm{x}$ & $\mathrm{X}$ & $\mathrm{x}$ & $x$ & $\mathrm{x}$ & $\mathrm{X}$ & $x$ & $x$ & $x$ & \begin{tabular}{l|l}
$x$ & $x$ \\
\end{tabular} & $x$ & $\mathrm{x}, \mathrm{x}$ & $\mathrm{x}$ & & & & & . & & & & & & & & & & & \\
\hline 50 \% /74• & & & & $\mathrm{x}$ & $x$ & $\mathrm{x}$ & $\mathrm{X}$ & $\mathrm{x}$ & $x$ & $\mathrm{x}$ & $x$ & $x$ & $x$ & $x$ & \begin{tabular}{l|l}
$x$ & $x$ \\
\end{tabular} & $x$ & $x$ & $\mathrm{X}$ & $\mathrm{x}$ & $\mathrm{x}$ & $\mathrm{X}$ & $\mathrm{X}$ & $\mathrm{X}$ & $x$ & & & & & & & & & & \\
\hline $51+/ 69 \bullet$ & & & & $\mathrm{x}$ & $x$ & $\mathrm{x}$ & $x$ & $\mathrm{x}$ & $\mathrm{x}$ & $x$ & $x$ & $x$ & $x$ & $x$ & \begin{tabular}{l|l}
$x$ & $x$ \\
\end{tabular} & $x \mid x$ & $x$ & $\mathrm{x}$ & $\mathrm{x}$ & $\mathrm{X}$ & $\mathrm{x}$ & $x$ & $\mathrm{X}$ & $x$ & & & & & & & & & & \\
\hline $52+/ 87$ & & & & $\mathrm{X}$ & $\mathrm{x}$ & $\mathrm{x}$ & $\mathrm{X}$ & $\mathrm{x}$ & $\mathrm{x}$ & $\mathrm{X}$ & $\mathrm{X}$ & $\mathrm{X}$ & $x$ & $x$ & \begin{tabular}{l|l}
$x$ & $x$ \\
\end{tabular} & $x \mid x$ & 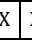 & $\mathrm{x}$ & $\mathrm{x}$ & $\mathrm{X}$ & $\mathrm{x}$ & $\mathrm{x}$ & $\mathrm{X}$ & $x$ & & & & & & & & & & \\
\hline $53+/ 83$ & & & & $\mathrm{x}$ & $x$ & $\mathrm{x}$ & $\mathrm{X}$ & $\mathrm{x}$ & $x$ & $x$ & $\mathrm{X}$ & $x$ & $x$ & $x$ & \begin{tabular}{l|l}
$x$ & $x$ \\
\end{tabular} & $x$ & $\mathrm{x}, \mathrm{x}$ & $\mathrm{X}$ & $\mathrm{x}$ & $\mathrm{x}$ & $\mathrm{X}$ & $\mathrm{X}$ & $\mathrm{x}$ & $x$ & & & & & & & & & & \\
\hline $54+/ 70$ & & & & $\mathrm{x}$ & $x$ & $\mathrm{x}$ & $x$ & $\mathrm{x}$ & $\mathrm{x}$ & $x$ & $x$ & $x$ & $x$ & $x$ & \begin{tabular}{l|l}
$x$ & $x$ \\
\end{tabular} & $x \mid x$ & $\mathrm{x}, \mathrm{x}$ & $\mathrm{x}$ & $\mathrm{x}$ & $\mathrm{x}$ & $\mathrm{x}$ & $x$ & $\mathrm{X}$ & $x$ & & & & & & & & & & \\
\hline $55 \AA / 75$ & & & & $\mathrm{x}$ & $x$ & $\mathrm{x}$ & $\mathrm{X}$ & $\mathrm{x}$ & $\mathrm{x}$ & $x$ & $x$ & $x$ & $x$ & $x$ & \begin{tabular}{l|l}
$\mathrm{X}$ & $\mathrm{X}$ \\
\end{tabular} & $x$ & $\bar{x}$ & $\mathrm{X}$ & $\mathrm{X}$ & $\mathrm{X}$ & $x$ & $\mathrm{x}$ & $\mathrm{X}$ & $x$ & & & & & & & & & & \\
\hline 56 + $/ 89 \bullet$ & & & & $\mathrm{x}$ & $x$ & $\mathrm{x}$ & $\mathrm{X}$ & $\mathrm{x}$ & $\mathrm{x}$ & $x$ & $\mathrm{X}$ & $x$ & $x$ & $x$ & \begin{tabular}{l|l}
$x$ & $x$ \\
\end{tabular} & $x$ & 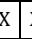 & $\mathrm{x}$ & $\mathrm{x}$ & $\mathrm{x}$ & $x$ & $x$ & $\mathrm{X}$ & $x$ & & & & & & & & & & \\
\hline $57+/ 70$ & & & & $\mathrm{x}$ & $\mathrm{x}$ & $\mathrm{x}$ & $\mathrm{X}$ & $\mathrm{x}$ & $\mathrm{x}$ & $\mathrm{X}$ & $\mathrm{X}$ & $\mathrm{x}$ & $x$ & $x$ & \begin{tabular}{l|l}
$x$ & $x$ \\
\end{tabular} & $x$ & $x$ & $\mathrm{x}$ & & & & & & & & & & & & & & & & \\
\hline $58+/ 96 \bullet$ & & & & $\mathrm{x}$ & $\mathrm{x}$ & $\mathrm{x}$ & $X$ & $\mathrm{x}$ & $\mathrm{x}$ & $\mathrm{X}$ & $x$ & $\mathrm{x}$ & $x$ & $x$ & \begin{tabular}{l|l}
$x$ & $x$ \\
\end{tabular} & $x$ & $x$ & $\mathrm{x}$ & $\mathrm{x}$ & $\mathrm{x}$ & $\mathrm{x}$ & $x$ & $\mathrm{x}$ & $x$ & & & & & & & & & & \\
\hline $59 \delta /-$ & & & & $\mathrm{X}$ & $x$ & $\mathrm{x}$ & $\mathrm{X}$ & $\mathrm{x}$ & $\mathrm{x}$ & $x$ & $\mathrm{X}$ & $x$ & $x$ & $x$ & \begin{tabular}{l|l}
$x$ & $x$ \\
\end{tabular} & $x$ & \begin{tabular}{l|l}
$X$ \\
$X$
\end{tabular} & $\mathrm{x}$ & $\mathrm{x}$ & $\mathrm{x}$ & $x$ & $x$ & $\mathrm{X}$ & $x$ & & & & & & & & & & \\
\hline $60+/ 90$ & & & & $\mathrm{x}$ & $\mathrm{x}$ & $x$ & $\mathrm{X}$ & $\mathrm{x}$ & $\mathrm{x}$ & $\mathrm{X}$ & $\mathrm{X}$ & $x$ & $x$ & $\mathrm{X}$ & \begin{tabular}{l|l}
$x$ & $x$ \\
\end{tabular} & $x$ & $\mathrm{x}$ & $\mathrm{x}$ & $\mathrm{x}$ & $\mathrm{x}$ & $\mathrm{x}$ & $x$ & $\mathrm{X}$ & $x$ & & & & & & & & & & \\
\hline $61 \delta / 79$ & & & & $\mathrm{x}$ & $\mathrm{x}$ & $\mathrm{x}$ & $\mathrm{X}$ & $\mathrm{x}$ & $\mathrm{x}$ & $\mathrm{x}$ & $x$ & $\mathrm{X}$ & $x$ & $x$ & \begin{tabular}{l|l}
$\mathrm{x}$ & $\mathrm{X}$ \\
\end{tabular} & $x \mid x$ & \begin{tabular}{l|l}
$X$ \\
\end{tabular} & $\mathrm{X}$ & & & & & & & & & & & & & & & & \\
\hline $62 \lesssim / 82 \bullet$ & & & & $\mathrm{X}$ & $\mathrm{X}$ & $x$ & $\mathrm{X}$ & $\mathrm{x}$ & $\mathrm{x}$ & $\mathrm{X}$ & $\mathrm{X}$ & $\mathrm{X}$ & $x$ & $\mathrm{X}$ & \begin{tabular}{l|l}
$x$ & $x$ \\
\end{tabular} & \begin{tabular}{l|l}
$x$ \\
\end{tabular} & \begin{tabular}{l|l}
$X$ & $Y$ \\
\end{tabular} & $\mathrm{x}$ & $\mathrm{x}$ & $\mathrm{x}$ & $\mathrm{X}$ & $x$ & $\mathrm{X}$ & $X$ & & & & & & & & & & \\
\hline $63 \delta / 75$ & & & & $\mathrm{x}$ & $\mathrm{x}$ & $x$ & $X$ & $\mathrm{x}$ & $\mathrm{x}$ & $\mathrm{X}$ & $\mathrm{X}$ & $x$ & $x$ & $\mathrm{X}$ & \begin{tabular}{l|l}
$x$ & $x$ \\
\end{tabular} & $x$ & $\begin{array}{ll}\mathrm{x} \\
\end{array}$ & $\mathrm{x}$ & & & & & & & & & & & & & & & & \\
\hline $64+/-$ & & & & $?$ & $?$ & $?$ & $x$ & $\mathrm{x}$ & $x$ & $\mathrm{x}$ & $x$ & $?$ & $?$ & $x$ & $\begin{array}{ll} \\
\end{array}$ & $? ?$ & ? & $\mathrm{x}$ & $\mathrm{x}$ & $\mathrm{x}$ & $\mathrm{X}$ & $X$ & $\mathrm{x}$ & $?$ & & & & & & & & & & \\
\hline
\end{tabular}

*: genes covered by the P250 kit; \#: genes covered by the P324 kit; •: suffered from psychotic problems during life 


\section{References}

Antshel, K. M., Fremont, W., \& Kates, W. R. (2008). The neurocognitive phenotype in velo-cardio-facial syndrome: a developmental perspective. Dev Disabil Res Rev, 14(1), 43-51.

Bittel, D. C., Yu, S., Newkirk, H., Kibiryeva, N., Holt, A., 3rd, Butler, M. G., \& Cooley, L. D. (2009). Refining the 22q11.2 deletion breakpoints in DiGeorge syndrome by aCGH. Cytogenet Genome Res, 124(2), 113-120.

Botto, L. D., May, K., Fernhoff, P. M., Correa, A., Coleman, K., Rasmussen, S. A.,... Campbell, R. M. (2003). A population-based study of the 22q11.2 deletion: phenotype, incidence, and contribution to major birth defects in the population. Pediatrics, 112(1 Pt 1), 101-107.

Carmel, M., Zarchi, O., Michaelovsky, E., Frisch, A., Patya, M., Green, T.,... Weizman, A. (2014). Association of COMT and PRODH gene variants with intelligence quotient (IQ) and executive functions in 22q11.2DS subjects. J Psychiatr Res, 56, 28-35.

Chow, E. W., Watson, M., Young, D. A., \& Bassett, A. S. (2006). Neurocognitive profile in 22q11 deletion syndrome and schizophrenia. Schizophr Res, 87(1-3), 270-278.

Coffa, J., \& Berg van de, J. . (2011). Analysis of MLPA Data Using Novel Software Coffalyser.NET by MRCHolland, . In Dr. Ahmed Badr Eldin (Ed.), Modern Approaches To Quality Control: InTech.

de Koning, M. B., Boot, E., Bloemen, O. J., van Duin, E. D., J.A., Bakker, Abel, K. M., \& van Amelsvoort, T. A. (2015). PRODH RS450046 and proline x COMT Val158Met Interaction effects on Intelligence and Startle in Adults with 22q11 Deletion Syndrome. Psychopharmacology, 232(17):3111-22.

De Smedt, B., Devriendt, K., Fryns, J. P., Vogels, A., Gewillig, M., \& Swillen, A. (2007). Intellectual abilities in a large sample of children with Velo-Cardio-Facial Syndrome: an update. J Intellect Disabil Res, 51(Pt 9), 666-670.

Devriendt, K., Thienen, M. N., Swillen, A., \& Fryns, J. P. (1996). Cerebellar hypoplasia in a patient with velo-cardio-facial syndrome. Dev Med Child Neurol, 38(10), 949-953.

Evers, L. J., De Die Smulders, C. E., Smeets, E. E., Clerkx, M. G., \& Curfs, L. M. (2009). The velo-cardio-facial syndrome: the spectrum of psychiatric problems and cognitive deterioration at adult age. Genet Couns, 20(4), 307-315.

Evers, L. J., van Amelsvoort, T. A., Candel, M. J., Boer, H., Engelen, J. J., \& Curfs, L. M. (2014). Psychopathology in adults with 22q11 deletion syndrome and moderate and severe intellectual disability. J Intellect Disabil Res, 58(10), 915-925.

Evers, L.J.M., van Amelsvoort, A.M.J. , Bakker, J.A., de Koning, M.B. , Drukker, M. , \& Curfs, L.M.G. (2015). Glutamatergic markers, age, intellectual functioning and psychosis in 22q11 deletion syndrome. Psychopharmacology, 232(18):3319-25.

Gao, S., Li, X., \& Amendt, B. A. (2013). Understanding the role of Tbx1 as a candidate gene for 22q11.2 deletion syndrome. Curr Allergy Asthma Rep, 13(6), 613-621.

Grati, F. R., Molina Gomes, D., Ferreira, J. C., Dupont, C., Alesi, V., Gouas, L.,... Vialard, F. (2015). Prevalence of recurrent pathogenic microdeletions and microduplications in over 9,500 pregnancies. Prenatal diagnosis. 35(8):801-9

Henry, J. C., van Amelsvoort, T., Morris, R. G., Owen, M. J., Murphy, D. G., \& Murphy, K. C. (2002). An investigation of the neuropsychological profile in adults with velo-cardio-facial syndrome (VCFS). Neuropsychologia, 40(5), 471-478.

Hiroi, N., Hiramoto, T., Harper, K. M., Suzuki, G., \& Boku, S. (2012). Mouse Models of 22q11.2-Associated Autism Spectrum Disorder. Autism-open access, Suppl 1, 001.

Hiroi, N., Takahashi, T., Hishimoto, A., Izumi, T., Boku, S., \& Hiramoto, T. (2013). Copy number variation at 22q11.2: from rare variants to common mechanisms of developmental neuropsychiatric disorders. Mol Psychiatry, 18(11), 1153-1165.

Iascone, M. R., Vittorini, S., Sacchelli, M., Spadoni, I., Simi, P., \& Giusti, S. (2002). Molecular characterization of 22q11 deletion in a three-generation family with maternal transmission. Am J Med Genet, 108(4), 319-321.

Jalali, G. R., Vorstman, J. A., Errami, A., Vijzelaar, R., Biegel, J., Shaikh, T., \& Emanuel, B. S. (2008). Detailed analysis of 22q11.2 with a high density MLPA probe set. Hum Mutat, 29(3), 433-440. 
Kozma, C. (1998). On cognitive variability in velocardiofacial syndrome: profound mental retardation and autism. Am J Med Genet, 81(3), 269-270.

Kraijer, D.W., \& Plas, J.J. (2006). Handboek psychodiagnostiek en beperkte begaafdheid (4 ed.). Amsterdam: Harcourt Assesment B.V.

Lindsay, E. A. (2001). Chromosomal microdeletions: dissecting del22q11 syndrome. Nat Rev Genet, 2(11), 858-868.

McDonald-McGinn, D. M., Kirschner, R., Goldmuntz, E., Sullivan, K., Eicher, P., Gerdes, M.,... Zackai, E. H. (1999). The Philadelphia story: the 22q11.2 deletion: report on 250 patients. Genet Couns, 10(1), 11-24.

Michaelovsky, E., Frisch, A., Carmel, M., Patya, M., Zarchi, O., Green, T.,... Gothelf, D. (2012). Genotypephenotype correlation in 22q11.2 deletion syndrome. BMC Med Genet, 13, 122.

Miller, K.A. (2008). FISH Diagnosis of 22q11.2 Deletion Syndrome. Newborn Infant Nurs Rev, 8(1), e11q19.

Niklasson, L., \& Gillberg, C. (2010). The neuropsychology of 22q11 deletion syndrome. A neuropsychiatric study of 100 individuals. Res Dev Disabil, 31(1), 185-194.

Paylor, R., Glaser, B., Mupo, A., Ataliotis, P., Spencer, C., Sobotka, A.,... Lindsay, E. (2006). Tbx1 haploinsufficiency is linked to behavioral disorders in mice and humans: implications for 22q11 deletion syndrome. Proc Natl Acad Sci USA, 103(20), 7729-7734.

Prosser, H., Moss, S., Costello, H., Simpson, N., Patel, P., \& Rowe, S. (1998). Reliability and validity of the Mini PAS-ADD for assessing psychiatric disorders in adults with intellectual disability. J Intellect Disabil Res, 42 ( Pt 4), 264-272.

Radoeva, P. D., Coman, I. L., Salazar, C. A., Gentile, K. L., Higgins, A. M., Middleton, F. A.,... Kates, W. R. (2014). Association between autism spectrum disorder in individuals with velocardiofacial (22q11.2 deletion) syndrome and PRODH and COMT genotypes. Psychiatr Genet, 24(6), 269-272.

Rauch, A., Zink, S., Zweier, C., Thiel, C. T., Koch, A., Rauch, R.,... Hofbeck, M. (2005). Systematic assessment of atypical deletions reveals genotype-phenotype correlation in 22q11.2. J Med Genet, 42(11), 871-876.

Shaffer, L. G., Bejjani, B. A., Torchia, B., Kirkpatrick, S., Coppinger, J., \& Ballif, B. C. (2007). The identification of microdeletion syndromes and other chromosome abnormalities: cytogenetic methods of the past, new technologies for the future. Am J Med Genet C Semin Med Genet. 15;145C(4):335-45

Sheehan, D. V., Lecrubier, Y., Sheehan, K. H., Amorim, P., Janavs, J., Weiller, E.,... Dunbar, G. C. (1998). The Mini-International Neuropsychiatric Interview (M.I.N.I.): the development and validation of a structured diagnostic psychiatric interview for DSM-IV and ICD-10. J Clin Psychiatry, 59 Suppl 20, 2233; quiz 34-57.

Shprintzen, R. J. (2008). Velo-cardio-facial syndrome: 30 Years of study. Dev Disabil Res Rev, 14(1), 3-10.

Shprintzen, R. J., Higgins, A. M., Antshel, K., Fremont, W., Roizen, N., \& Kates, W. (2005). Velo-cardiofacial syndrome. Curr Opin Pediatr, 17(6), 725-730.

StataCorp. (2011). Stata Statistical Software. Texas: StataCorparation.

Stuppia, L., Antonucci, I., Palka, G., \& Gatta, V. (2012). Use of the MLPA Assay in the Molecular Diagnosis of Gene Copy Number Alterations in Human Genetic Diseases. Int J Mol Sci, 13(3), 3245-3276.

Swillen, A., Devriendt, K., Legius, E., Eyskens, B., Dumoulin, M., Gewillig, M., \& Fryns, J. P. (1997). Intelligence and psychosocial adjustment in velocardiofacial syndrome: a study of 37 children and adolescents with VCFS. J Med Genet, 34(6), 453-458.

van Amelsvoort, T., Henry, J., Morris, R., Owen, M., Linszen, D., Murphy, K., \& Murphy, D. (2004). Cognitive deficits associated with schizophrenia in velo-cardio-facial syndrome. Schizophr Res, 70(2-3), 223-232.

Wechsler, D. (2001). WAIS-III, nederlandstalige bewerking: Technische handleiding. Lisse.

Yagi, H., Furutani, Y., Hamada, H., Sasaki, T., Asakawa, S., Minoshima, S.,... Matsuoka, R. (2003). Role of TBX1 in human del22q11.2 syndrome. Lancet, 362(9393), 1366-1373.

Zarchi, O., Carmel, M., Avni, C., Attias, J., Frisch, A., Michaelovsky, E.,... Gothelf, D. (2013). Schizophrenialike neurophysiological abnormalities in 22q11.2 deletion syndrome and their association to COMT and PRODH genotypes. J Psychiatr Res, 47(11), 1623-1629. 



\section{CHAPTER 5}

Serotonergic, noradrenergic and dopaminergic markers are related to cognitive function in adults with 22q11 deletion syndrome

published as:

Evers LJ, Curfs LM, Bakker JA, Boot E, da Silva Alves F, Abeling N, Bierau J, Drukker M, van Amelsvoort TA. (2014)

Int J Neuropsychopharmacol. Aug;17(8):1159-65. 


\begin{abstract}
Patients with 22q11 deletion syndrome (22q11DS) have a high prevalence of psychiatric disorders and intellectual disability. At present the neurobiology underlying psychopathology in 22q11DS is still not understood. In the present study, we analyzed urinary serotonergic, dopaminergic and noradrenergic markers in 67 adults with 22q11DS. Levels of serotonin, and the catecholamine metabolite homovanillic acid were significantly lower in the 22q11DS subjects compared to healthy controls. Within the 22q11DS group, levels of dopamine, homovanillic acid, norepinephrine, vanillyl mandelic acid and serotonin positively correlated with Full Scale Intelligence Quotient scores. Our results suggest that cognitive deficits in 22q11DS are associated with abnormal function of several neurotransmitters.
\end{abstract}

Keywords: 22q11 deletion syndrome, dopamine, norepinephrine, serotonin, cognitive function 


\section{Introduction}

22q11 deletion syndrome (22q11DS) is a genetic syndrome caused by a microdeletion on the long arm of chromosome 22. Since the first description it has been increasingly recognized and its prevalence is currently estimated to be 1:4000 (Oskarsdottir, Vujic \& Fasth, 2004; McDonald McGinn and Sullivan, 2011). The clinical picture is variable not only in terms of physical characteristics, but also for the highly prevalent cognitive deficits, behavioural and psychiatric problems (Hiroi, Takahashi, Hishimoto, Izumi, Boku \& Hiramoto, 2013; Jonas, Montojo \& Bearden, 2014). One of the most striking recent observations has been the dramatic cognitive and functional decline in some adults with 22q11DS (Evers, De Die Smulders, Smeets, Clerkx \& Curfs, 2009; Evers, van Amelsvoort, Candel, Boer, Engelen \& Curfs, 2014). Moreover, a recent study suggests that cognitive decline may start already in childhood (Duijff, Klaassen, de Veye, Beemer, Sinnema \& Vorstman, 2012). Idiopathic schizophrenia is often preceded by cognitive dysfunction prior to the onset of psychotic symptoms (Kahn and Keefe, 2013).

Owing to the occurrence of several psychiatric disorders, in adulthood psychosis, anxiety and mood disorders particularly (Bassett, Chow, Husted, Weksberg, Caluseriu, Webb \& Gatzoulis, 2005; Tunbridge and Harrison, 2011), it could be hypothesized that these are accompanied by a disruption of neurotransmitter systems that are known to be involved in these disorders (Nikolaus, Antke, Beu, Muller, 2010).

The gene for catechol-O-methyl-transferase (COMT), an enzyme involved in the degradation of dopamine (DA) and norepinephrine (NE), is located at 22q11, and therefore people with 22q11DS have a reduced gene dosage for COMT. We previously demonstrated reduced COMT expression (van Beveren, Krab, Swagemakers, Buitendijk, Boot, van der Spek, Elgersma \& van Amelsvoort, 2012) and disrupted dopaminergic neurotransmission in adult 22q11DS patients (Boot, Booij, Zinkstok, Abeling, de Haan, Baas, Linszen \& van Amelsvoort, 2008). Thus, COMT hemizygosity in 22q11DS may have effect on catecholamine levels and thereby disturb brain function.

The role of dopamine (DA) in the development of psychotic symptoms in the general population is pivotal as is its role in cognitive dysfunction (most consistent finding is its role in working memory), in schizophrenia (Howes, Fusar Poli, Bloomfield, Selvaraj \& McGuire, 2012). Its role in intelligence in general is less clear. Because of the high prevalence of psychosis in 22q11DS, research on this syndrome has particularly focused on the dopaminergic system.

Besides psychotic disorders, anxiety and mood disorders are also highly prevalent in patients with 22q11DS (Bassett et al., 2005; Nikolaus et al., 2010; Tunbridge and Harrison, 2011). Central serotonergic abnormalities are thought to underlie these disorders as well as central dopaminergic and noradrenergic abnormalities (aan het Rot, Mathew \& Charney, 2009; Drago, Crisafulli, Sidoti \& Ser- 
retti, 2011). The combination of increased vulnerability to anxiety and mood disorders and the good treatment response to selective serotonergic re-uptake Inhibitors (SSRI's) in 22q11DS (Stachon \& De Souza, 2011) makes serotonin (5-hydroxytryptamine, 5-HT) involvement in the development of psychopathology in 22q11DS plausible. However, to the best of our knowledge the serotonergic system so far has not been investigated in 22q11DS.

The present study is the first to investigate serotonergic markers in adults with 22q11DS. In addition we report on dopaminergic and noradrenergic markers in a larger sample $(n=67)$ than we reported previously. By extending our original sample of adults (Boot et al., 2008; Boot, Booij, Abeling, Meijer, da Silva Alves, Zinkstok, Baas, Linszen \& van Amelsvoort 2011), we covered a broader range of psychiatric and cognitive symptoms and were able to address the complex interplay of mood, cognitive and psychotic symptoms that are present in 22q11DS.

This study has two research questions: 1) Do serotonergic, noradrenergic and dopaminergic markers differ between 22q11DS patients and controls? 2) Do these markers within the 22q11DS group correlate with cognitive functioning and other clinical outcome measures?

\section{Patients and methods}

The study was approved by the Medical Ethics Committee of the University of Maastricht, Maastricht and the University of Amsterdam, Amsterdam, The Netherlands and is part of a larger research project on neurotransmitter function in 22q11DS adults.

Participants were recruited through the Dutch 22q11DS family network, a specialized psychiatric 22q11DS outpatient clinic, and through several learning disability centers in the Netherlands. Patients with a confirmed deletion at chromosome 22q11.2 were included. Exclusion criteria were age below 18 and medical conditions affecting brain function, mimicking dementia-like features such as Alzheimers dementia. Sixty-seven 22q11DS patients were included. All patients and/or their caretakers were informed about the study and written informed consent was obtained.

Healthy controls $(n=29)$ were recruited by advertisement.

\section{Metabolic and clinical assessment}

\section{Metabolic measurements}

Morning urine samples were collected for determination of DA, homo vanillic acid (HVA), NE, vanillyl mandelic acid (VMA), 3-methoxy-4-hydroxyphenylglycol (MHPG), 5-HT and 5-hydroxyindoleacetic acid (5-HIAA). 
These compounds were determined using reverse-phase high-performance liquid chromatography (RP-HPLC) with fluorometric detection (Abeling, van Gennip, Overmars \& Voute, 1984; Stroomer, Overmars, Abeling \& van Gennip, 1990). For urinary levels of the biogenic amines and their metabolites, inter-assay variation, calculated on three different levels, ranged from 2.7 to $8.5 \%$.

\section{IQ measurements}

Full scale Intelligence Quotient (FSIQ) scores were obtained in the 22q11DS group using a shortened version of the Wechsler Adult Intelligence Scale (WAIS) version III (Wechsler, 2001). Patients unable to perform a WAIS, were investigated using a Vineland-screener. The outcome of this test was converted to a FSIQ rating as described earlier (Kraijer and Plas, 2006).

\section{Psychopathology outcome measures}

We determined whether anyone suffered from psychotic symptoms during life, based on information obtained from medical records and/or the present score on the Mini PAS-ADD, (Psychiatric Assessment Schedules for Adults with Developmental Disabilities)(Prosser, Moss, Costello, Simpson, Patel \& Rowe, 1998), MINI (Mini-International Neuropsychiatric Interview)(Sheehan, Lecrubier, Sheehan, Amorim, Janavs, Weiller,... Dunbar, 1998) or PANSS (Positive And Negative Syndrome scale for Schizophrenia)(Kay, Fiszbein \& Opler, 1987). Depressive symptomatology was determined using the Beck Depression Inventory (BDI) (Beck, Steer, Ball \& Ranieri, 1996) and/or the depression score on the mini PAS-ADD. Depression scale values were dichotomized to determine if a patient fulfilled criteria for a depression (Beck et al., 1996; Prosser et al., 1998).

\section{Use of psychotropic drugs}

The use of psychotropic drugs was noted and classified as antipsychotics, antidepressants and mood stabilizers.

\section{Statistical analysis}

All statistical analyses were performed using Stata version 12.1 (StataCorp., 2011). First, (crude) differences in age and metabolic outcomes between the groups (22q11DS or control) were examined using a $t$-test, whereas gender differences were analyzed using a chi-square test. After the crude analyses, the association between metabolic outcomes and group were analyzed using Analysis of Covariance(ANCOVA) in order to control for age and gender. To correct for multiple comparison the $\alpha$ was set at 0.007 (Bonferroni correction). Second, regression analyses were performed using data of the 22q11DS patients only. DA, HVA, NE, MHPG, VMA, 5-HT and 5-HIAA were employed as dependent variables in seven separate models. FSIQ was the main independent variable in all models. Presence of psychosis during life-time, age and gender were also included as independent 
variables. To explore the effect of use of psychotropic medication on metabolic outcomes in the patients with 22q11DS we added this factor in the regression analysis.

Table 1: Use of psychotropic medication

\begin{tabular}{|c|c|c|c|}
\hline Drugs & $\begin{array}{l}\text { Dosage } \\
(\mathrm{mg} / \mathrm{d})\end{array}$ & $\begin{array}{l}\text { Haloperidol equivalent } \\
\text { (mg/d) }\end{array}$ & $\mathrm{N}$ \\
\hline Alprazolam & 1 & & 1 \\
\hline Aripiprazole & $7.5-15$ & $1.5-3$ & 2 \\
\hline Atomoxetine & 80 & & 1 \\
\hline Carbamazepine & 600 & & 2 \\
\hline Citalopram & 40 & & 1 \\
\hline Clorazepate & 100 & & 1 \\
\hline Clobazam & 30 & & 1 \\
\hline Clomipramine & 150 & & 1 \\
\hline Clozapine & $50-400$ & $0.5-6$ & 10 \\
\hline Lamotrigine & $25-150$ & & 3 \\
\hline Levomepromazine & 50 & & 1 \\
\hline Lithium & $500-1200$ & & 3 \\
\hline Lorazepam & 2.5 & & 2 \\
\hline Methylphenidate & 36 & & 1 \\
\hline Nitrazepam & 2.5 & & 2 \\
\hline Olanzapine & $2.5-20$ & & 8 \\
\hline Oxazepam & $30-100$ & & 2 \\
\hline Paroxetine & $20-30$ & & 7 \\
\hline Pipamperone & $40-120$ & $1-3$ & 2 \\
\hline Quetiapine & $50-400$ & $0.5-6$ & 5 \\
\hline Risperidone & $2-7,5$ & $3.4-12.5$ & 6 \\
\hline Toparimate & 400 & & 1 \\
\hline Trazolone & 150 & & 1 \\
\hline Valproïc acid & $600-1800$ & & 10 \\
\hline Venlafaxine & 75 & & 2 \\
\hline Zuclopentixol & 6 & 1.2 & 2 \\
\hline
\end{tabular}

\section{Results}

\section{Demographics}

Forty-six percent $(n=31)$ of the 22q11DS group and 66\% $(n=19)$ of the control group were male; this difference was statistically imprecise by conventional alpha 
(chi-square=3.00, p=0.08). Age (mean $\pm \mathrm{SD}$ ) in the 22q11DS group was 35.0 years \pm 10.9 and in the control group 30.8 years \pm 9.7 . This difference was also statistically imprecise by conventional alpha $(\mathrm{t}=-1.79, \mathrm{p}=0.08)$. Average FSIQ in the $22 q 11 D S$ group was $52.3 \pm 25.7$ (range $7-96$ ). Of the 67 patients with $22 q 11 D S, 34$ patients were treated with antipsychotic drugs; 12 were on antidepressants and 18 on mood stabilisers. Only 3 patients with a prescription for a mood stabiliser and/or antidepressant used no antipsychotic drugs. See table 1 for use of psychotropic medication. None of the controls used psychotropic medication. Thirty-four patients had a history of psychosis and 11 patients would be diagnosed having a depression according to the scales used. Ten 22q11DS patients smoked tobac$\operatorname{co}(14.9 \%)$.

\section{Metabolic outcomes per group}

The concentration of excreted metabolites for both groups are presented in Table 2. After correction for age and gender, urinary HVA and 5-HT concentrations were significantly lower in the 22q11DS group compared to controls.

Table 2: ANCOVA for metabolic measurements in urine* in 22q11DS subjects and controls

\begin{tabular}{lllll}
\hline & $\begin{array}{l}22 q 11 D S \\
\text { Mean }( \pm \mathrm{SD})\end{array}$ & $\begin{array}{l}\text { Controls } \\
\text { Mean }( \pm \mathrm{SD})\end{array}$ & P-value** & $\mathrm{F}^{* *}$ \\
\hline DA & $154( \pm 78.7)$ & $155( \pm 62.8)$ & .21 & 1.61 \\
HVA & $1.83( \pm .78)$ & $2.50( \pm 1.00)$ & $.002^{* * *}$ & 11.01 \\
NE & $26.55( \pm 26.1)$ & $28.48( \pm 15.3)$ & .46 & 0.56 \\
MHPG & $1.10( \pm .40)$ & $1.13( \pm .47)$ & .06 & 3.77 \\
VMA & $1.44( \pm .56)$ & $1.68( \pm .55)$ & .04 & 4.23 \\
5-HT & $50.0( \pm 36.0)$ & $74.5( \pm 33.9)$ & $.003^{* * *}$ & 10.68 \\
5-HIAA & $2.94( \pm 2.95)$ & $2.86( \pm 1.52)$ & .68 & .17 \\
\hline
\end{tabular}

*DA, NE, 5-HT in nmol/mmol kreat; HVA, MHPG, VMA and 5-HIAA in mmol/mol kreat

**After ANCOVA correction with age and gender ${ }^{* * *}$-value $\leq 0.007$ (after Bonferroni correction)

\section{Metabolic outcomes within the $22 q 11 D S$ group}

Within the 22q11DS group, regression analysis revealed that FSIQ was significantly associated with DA, HVA, NE, VMA and 5-HT excretion (Table 3). Life-time presence of psychosis was only positively associated with NE. Age, gender and whether subjects scored positive for a depression, were not associated with any of the metabolic outcome measures.

The use of psychotropic medication did not change any of the results after regression analysis. 


\section{Discussion}

Our findings indicate that FSIQ is associated with dopaminergic, noradrenergic and serotonin markers in adults with 22q11DS (Fig. 1). In addition to previously reported disturbances in dopaminergic markers in 22q11DS, for the first time we report decreased urinary 5-HT concentrations in 22q11DS adults in comparison to healthy controls.

We previously reported elevated urinary DA levels and reduced metabolites (Boot et al., 2008) in a small, relatively young and healthy group of people with 22q11DS. This was thought to be the result of COMT haplo-insufficiency resulting in reduced degradation of DA. In our current extended study however, we did not replicate our previous finding of increased DA levels. However decreased DA and NE metabolites persisted, probably as a result of chronic reduced COMT activity. One possible explanation for our current findings could be a down regulation of aromatic L-amino acid decarboxylase (AADC) also known as dopa decarboxylase (DDC)(Christenson, Dairman \& Udenfriend, 1972), due to an assumed increased tonic DA activity which might result in reduced DA synthesis over time. AADC is the catalysing enzyme involved in the last step before formation of DA. In addition to $\mathrm{DA}, \mathrm{AADC}$ is also the catalysing enzyme involved in the last step before formation of 5-HT (Christenson et al., 1972). By the same feedback mechanism as described above, a reduction of the AADC could lead to a decrease of 5-HT. This mechanism could also explain the good response to SSRIs in people with 22q11DS (Stachon \& De Souza, 2011).

Another possible mechanism explaining reduced 5-HT in 22q11DS, could be related to a reduced gene dosage of SEPT5. The SEPT5 gene is also located at $22 q 11$ and codes for septin-5, a protein important for active membrane movement such as vesicle trafficking and exocytosis in non-dividing cells as platelets and neurons (Bartsch, Sandrock, Lanza, Nurden, Hainmann, Pavlova,... Zieger, 2011). Septin-5 is involved in 5-HT release in platelets (Dent, Kato, Peng, Martinez, Cattaneo, Poujol,... Ware, 2002) and the majority of 5-HT in the body is transported by platelets (Anderson, Feibel \& Cohen, 1987). Since low platelet counts are frequently observed in people with 22q11DS, (Latger-Cannard, Bensoussan, Gregoire, Marcon, Cloez, Leheup,... Bordigoni, 2004; Saito, Ishikawa, Ito \& Shimizu, 2004), this may indicate that the combination of reduced SEPT5 gene dosage, low platelet counts and, as a consequence, the observed low 5-HT levels are possibly related to each other. Results from studies in mice suggest that SEPT5 deficiency is related to psychiatric disorders seen in 22q11DS such as schizophrenia (Suzuki, Harper, Hiramoto, Sawamura, Lee, Kang,... Hiroi, 2009; Harper, Hiramoto, Tanigaki, Kang, Suzuki, Trimble \& Hiroi, 2012). Thus, taken together we hypothesize that in 22q11DS reduced SEPT5 gene dosage as well as altered AADC activity secondary to reduced COMT activity may play a role in the development of psychopathology seen in 22q11DS. Further studies are requested to test these hypotheses. For ex- 
ample, studies may include imaging studies assessing AADC activity (Park, Kwon, Mok \& Chung, 2013). Comparable research should be done for SEPT5 involvement to clarify our hypothesis.

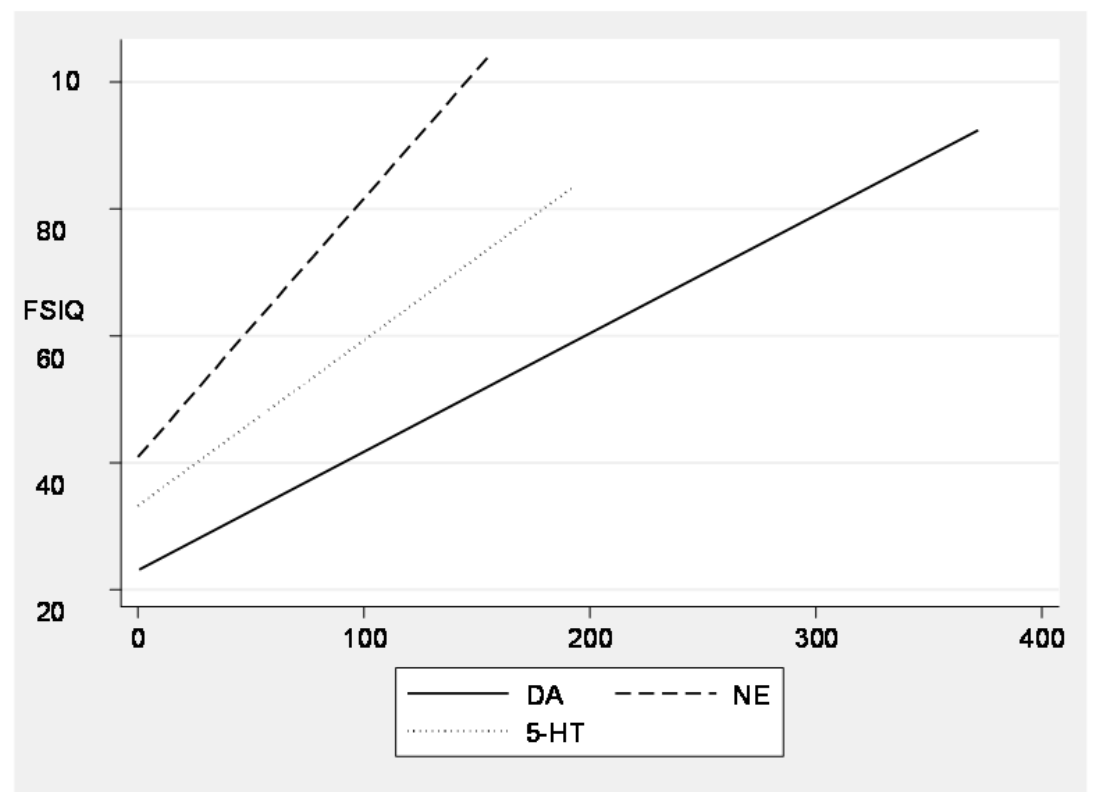

Figure 1. Two way graph with fit plots and linear prediction. On $\mathrm{X}$-axis concentration $(\mathrm{nmol} / \mathrm{mmol}$ kreatinine) of DA, NE and 5-HT, on Y-axis FSIQ

All three neurotransmitters we studied were significantly related to IQ (Fig. 1). They all three play an important role in the normal functioning brain with regards to cognitive abilities, especially in executive functioning (Robbins and Arnsten, 2009; Barnes, Dean, Nandam, O'Connell \& Bellgrove, 2011), learning and cognitive flexibility (Kehagia, Murray \& Robbins, 2010). In addition, there have been recent reports of early-onset Parkinson's disease, a progressive neurodegenerative disorder, in 22q11DS (Zaleski, Bassett, Tam, Shugar, Chow \& McPherson, 2009; Booij, van Amelsvoort \& Boot, 2010). 
Table 3: Regression analysis for DA, HVA, NE, MHPG, VMA, HT and 5-HIAA in urine within 22q11DS group

\begin{tabular}{|c|c|c|c|c|c|}
\hline & & Coef & Std. Error & P-value & $95 \% \mathrm{CI}$ \\
\hline \multirow[t]{5}{*}{$\overline{D A}$} & FSIQ & 1.81 & .45 & $<.001^{*}$ & $.91-2.71$ \\
\hline & Psychosis & 6.51 & 18.17 & 72 & $-29.87-42.90$ \\
\hline & Depression & 4.10 & 24.24 & .87 & $-44.43-55.64$ \\
\hline & Age & .25 & 1.04 & .81 & $-1.82-2.32$ \\
\hline & Gender & 17.32 & 18.85 & .36 & $-20.43-55.06$ \\
\hline \multirow[t]{5}{*}{ HVA } & FSIQ & .02 & .00 & $<.001^{*}$ & $.01-.03$ \\
\hline & Psychosis & .21 & .16 & .20 & $-.12-.54$ \\
\hline & Depression & .26 & .22 & .243 & $-.18-.69$ \\
\hline & Age & .01 & .01 & .26 & $-.01-.03$ \\
\hline & Gender & .22 & .17 & .20 & $-.11-.55$ \\
\hline \multirow[t]{5}{*}{$\mathrm{NE}$} & FSIQ & .64 & .00 & $<.001^{*}$ & $.34-.94$ \\
\hline & Psychosis & 20.72 & 6.09 & $.001 *$ & $8.53-32.90$ \\
\hline & Depression & 5.93 & 8.11 & .47 & $-10.32-22.19$ \\
\hline & Age & .36 & .35 & .30 & $-.33-1.06$ \\
\hline & Gender & -.31 & 6.31 & .96 & $-12.33-12.95$ \\
\hline \multirow[t]{5}{*}{ MHPG } & FSIQ & .00 & .00 & .28 & $-.00-.01$ \\
\hline & Psychosis & -.12 & .11 & .26 & $-.34-.10$ \\
\hline & Depression & -.04 & .16 & .81 & $-.36-.28$ \\
\hline & Age & .00 & .01 & .79 & $-.01-.01$ \\
\hline & Gender & .05 & .12 & .66 & $-.19-.30$ \\
\hline \multirow[t]{5}{*}{ VMA } & FSIQ & .01 & .00 & $.005^{*}$ & $.00-.02$ \\
\hline & Psychosis & .17 & .14 & .22 & $-.10-.44$ \\
\hline & Depression & .03 & .18 & .86 & $-.33-.40$ \\
\hline & Age & -.001 & .01 & .89 & $-.02-.01$ \\
\hline & Gender & .26 & .14 & .06 & $-.02-.54$ \\
\hline \multirow[t]{5}{*}{$5-\mathrm{HT}$} & FSIQ & .62 & .28 & $.029^{*}$ & $.07-1.18$ \\
\hline & Psychosis & -2.97 & 11.28 & .79 & $-25.71-19.77$ \\
\hline & Depression & 2.26 & 13.87 & .87 & $-25.71-30.24$ \\
\hline & Age & .46 & .59 & .44 & $-.73-1.65$ \\
\hline & Gender & -1.19 & 11.49 & .92 & $-24.36-21.98$ \\
\hline \multirow[t]{5}{*}{ 5-HIAA } & FSIQ & .02 & .02 & .36 & $-.02-.06$ \\
\hline & Psychosis & -.29 & .84 & .73 & $-1.97-1.38$ \\
\hline & Depression & .13 & 1.09 & .91 & $-2.05-2.32$ \\
\hline & Age & -.00 & .05 & .989 & $-.10-.09$ \\
\hline & Gender & .81 & .87 & .36 & $-.94-2.55$ \\
\hline
\end{tabular}

$*$ P value $<0.05$ 
It is becoming increasingly clear that in Parkinson disease besides dopaminergic dysfunction, serotonergic abnormalities are responsible for mood and non-motor symptoms that are frequently seen in this disorder (Strecker, Wegner, Hesse, Becker, Patt, Meyer,... Sabri, 2011; Drijgers, Verhey, Tissingh, van Domburg, Aalten, Leentjens, 2012; Politis, Wu, Loane, Quinn, Brooks, Oertel,... Piccini, 2012; Butcher, Kiehl, Hazrati, Chow, Rogaeva, Lang \& Bassett, 2013).

In addition, the combined loss of dopaminergic and noradrenergic innervation of the limbic system is associated with cognitive and neurobehavioral problems (Delaville, Deurwaerdere \& Benazzouz, 2011). Low 5-HT levels have been associated with low DA in the substantia nigra (Fahn, 2008) and might be related to high prevalence of psychopathology (Fernandez, 2012).

Taken together, our results and the recent literature may suggest that a subgroup of adults with 22q11DS may be affected by a neurodegenerative process affecting at least three neurotransmitter systems. Besides ample knowledge of their role in 22q11DS in general, the precise mechanism in the clinical deterioration as seen in 22q11DS, has to be elucidated.

\section{Strengths and limitations}

The present study consisted of a relative large group of 22q11DS subjects.

The use of urinary markers is based on the assumptions that neurotransmitter synthesis, release, metabolism and neuronal activity are all linked and that these measurements, indirectly reflect (central) monoamine function (Amin, Davidson \& Davis, 1992, Amin, Davidson, Kahn, Schmeidler, Stern, Knott \& Apter, 1995). However, many unrelated factors can confound these assessments when studying central monoamine systems. Nevertheless, peripheral monoamine (metabolite) levels may reflect (major) changes in the overall central monoamine turnover, and, hence, central monoamine function (Boot, 2010). Previous observations of elevated DA levels in a smaller, healthier and slightly younger group of 22q11DS patients (Boot et al, 2008) may reflect an effect of medication in our current study, although introducing use of psychotropic medication as an independent variable did not change the results.

In conclusion, we report for the first time decreased 5-HT concentrations in 22q11DS adults in comparison to healthy controls. We also report an association between three neurotransmitter systems and cognitive functioning in 22q11DS patients. These findings require further studies investigating central neurotransmitter systems and its implications for psychopathology in 22q11DS.

\section{Acknowledgement}

We acknowledge all the participating patients and their families.

Statement of interest

None. 


\section{References}

aan het Rot M, Mathew SJ, Charney DS (2009) Neurobiological mechanisms in major depressive disorder. CMAJ 180:305-313.

Abeling NG, van Gennip AH, Overmars H, Voute PA (1984) Simultaneous determination of catecholamines and metanephrines in urine by HPLC with fluorometric detection. Clin Chim Acta 137:211226.

Amin F, Davidson M, Davis KL (1992) Homovanillic acid measurement in clinical research: a review of methodology. Schizophr Bull 18:123-148.

Amin F, Davidson M, Kahn RS, Schmeidler J, Stern R, Knott PJ, Apter S (1995) Assessment of the central dopaminergic index of plasma HVA in schizophrenia. Schizophr Bull 21:53-66.

Anderson GM, Feibel FC, Cohen DJ (1987) Determination of serotonin in whole blood, platelet-rich plasma, platelet-poor plasma and plasma ultrafiltrate. Life Sci 40:1063-1070.

Barnes JJ, Dean AJ, Nandam LS, O'Connell RG, Bellgrove MA (2011) The molecular genetics of executive function: role of monoamine system genes. Biol Psychiatry 69:e127-143.

Bartsch I, Sandrock K, Lanza F, Nurden P, Hainmann I, Pavlova A, Greinacher A, Tacke U, Barth M, Busse A, Oldenburg J, Bommer M, Strahm B, Superti Furga A, Zieger B (2011) Deletion of human GP1BB and SEPT5 is associated with Bernard-Soulier syndrome, platelet secretion defect, polymicrogyria, and developmental delay. Thromb Haemost 106:475-483.

Bassett AS, Chow EW, Husted J, Weksberg R, Caluseriu O, Webb GD, Gatzoulis MA (2005) Clinical features of 78 adults with 22q11 Deletion Syndrome. Am J Med Genet A 138:307-313.

Beck AT, Steer RA, Ball R, Ranieri W (1996) Comparison of Beck Depression Inventories -IA and -II in psychiatric outpatients. J Pers Assess 67:588-597.

Booij J, van Amelsvoort T, Boot E (2010) Co-occurrence of early-onset Parkinson disease and 22q11.2 deletion syndrome: Potential role for dopamine transporter imaging. Am J Med Genet A 152a:29372938.

Boot E (2010) 22q11 Deletion syndrome and neurotransmitter system in unchallenged and challenged conditions. In: Faculty of medicine, p 176. Amsterdam: University of Amsterdam.

Boot E, Booij J, Zinkstok J, Abeling N, de Haan L, Baas F, Linszen D, van Amelsvoort T (2008) Disrupted dopaminergic neurotransmission in 22q11 deletion syndrome. Neuropsychopharmacology 33:1252-1258.

Boot E, Booij J, Abeling N, Meijer J, da Silva Alves F, Zinkstok J, Baas F, Linszen D, van Amelsvoort T (2011) Dopamine metabolism in adults with 22q11 deletion syndrome, with and without schizophrenia--relationship with COMT Val(1)/(1)Met polymorphism, gender and symptomatology. J Psychopharmacol 25:888-895.

Butcher NJ, Kiehl TR, Hazrati LN, Chow EW, Rogaeva E, Lang AE, Bassett AS (2013) Association between early-onset Parkinson disease and 22q11.2 deletion syndrome: identification of a novel genetic form of Parkinson disease and its clinical implications. JAMA Neurol 70:1359-1366.

Christenson JG, Dairman W, Udenfriend S (1972) On the Identity of DOPA Decarboxylase and 5Hydroxytryptophan Decarboxylase. Proceedings of the National Academy of Sciences 69:343-347.

Delaville C, Deurwaerdere PD, Benazzouz A (2011) Noradrenaline and Parkinson's disease. Front Syst Neurosci 5:31.

Dent J, Kato K, Peng XR, Martinez C, Cattaneo M, Poujol C, Nurden P, Nurden A, Trimble WS, Ware J (2002) A prototypic platelet septin and its participation in secretion. Proc Natl Acad Sci USA 99:3064-3069.

Drago A, Crisafulli C, Sidoti A, Serretti A (2011) The molecular interaction between the glutamatergic, noradrenergic, dopaminergic and serotoninergic systems informs a detailed genetic perspective on depressive phenotypes. Prog Neurobiol 94:418-460.

Drijgers RL, Verhey FR, Tissingh G, van Domburg PH, Aalten P, Leentjens AF (2012) The role of the dopaminergic system in mood, motivation and cognition in Parkinson's disease: a double blind randomized placebo-controlled experimental challenge with pramipexole and methylphenidate. J Neurol Sci 320:121-126. 
Duijff SN, Klaassen PW, de Veye HF, Beemer FA, Sinnema G, Vorstman JA (2012) Cognitive development in children with 22q11.2 deletion syndrome. BrJ Psychiatry 200:462-468.

Evers LJ, De Die Smulders CE, Smeets EE, Clerkx MG, Curfs LM (2009) The velo-cardio-facial syndrome: the spectrum of psychiatric problems and cognitive deterioration at adult age. Genet Couns 20:307315.

Evers LJ, van Amelsvoort TA, Candel MJ, Boer H, Engelen JJ, Curfs LM (2014) Psychopathology in adults with 22q11 deletion syndrome and moderate and severe intellectual disability. J Intellect Disabil Res, 58(10):915-25.

Fahn S (2008) The history of dopamine and levodopa in the treatment of Parkinson's disease. Mov Disord 23 Suppl 3:S497-508.

Fernandez HH (2012) Nonmotor complications of Parkinson disease. Cleve Clin J Med 79 Suppl 2:S1418.

Harper KM, Hiramoto T, Tanigaki K, Kang G, Suzuki G, Trimble W, Hiroi N (2012) Alterations of social interaction through genetic and environmental manipulation of the 22q11.2 gene Sept5 in the mouse brain. Hum Mol Genet 21:3489-3499.

Hiroi N, Takahashi T, Hishimoto A, Izumi T, Boku S, Hiramoto T (2013) Copy number variation at 22q11.2: from rare variants to common mechanisms of developmental neuropsychiatric disorders. Mol Psychiatry 18:1153-1165.

Howes OD, Fusar Poli P, Bloomfield M, Selvaraj S, McGuire P (2012) From the prodrome to chronic schizophrenia: the neurobiology underlying psychotic symptoms and cognitive impairments. Curr Pharm Des 18:459-465.

Jonas RK, Montojo CA, Bearden CE (2014) The 22q11.2 Deletion Syndrome as a Window into Complex Neuropsychiatric Disorders Over the Lifespan. Biol Psychiatry 75:351-360.

Kahn RS, Keefe RS (2013) Schizophrenia is a cognitive illness: time for a change in focus. JAMA Psychiatry 70:1107-1112.

Kay SR, Fiszbein A, Opler LA (1987) The positive and negative syndrome scale (PANSS) for schizophrenia. Schizophr Bull 13:261-276.

Kehagia AA, Murray GK, Robbins TW (2010) Learning and cognitive flexibility: frontostriatal function and monoaminergic modulation. Curr Opin Neurobiol 20:199-204.

Kraijer DW, Plas JJ (2006) Handboek psychodiagnostiek en beperkte begaafdheid, 4 Edition. Amsterdam: Harcourt Assesment B.V.

Latger-Cannard V, Bensoussan D, Gregoire MJ, Marcon F, Cloez JL, Leheup B, Jonveaux P, Lecompte T, Bordigoni P (2004) Frequency of thrombocytopenia and large platelets correlates neither with conotruncal cardiac anomalies nor immunological features in the chromosome 22q11.2 deletion syndrome. Eur J Pediatr 163:327-328.

McDonald McGinn DM, Sullivan KE (2011) Chromosome 22q11.2 deletion syndrome (DiGeorge syndrome/velocardiofacial syndrome). Medicine, 90:1-18.

Nikolaus S, Antke C, Beu M, Muller HW (2010) Cortical GABA, striatal dopamine and midbrain serotonin as the key players in compulsive and anxiety disorders--results from in vivo imaging studies. Rev Neurosci 21:119-139.

Oskarsdottir S, Vujic M, Fasth A (2004) Incidence and prevalence of the 22q11 deletion syndrome: a population-based study in Western Sweden. Arch Dis Child 89:148-151.

Park SY, Kwon D, Mok H, Chung BH (2013) Simple and rapid detection of L-Dopa decarboxylase activity using gold nanoparticles. Analyst 138:3146-3149.

Politis M, Wu K, Loane C, Quinn NP, Brooks DJ, Oertel WH, Bjorklund A, Lindvall O, Piccini P (2012) Serotonin neuron loss and nonmotor symptoms continue in Parkinson's patients treated with dopamine grafts. Sci Transl Med 4:128ra141.

Prosser H, Moss S, Costello H, Simpson N, Patel P, Rowe S (1998) Reliability and validity of the Mini PASADD for assessing psychiatric disorders in adults with intellectual disability. J Intellect Disabil Res 42 ( Pt 4):264-272.

Robbins TW, Arnsten AF (2009) The neuropsychopharmacology of fronto-executive function: monoaminergic modulation. Annu Rev Neurosci 32:267-287. 
Saito M, Ishikawa T, Ito Y, Shimizu H (2004) Hematological abnormalities in a patient with a 22q11.2 deletion. Brain Dev 26:342-344.

Sheehan DV, Lecrubier Y, Sheehan KH, Amorim P, Janavs J, Weiller E, Hergueta T, Baker R, Dunbar GC (1998) The Mini-International Neuropsychiatric Interview (M.I.N.I.): the development and validation of a structured diagnostic psychiatric interview for DSM-IV and ICD-10. J Clin Psychiatry 59 Suppl 20:22-33;quiz 34-57.

Stachon AC, De Souza C (2011) Anxiety Disorders and Perceptual Disturbances in Adolescents with 22q11.2 Deletion Syndrome Treated with SSRI: A Case Series. J Can Acad Child Adolesc Psychiatry 20:305-310.

StataCorp. (2011) Stata Statistical Software. In, 12 Edition. College Station, Texas: Stata Corporation.

Strecker K, Wegner F, Hesse S, Becker GA, Patt M, Meyer PM, Lobsien D, Schwarz J, Sabri O (2011) Preserved serotonin transporter binding in de novo Parkinson's disease: negative correlation with the dopamine transporter. J Neurol 258:19-26.

Stroomer AE, Overmars H, Abeling NG, van Gennip AH (1990) Simultaneous determination of acidic 3,4dihydroxyphenylalanine metabolites and 5-hydroxyindole-3-acetic acid in urine by highperformance liquid chromatography. Clin Chem 36:1834-1837.

Suzuki G, Harper KM, Hiramoto T, Sawamura T, Lee M, Kang G, Tanigaki K, Buell M, Geyer MA, Trimble WS, Agatsuma S, Hiroi N (2009) Sept5 deficiency exerts pleiotropic influence on affective behaviors and cognitive functions in mice. Hum Mol Genet 18:1652-1660.

Tunbridge EM, Harrison PJ (2011) Importance of the COMT gene for sex differences in brain function and predisposition to psychiatric disorders. Curr Top Behav Neurosci 8:119-140.

van Beveren NJ, Krab LC, Swagemakers S, Buitendijk GH, Boot E, van der Spek P, Elgersma Y, van Amelsvoort TA (2012) Functional gene-expression analysis shows involvement of schizophreniarelevant pathways in patients with 22q11 deletion syndrome. PLoS One 7:e33473.

Wechsler D (2001) WAIS-III, nederlandstalige bewerking: Technische handleiding. In. Lisse: Swets Test Publishers.

Zaleski C, Bassett AS, Tam K, Shugar AL, Chow EW, McPherson E (2009) The co-occurrence of early onset Parkinson disease and 22q11.2 deletion syndrome. Am J Med Genet A 149A:525-528. 


\section{CHAPTER 6}

Glutamatergic markers, age, intellectual functioning and psychosis in $22 \mathrm{q} 11$ deletion syndrome

Published as:

Evers LJ, van Amelsvoort TA, Bakker JA, de Koning M, Drukker M, Curfs LM (2015). Psychopharmacology, Sep;232(18):3319-25. 


\section{Abstract}

Rationale Patients with 22q11 deletion syndrome (22q11DS) have a high prevalence of intellectual disabilities and psychiatric disorders, including psychosis. Haplo-insufficiency of genes in the deleted region may offer a partial explanation for the increased vulnerability for psychosis and intellectual disability. One gene of particular interest is the gene coding for proline dehydrogenase (PRODH), an enzyme responsible for the conversion of proline into glutamate.

Objectives Because abnormalities in glutamatergic signaling are thought to be responsible for cognition and psychosis in the general population, we hypothesized that PRODH haplo-insufficiency may underlie some of the cognitive and psychotic features seen in 22q11DS.

MethodsIn this explorative study, we investigated the relation between plasma proline, glutamate and glutamine and age, intelligence and psychosis in 64 adults with 22q11DS.

Results Hyperprolinemia was found in $31.3 \%$ of subjects with 22q11DS. A relation between glutamine, glutamate, proline and presence of psychosis was not observed. Regression analysis revealed a positive relation between plasma glutamate and age, a positive relation of glutamate with antipsychotic drugs, a relation of glutamine and gender, and a positive relation of glutamine and mood stabilizing drugs and a negative relation of the ratio glutamine/glutamate and age. The group with relatively lower IQ had higher glutamate levels compared to the group with relatively higher IQ.

Conclusions Our results suggest that 22q11DS is accompanied by abnormalities in glutamatergic metabolism. Future longitudinal studies are needed to further investigate the glutamatergic system in 22q11DS and how this affects the development of cognitive problems and psychopathology.

Keywords: Proline, Glutamate, Glutamine, 22q11 deletion syndrome, Age, Cognition, Psychosis 


\section{Introduction}

22q11 deletion syndrome (22q11DS) is a genetic disorder caused by a microdeletion on the long arm of chromosome 22. Its prevalence is estimated to be 1:4000 (McDonald McGinn and Sullivan 2011). Besides a variety of physical symptoms, patients with 22q11DS frequently suffer from psychiatric disorders (Hiroi, Takahashi, Hishimoto, Izumi, Boku, Hiramoto, 2013; Schneider, Debbane, Bassett, Chow, Fung, van den Bree,... Eliez, 2014). There has been a particular interest in schizophrenia because patients with 22q11DS have a 25-30 times higher risk of developing schizophrenia (Murphy, Jones \& Owen, 1999). In addition, an increased prevalence of a 22q11 deletion (0-5.3\%) among patients with schizophrenia has been observed in some studies (Sporn, Addington, Reiss, Dean, Gogtay, Potocnik,... Rapoport, 2004; Wiehahn, Bosch, du Preez, Pretorius, Karayiorgou \& Roos, 2004) but not in others (Hoogendoorn, Vorstman, Jalali, Selten, Sinke, Emanuel \& Kahn, 2008). Especially the high prevalence of schizophrenia in people with 22q11DS has led to speculations about how a reduced dosage of genes located at 22q11 could be implicated in the etiology of schizophrenia. One gene of particular interest is the gene coding for proline dehydrogenase (PRODH), an enzyme responsible for the conversion of proline (Pro) into glutamate (Glu). Because of reduced PRODH gene dosage, it is expected that people with 22q11DS have reduced PRODH enzyme activity and increased Pro levels (Goodman, Rutberg, Lin, Pulver, Thomas, 2000; Magnee, Lamme, de Sain-van der Velden, Vorstman, Kemner, 2011; Raux, Bumsel, Hecketsweiler, van Amelsvoort, Zinkstok, Manouvrier-Hanu,... Campion,2007). Increased Pro levels (plasma Pro 350-550 $\mu \mathrm{mol} / \mathrm{l}$ ) may be a risk factor for schizoaffective disorders (Jacquet, Demily, Houy, Hecketsweiler, Bou, Raux,... Campion, 2005). Type 1 hyperprolinemia resulting from an inherited PRODH deficiency is a disease characterized by severe hyperprolinemia ( $>550 \mu \mathrm{mol} / \mathrm{l}$ ), seizures, intellectual disability and psychiatric symptoms (Jacquet, Raux, Thibaut, Hecketsweiler, Houy, Demilly,... Frebourg, 2002).

Taken together, it seems plausible that high Pro levels could play a role in the development of psychosis, neurological and cognitive deficits in 22q11DS. Pro, a precursor of Glu, has been the subject of several studies in 22q11DS (Goodman et al. 2000; Raux et al. 2007; Vorstman, Turetsky, Sijmens Morcus, de Sain, Dorland, Sprong,... Kemner, 2009), and all conclude that hyperprolinemia is common in 22q11DS patients.

Glu is the principal excitatory neurotransmitter in the brain (Nedergaard, Takano \& Hansen, 2002) and plays an important role in learning, memory (Cotman, Monaghan \& Ganong, 1988), emotional regulation and motivational behavior (Mora and Cobo 1990). However, excessive concentrations of Glu are toxic and result in cell death (Lau \& Tymianski 2010). Abnormal Glu neurotransmission is thought to play a crucial role in epilepsy and several chronic neurodegenerative disorders, including Parkinson's disease (Marsman, Mandl, van den Heuvel, Boer, 
Wijnen, Klomp,... Hilleke, 2013; Mehta, Prabhakar, Kumar, Deshmukh \& Sharma, 2013). Both Parkinson's disease (Booij, van Amelsvoort \& Boot, 2010; Butcher, Kiehl, Hazrati, Chow, Rogaeva, Lang \& Bassett, 2013) and epilepsy (Mori, Mori, Fujii, Toda, Miyazaki, Harada \& Kagami, 2011) have been associated with 22q11DS. Moreover, pharmacological treatment for these disorders sometimes targets the glutamatergic system (Bleich, Romer, Wiltfang \& Kornhuber, 2003). The role of the glutamatergic neurotransmission in the etiology of schizophrenia has received increased interest, in addition to the existing dopaminergic theory. Molecular imaging studies in schizophrenia point to an excess of dopamine in the associative striatum, explaining mainly positive symptoms, and a hypodopaminergic state in the prefrontal cortex (Stone, Morrison \& Pilowsky 2007). However, Kambeitz et al. (Kambeitz, Abi Dargham, Kapur \& Howes 2014) recently stated that there is insufficient in-vivo evidence of altered dopaminergic function in cortical and extrastriatal regions that could explain negative or cognitive symptoms. It is now hypothesized that decreased glutamatergic neurotransmission via hypofunctional NMDA receptors leads to increased prefrontal glutamatergic activity in schizophrenia, possibly contributing to negative cognitive symptoms (Poels, Kegeles, Kantrowitz, Javitt, Lieberman, Abi Dargham \& Girgis, 2014). A recent meta-analysis (Song, Viggiano, Monda \& De Luca, 2014) shows that the peripheral measured Glu in patients with schizophrenia is elevated compared to controls. Compared to peripheral levels, levels in the brain, measured with MRS, vary with different brain regions (Marsman et al. 2013). Peripheral levels of Glu are therefore not necessarily related to levels measured in the brain. High peripheral levels of glutamate have been considered a trait marker for schizophrenia (De Luca,Viggiano, Messina, Viggiano, Borlido, Viggiano \& Monda, 2008).

There is limited in-vivo research on the function and modulation of the glutamatergic system in adult 22q11DS patients. The only magnetic resonance spectroscopy (MRS) study in adult 22q11DS patients with schizophrenia showed that, compared to 22q11DS patients without schizophrenia, Glu was increased in the hippocampus, with no differences in Glu concentrations in the dorsolateral prefrontal region (da Silva Alves, Boot, Schmitz, Nederveen, Vorstman, Lavini,... van Amelsvoort, 2011). To our knowledge, plasma glutamine (Gln) levels have only been investigated in 22q11DS in a small sample group $(n=9)$ by da Silva Alves et al. (2011). This study did not find any differences in Gln or Pro plasma levels between 22q11DS subjects with and without psychosis. Because of its role both in psychosis and in cognition in this study, we assessed Glu, Gln, the ratio of Gln/Glu and Pro in plasma of adult 22q11DS patients and hypothesized that a) Pro, Glu and Gln levels are related to the presence of psychosis; b) Pro, Glu and Gln levels are related to intellectual functioning; c) hyperprolinemia is highly prevalent among adult 22q11DS patients. 


\section{Methods}

The study was approved by the Medical Ethics Committee of the University of Maastricht, Maastricht, and the University of Amsterdam, Amsterdam, the Netherlands, and is part of an ongoing multi-center research project on neurotransmitter functioning in 22q11DS adults.

\section{Subjects}

Participants were recruited through the Dutch 22q11DS family network, a specialized psychiatric 22q11DS outpatient clinic, and through several intellectual disability centers in the Netherlands. A subset of this group enrolled previously in an earlier study by Raux et al. (2007), in which Pro was the only investigated amino acid. Because we have extended the original cohort of adults and added Glu, Gln, and the ratio of Gln/Glu as outcome measures, we were able to address the complex interplay of cognitive level and psychosis that are present in 22q11DS. Sixtyfour patients with a confirmed deletion at chromosome 22q11.2 were included. Exclusion criteria were age below 18 years and medical conditions that affect brain functions not associated with 22q11DS, e.g., Alzheimer's disease. All patients and their carers were informed about the study, and written informed consent was obtained.

\section{Clinical assessment}

\section{IQ measurements}

Full-scale IQ (FSIQ) scores were obtained in the 22q11DS group using a shortened version of the Wechsler Adult Intelligence Scale (WAIS) version III (Wechsler 1997). Patients unable to perform the WAIS because of their low intelligence were investigated using a Vineland screener (Scholte, Duijn v, Dijkxhoorn, Noens, Berckelaer-Onnes, 2008). The outcome of this test was converted to a FSIQ rating as described earlier (Evers, van Amelsvoort, Candel, Boer, Engelen \& Curfs, 2014b; Kraijer and Plas 2006).

\section{Psychopathology outcome measures}

All patients were assessed for lifetime presence of a psychotic disorder based on information obtained from medical records and/or the present score on the Mini PAS-ADD (Psychiatric Assessment Schedules for Adults with Developmental Disabilities) (Prosser, Moss, Costello, Simpson, Patel \& Rowe, 1998) or MINI (MiniInternational Neuropsychiatric Interview) (Sheehan, Lecrubier, Sheehan, Amorim, Janavs, Weiller,... Dunbar, 1998). The mini PAS-ADD was used in patients functioning at a level below IQ 55 and the remaining were evaluated with the MINI. 


\section{Use of psychotropic drugs}

The dosage of prescribed antipsychotic drugs was rated according to haloperidol equivalents. The use of mood stabilizing drugs was noted as present or absent.

\section{Amino acid analysis}

Blood samples were obtained by venipuncture for the determination of amino acids (Pro, Gln and Glu). The samples were cooled on ice and centrifuged, and plasma was frozen at $-20^{\circ} \mathrm{C}$ until analysis. Concentrations in plasma were determined using a standardized procedure for the quantification of amino acids in biological fluids. Analyses were performed using ultra performance liquid chromatography combined with tandem mass spectrometry [Acquity UPLC - Micromass Quattro Premier XE TandemMass Spectrometer (Waters, Milford, MA)] (Waterval, Scheijen, Ortmans Ploemen, Habets van der Poel \& Bierau, 2009). Local reference ranges were used in line with published values (Blau, Duran \& Gibson, 2008). The ratio Gln/Glu was defined as the concentration of Gln divided by Glu concentration.

\section{Statistical analysis}

All statistical analyses were performed using Stata version 12.1 (StataCorp 2011). Mean levels of amino acids with distribution and reference range were obtained. Descriptive statistics were used to determine percentages of high Pro levels (hyperprolinemia) as described by Jacquet et al. (2005). The relation of psychosis with Pro, Glu, Gln and the ratio Gln/Glu was investigated with a regression analysis which was performed in four separate models with Glu, Gln, the ratio of Gln/Glu and Pro, respectively, as dependent variables. Age, use of antipsychotic medication, presence of lifetime psychosis, gender and use of mood stabilizing drugs were the main independent variables in all models. We have not corrected for multiple comparison due to a limited power. Because of the use of two different methods to establish intelligence (Vineland-S in the lower functioning group in contrast to the WAIS in the relatively higher functioning group (FSIQ > 55)), the method refers automatically to subgroups of higher and lower intelligence and is shown to act as a powerful confounder or as a mediator. We, therefore, analyzed only the dichotomized IQ. If IQ was assessed with the Vineland screener rather than the Wechsler Adult Intelligence Scale (WAIS) version III, subjects were categorized in the "lower IQ" category. To establish the relation of Glu, Gln and the ratio Gln/Glu with intelligence, we performed a $t$-test analysis to compare amino acid levels in "lower IQ" and "higher IQ" subgroups. 


\section{Results}

Thirty (47\%) of the patients were male. Mean age was 33.7 years (SE 1.1, range 1859) (Table 1). Twenty-nine out of 64 patients (45\%) had a history of psychosis, and 29 out of 64 (45\%) used prescribed antipsychotic drugs. Eight out of the 64 patients (13\%) had both a psychotic disorder and a depressive disorder diagnosed; twenty-six out of the 64 patients (40\%) were diagnosed with only a psychotic disorder and 3 out of 64 patients (5\%) only with a depressive disorder. Twenty-seven out of 64 patients had no psychiatric diagnosis (42\%). Presence of depressive disorder (alone or combined with psychosis) was not related to Pro, Glu or Gln. Twenty out of 64 patients (31.3\%) had hyperprolinemia (proline 316$550 \mu \mathrm{mol} / \mathrm{L}$ in female and 377-550 in male), and six of these had severe hyperprolinemia, (proline $>550 \mu \mathrm{mol} / \mathrm{L}$ ) (9.4\%) (Jacquet et al. 2005). In 13 out of the 64 subjects, glutamatergic values were not available because they were a subset from the original Raux et al. study (2007) and did not include glutamatergic metabolites. One out of 53 subjects had a Glu level above the reference range, and another one out of 53 subjects had a Gln level below the reference range.

Table 1 Descriptives

\begin{tabular}{|c|c|c|c|c|c|}
\hline & $\mathrm{N}$ & Mean & SE & Range & \\
\hline$\overline{\text { FSIQ }}$ & 64 & 51.8 & 3.19 & $7-96$ & \\
\hline Age (years) & 64 & 33.7 & 1.1 & $18-59$ & \\
\hline Sex: M:F & 64 & $30: 34$ & & & \\
\hline $\begin{array}{l}\text { Treated with antipsychotic } \\
\text { drugs }\end{array}$ & $29 / 64(45 \%)$ & & & & \\
\hline $\begin{array}{l}\text { Treated with mood } \\
\text { stabilizing drugs }\end{array}$ & $20 / 64(31 \%)$ & & & & \\
\hline History of psychosis & $29 / 64(45 \%)$ & & & & \\
\hline Amino Acids & $\mathrm{N}$ & Level (mean) & SE & $\mathrm{CI}$ & reference range \\
\hline Proline $(\mu \mathrm{mol} / \mathrm{L})^{1}$ & 64 & 316.3 & 18.6 & $279.1-353.6$ & $\begin{array}{l}\text { 77-316 (ํ) } \\
77-377(ð))\end{array}$ \\
\hline Glutamate $(\mu \mathrm{mol} / \mathrm{L})^{2}$ & 51 & 53.33 & 3.2 & $48.9-61.7$ & $<121$ \\
\hline Glutamine $(\mu \mathrm{mol} / \mathrm{L})^{3}$ & 51 & 529.9 & 12.7 & $504.5-555.3$ & $344-743$ \\
\hline $\begin{array}{l}\text { Ratio glutamine/ } \\
\text { Glutamate }\end{array}$ & 51 & 11.2 & .79 & $9.6-12.8$ & \\
\hline
\end{tabular}

${ }^{1}$ Twenty out of 64 subjects (31.3\%) had hyperprolinemia (Pro 350-550 $\mu \mathrm{mol} / \mathrm{l}$ ), six of them severe hyperprolinemia (Pro > 550 $\mu \mathrm{mol} / \mathrm{l}$ ) (9.4\%) (Jacquet et al. 2005).

2 One out of 51 had glutamate above normal level

${ }^{3}$ One out of 51 had glutamine below normal level

In the regression models, psychosis was not associated with any of the four outcome variables (Table 2). Age was negatively associated with Gln and ratio of Gln/Glu and positively associated with Glu. Glu was positively related with dosage 
of antipsychotic medication (Table 2). Gender affected Glu and Gln with higher Glu and Gln in men compared to women (50.9 and 569 vs 50.6 and 488). Pro, Glu, Gln or the ratio Gln/Glu were not significantly related to any other included variables.

Table 2. Regression analysis in four models with age, antipsychotic drugs life time psychosis and use of mood stabilizing drugs as dependent variables.

\begin{tabular}{|c|c|c|c|c|c|}
\hline & & Coef & S.E. & P-value & $95 \% \mathrm{CI}$ \\
\hline \multirow[t]{5}{*}{ Proline } & Age & -1.02 & 2.12 & .63 & $-5.28-3.24$ \\
\hline & Antipsychotic drugs ${ }^{2}$ & 5.15 & 7.03 & .47 & $-8.96-19.26$ \\
\hline & Life time psychosis & -81.55 & 46.93 & .09 & $-175.81-12.72$ \\
\hline & Gender & -78.81 & 42.92 & .07 & $-165.02-7.39$ \\
\hline & Mood stabilizing drugs & -56.78 & 52.74 & .29 & $-162.70-49.14$ \\
\hline \multirow[t]{5}{*}{ Glutamate } & Age & .80 & .32 & $.018^{1}$ & $.14-1.46$ \\
\hline & Antipsychotic drugs ${ }^{2}$ & 2.07 & 1.01 & $.046^{1}$ & $.04-4.10$ \\
\hline & Life time psychosis & -6.68 & 6.94 & .34 & $-20.71-7.35$ \\
\hline & Gender & -11.18 & 6.64 & .10 & $-24.95--2.25$ \\
\hline & Mood stabilizing drugs & 3.29 & 8.03 & .68 & $-12.95-19.52$ \\
\hline \multirow[t]{5}{*}{ Glutamine } & Age & -1.18 & 1.10 & .29 & $-3.40-1.04$ \\
\hline & Antipsychotic drugs ${ }^{2}$ & 3.06 & 3.41 & .38 & $-3.84-9.95$ \\
\hline & Life time psychosis & 14.17 & 23.50 & .55 & $-33.37-61.72$ \\
\hline & Gender & -65.17 & 22.50 & $.006^{1}$ & $-110.53--19.51$ \\
\hline & Mood stabilizing drugs & 68.17 & 27.19 & $.016^{1}$ & $13.17-123.18$ \\
\hline \multirow[t]{5}{*}{ Ratio Gln/Glu } & Age & -.14 & .06 & $.003^{1}$ & $-.27--.02$ \\
\hline & Antipsychotic drugs ${ }^{2}$ & -.19 & .19 & .34 & $-.58-.21$ \\
\hline & Life time psychosis & 1.07 & 1.35 & .43 & $-1.65-3.79$ \\
\hline & Gender & 1.43 & 1.29 & .28 & $-1.18-4.03$ \\
\hline & Mood stabilizing drugs & 2.06 & 1.56 & .19 & $-1.09-5.12$ \\
\hline
\end{tabular}

${ }^{1} \mathrm{P} \leq .0 .05{ }^{2}$ In haloperidol equivalents

In the subgroup analysis, t-tests revealed that Glu was higher and ratio Gln/Glu lower in the Vineland "lower IQ" group compared to the WAIS "higher IQ" group (Table 3). There were no between-group differences in Pro levels and Gln levels.

Table 3. T-test analyses of proline, glutamate, glutamine and ratio glutamine/glutamate between different IQ measurement groups. ${ }^{1} \mathrm{p}<.05$

\begin{tabular}{lllll}
\hline MEAN $(\mathrm{SE})$ & WAIS group & Vineland-group & $\mathrm{t}$ & $\mathrm{p}$-Value \\
\hline Proline $(\mu \mathrm{mol} / \mathrm{L})$ & $338.8(31.6)$ & $302.3(22.8)$ & .95 & .345 \\
Glutamate $(\mu \mathrm{mol} / \mathrm{L})$ & $46.1(3.3)$ & $62.3(4.4)$ & -2.57 & $.0133^{1}$ \\
Glutamine $(\mu \mathrm{mol} / \mathrm{L})$ & $551.1(19.6)$ & $517.3(16.3)$ & 1.30 & .2007 \\
Ratio glutamine/glutamate & $13.0(1.2)$ & $9.4(.72)$ & 2.70 & .00971 \\
\hline
\end{tabular}




\section{Discussion}

This explorative study is the first describing plasma levels of Glu, Gln, Pro and ratio Gln/Glu in a group of adult 22q11DS patients.

While in schizophrenia, high ratios of Gln/Glu have been found in different brain regions (Shirayama, Obata, Matsuzawa, Nonaka, Kanazawa, Yoshitome,... Iyo, 2010), as well as high peripheral levels of Glu (Song et al. 2014; Tomiya, Fukushima, Watanabe, Fukami, Fujisaki, Iyo,... Toyo'oka, 2007), we did not observe a relation between Gln/Glu, Gln, Glu and Pro and presence of psychosis. These results reject our hypotheses concerning psychosis and its relation with Glu, Gln and Pro in our study. We showed, in a t-test analysis, between-group differences in Glu and ratio Gln/Glu with higher Glu and a lower ratio Gln/Glu in the lower IQ group. The relation of higher Glu and lower Gln/Glu ratios in the lower IQ group supports the hypothesis that Glu and Gln levels may be related to intellectual functioning. Because intellectual decline is a common feature in 22q11DS (Duijff, Klaassen, Swanenburg de Veye, Beemer, Sinnema \& Vorstman, 2013; Evers et al. 2014b) and Glu has neurotoxic proportions, high Glu levels may play a role in this decline. As far as we know, the relationship between peripheral ratio Gln/Glu and IQ in schizophrenia has never been investigated. Though not hypothesized, we found that Glu levels were positively, and ratio of Gln/Glu negatively, associated with age. Our Glu findings are in contrast with the literature in the general population, which suggests an age-related decline in Glu or no age-related change (Marsman et al. 2013; Sailasuta, Ernst \& Chang, 2008). An MRS study in the general population showed that Gln tended to increase with age (Kaiser, Schuff, Cashdollar \& Weiner, 2005), whereas our findings in plasma were in the opposite direction. Most age-related findings are from MRS studies, so comparisons with our results have to be interpreted with caution. The gender difference we observed, i.e., higher Glu and Gln levels in men, is also in contrast with the finding of Hädel et al. (Hädel, Wirth, Rapp, Gallinat \& Schubert, 2013). They demonstrated in a MRS study in the general population that females had higher Glu levels in the hippocampal region compared to males, whereas in the cortical region no differences were found. Jacquet et al. (2005) found higher Pro levels in plasma in healthy male subjects. In our study, we were unable to demonstrate a gender difference in Pro levels $(p=.07)$, which may have been caused by the smaller sample size of our group.

We found a positive relation between Glu levels and dosage of antipsychotic drugs and a positive relation between Gln levels and the use of mood stabilizing drugs. The positive relation of Glu with antipsychotic medication is in contrast to findings in MRS studies in the normal population where antipsychotic medication seemed to correct increased Glu levels in patients with schizophrenia (Poels et al. 2014). In a 22q11DS MRS study (da Silva Alves et al. 2011), a positive correlation was found between dosage of drugs and Gln concentrations in the dorsolateral prefrontal cortex, not in the hippocampus. Antipsychotic drugs are likely to correct 
increased Glu levels in schizophrenia (Goff, Hennen, Lyoo, Tsai, Wald, Evins,... Renshaw, 2002). In 22q11DS psychosis, it is sometimes difficult to treat (Kiehl, Chow, Mikulis, George \& Bassett, 2009), which theoretically could be indicative of antipsychotic drugs failing to correct Glu excess in 22q11DS. Butcher et al. (Butcher, Fung, Fitzpatrick, Guna, Andrade, Lang,... Bassett, 2015), however, demonstrated recently that patients with schizophrenia (half of them with 22q11DS) responded equally on clozapine treatment. Clozapine is the preferable antipsychotic treatment for treatment-resistant schizophrenia (Warnez, Alessi \& Severini 2014) and also in 22q11DS (Butcher et al. 2015). Clozapine has a receptor profile distinct from most antipsychotic drugs. In a recent study, patients with schizophrenia were compared depending on how they reacted to treatment with clozapine (Goldstein, Anderson, Pillai, Kydd \& Russell, 2015), indicating differences in glutamate levels between subgroups. We further hypothesized that hyperprolinemia is highly prevalent among adult 22q11DS patients. We confirmed that hyperprolinemia is a common finding in adults with 22q11DS. Twenty out of 64 subjects (31.3\%) were hyperprolinemic, with six of them severely hyperprolinemic $(9.4 \%)$. This is consistent with findings in two earlier studies in children and adults (50\% and 37\% hyperprolinemia) (Goodman et al. 2000; Raux et al. 2007) and is likely to be the result of hemizygosity of the PRODH gene in 22q11DS. We failed to confirm the hypothesis that high Pro levels may be related to psychosis and to intellectual functioning in the total 22q11DS group or in the subgroups. One previous study found a negative relation between Pro and intelligence scores (Raux et al. 2007), a finding we could not replicate and we are unable to explain. One possibility is that, compared to Raux et al. (2007), we included more 22q11DS patients with a low IQ and our sample had a lower mean IQ (mean IQ of 64 vs. 53).

Based on our findings regarding glutamatergic alterations in 22q11DS and our earlier observations on dopamine and serotonin (Evers, Curfs, Bakker, Boot, da Silva Alves, Abeling,... van Amelsvoort, 2014a), it would be interesting to consider new pharmacological strategies. These may include drugs targeting the glutamatergic system, combined with dopaminergic, noradrenergic and serotonergic action.

\section{Strength and limitations}

This study is the first investigating plasma amino acids in 22q11DS including Pro, Glu, Gln and the ratio Gln/Glu. However, it has some limitations. With the inclusion of 22q11DS patients that function at a lower intellectual level, we cover a broader range of this syndrome; however, it cannot be ruled out that low FSIQ is overrepresented. The use of two different methods to establish intelligence was unavoidable (IQs below 55 cannot be established by Wechsler instruments) but is a serious limitation in this study. The amino acids were measured in plasma, which is an indirect method, and caution in comparison with studies measuring directly 
in CSF or with MRS is recommended. However, peripheral concentrations of Glu seem to be positively correlated to Glu CSF levels (Alfredsson, Wiesel \& Tylec, 1988). It would be more informative to measure directly in the brain with CSF measurements or MRS techniques, but these techniques are more invasive and are difficult to perform in 22q11DS patients with a low IQ. Therefore, comparison of our results with results in MRS studies or in CSF studies should be interpreted with caution. Another limitation of this study is the lack of a control group and the relatively small sample size in the subgroups.

\section{Future/concluding remark}

The reported glutamatergic levels show an opposite pattern compared to those reported in the general population, and this may explain the cognitive problems in 22q11DS. Longitudinal studies in patients with 22q11DS are needed to follow the course of intellectual function and psychosis with special interest for the role of neurotransmitter systems. More insight into these mechanisms may result in possibilities for early treatment to prevent severe complications in this syndrome. Also, it will give us more insight into mechanisms of psychosis and intellectual decline in the normal population.

\section{Acknowledgement}

We thank the patients and their families for their participation in the study.

\section{Conflict of interest}

None 


\section{References}

Alfredsson G, Wiesel FA, Tylec A (1988) Relationships between glutamate and monoamine metabolites in cerebrospinal fluid and serum in healthy volunteers. Biol Psychiatry 23: 689-97.

Blau N, Duran M, Gibson KM (2008) Laboratory Guide to the Methods in Biochemical Genetics. Springer-Verlag, Berlin, Heidelberg

Bleich S, Romer K, Wiltfang J, Kornhuber J (2003) Glutamate and the glutamate receptor system: a target for drug action. Int J Geriatr Psychiatry 18: S33-40.

Booij J, van Amelsvoort T, Boot E (2010) Co-occurrence of early-onset Parkinson disease and 22q11.2 deletion syndrome: Potential role for dopamine transporter imaging. Am J Med Genet A 152a: 29378.

Butcher NJ, Fung WL, Fitzpatrick L, Guna A, Andrade DM, Lang AE, Chow EW, Bassett AS (2015) Response to clozapine in a clinically identifiable subtype of schizophrenia. Br J Psychiatry, 206(6):48491

Butcher NJ, Kiehl TR, Hazrati LN, Chow EW, Rogaeva E, Lang AE, Bassett AS (2013) Association between early-onset Parkinson disease and 22q11.2 deletion syndrome: identification of a novel genetic form of Parkinson disease and its clinical implications. JAMA Neurol 70: 1359-66.

Cotman CW, Monaghan DT, Ganong AH (1988) Excitatory amino acid neurotransmission: NMDA receptors and Hebb-type synaptic plasticity. Annu Rev Neurosci 11: 61-80.

da Silva Alves F, Boot E, Schmitz N, Nederveen A, Vorstman J, Lavini C, Pouwels PJ, de Haan L, Linszen D, van Amelsvoort T (2011) Proton magnetic resonance spectroscopy in 22q11 deletion syndrome. PLoS One 6: e21685.

De Luca V, Viggiano E, Messina G, Viggiano A, Borlido C, Viggiano A, MondaM(2008) Peripheral amino Acid levels in schizophrenia and antipsychotic treatment. Psychiatry Investig 5(4):203-208

Duijff SN, Klaassen PW, Swanenburg de Veye HF, Beemer FA, Sinnema G, Vorstman JA (2013) Cognitive and behavioral trajectories in 22q11DS from childhood into adolescence: a prospective 6-year follow-up study. Res Dev Disabil 34: 2937-45.

Evers LJ, Curfs LM, Bakker JA, Boot E, da Silva Alves F, Abeling N, Bierau J, Drukker M, van Amelsvoort TA (2014a) Serotonergic, noradrenergic and dopaminergic markers are related to cognitive function in adults with 22q11 deletion syndrome. Int J Neuropsychopharmacol 17: 1159-65.

Evers LJ, van Amelsvoort TA, Candel MJ, Boer H, Engelen JJ, Curfs LM (2014b) Psychopathology in adults with 22q11 deletion syndrome and moderate and severe intellectual disability. J Intellect Disabil Res 58: 915-25.

Goff DC, Hennen J, Lyoo IK, Tsai G, Wald LL, Evins AE, Yurgelun Todd DA, Renshaw PF (2002) Modulation of brain and serum glutamatergic concentrations following a switch from conventional neuroleptics to olanzapine. Biol Psychiatry 51: 493-7.

Goldstein ME, Anderson VM, Pillai A, Kydd RR, Russell BR (2015) Glutamatergic Neurometabolites in Clozapine-Responsive and -Resistant Schizophrenia. Int J Neuropsychopharmacol, 20;18(6).

Goodman BK, Rutberg J, Lin WW, Pulver AE, Thomas GH (2000) Hyperprolinaemia in patients with deletion (22)(q11.2) syndrome.J Jnherit Metab Dis 23: 847-8.

Hadel S, Wirth C, Rapp M, Gallinat J, Schubert F (2013) Effects of age and sex on the concentrations of glutamate and glutamine in the human brain.J Magn Reson Imaging 38: 1480-7.

Hiroi N, Takahashi T, Hishimoto A, Izumi T, Boku S, Hiramoto T (2013) Copy number variation at 22q11.2: from rare variants to common mechanisms of developmental neuropsychiatric disorders. Mol Psychiatry 18: 1153-65.

Hoogendoorn ML, Vorstman JA, Jalali GR, Selten JP, Sinke RJ, Emanuel BS, Kahn RS (2008) Prevalence of 22q11.2 deletions in 311 Dutch patients with schizophrenia. Schizophr Res 98: 84-8.

Jacquet H, Demily C, Houy E, Hecketsweiler B, Bou J, Raux G, Lerond J, Allio G, Haouzir S, Tillaux A, Bellegou C, Fouldrin G, Delamillieure P, Menard JF, Dollfus S, D'Amato T, Petit M, Thibaut F, Frebourg T, Campion D (2005) Hyperprolinemia is a risk factor for schizoaffective disorder. Mol Psychiatry 10: 479-85. 
Jacquet H, Raux G, Thibaut F, Hecketsweiler B, Houy E, Demilly C, Haouzir S, Allio G, Fouldrin G, Drouin V, Bou J, Petit M, Campion D, Frebourg T (2002) PRODH mutations and hyperprolinemia in a subset of schizophrenic patients. Hum Mol Genet 11: 2243-9.

Kaiser LG, Schuff N, Cashdollar N, Weiner MW (2005) Age-related glutamate and glutamine concentration changes in normal human brain: 1H MR spectroscopy study at 4 T. Neurobiol Aging 26: 665-72.

Kambeitz J, Abi Dargham A, Kapur S, Howes OD (2014) Alterations in cortical and extrastriatal subcortical dopamine function in schizophrenia: systematic review and meta-analysis of imaging studies. $\mathrm{Br}$ J Psychiatry 204: 420-9.

Kiehl TR, Chow EW, Mikulis DJ, George SR, Bassett AS (2009) Neuropathologic features in adults with 22q11.2 deletion syndrome. Cereb Cortex 19: 153-64.

Kraijer DW, Plas JJ (2006) Handboek psychodiagnostiek en beperkte begaafdheid, 4 edn. Harcourt Assesment B.V., Amsterdam

Lau A, Tymianski M (2010) Glutamate receptors, neurotoxicity and neurodegeneration. Pflugers Arch 460: 525-42.

Magnee MJ, Lamme VA, de Sain-van der Velden MG, Vorstman JA, Kemner C (2011) Proline and COMT status affect visual connectivity in children with 22q11.2 deletion syndrome. PLoS One 6: e25882.

Marsman A, Mandl RC, van den Heuvel MP, Boer VO, Wijnen JP, Klomp DW, Luijten PR, Hilleke EH (2013) Glutamate changes in healthy young adulthood. Eur Neuropsychopharmacol 23: 1484-90.

McDonald McGinn DM, Sullivan KE (2011) Chromosome 22q11.2 deletion syndrome (DiGeorge syndrome/velocardiofacial syndrome). Medicine (Baltimore) 90: 1-18.

Mehta A, Prabhakar M, Kumar P, Deshmukh R, Sharma PL (2013) Excitotoxicity: bridge to various triggers in neurodegenerative disorders. Eur J Pharmacol 698: 6-18.

Mora F, Cobo M (1990) The neurobiological basis of prefrontal cortex self-stimulation: a review and an integrative hypothesis. Prog Brain Res 85: 419-31.

Mori T, Mori K, Fujii E, Toda Y, Miyazaki M, Harada M, Kagami S (2011) Neuroradiological and neurofunctional examinations for patients with 22q11.2 deletion. Neuropediatrics 42: 215-21.

Murphy KC, Jones LA, Owen MJ (1999) High rates of schizophrenia in adults with velo-cardio-facial syndrome. Arch Gen Psychiatry 56: 940-5.

Nedergaard M, Takano T, Hansen AJ (2002) Beyond the role of glutamate as a neurotransmitter. Nat Rev Neurosci 3: 748-55.

Poels EM, Kegeles LS, Kantrowitz JT, Javitt DC, Lieberman JA, Abi Dargham A, Girgis RR (2014) Glutamatergic abnormalities in schizophrenia: a review of proton MRS findings. Schizophr Res 152: 325-32.

Prosser H, Moss S, Costello H, Simpson N, Patel P, Rowe S (1998) Reliability and validity of the Mini PASADD for assessing psychiatric disorders in adults with intellectual disability. J Intellect Disabil Res 42 ( Pt 4): 264-72.

Raux G, Bumsel E, Hecketsweiler B, van Amelsvoort T, Zinkstok J, Manouvrier-Hanu S, Fantini C, Breviere GM, Di Rosa G, Pustorino G, Vogels A, Swillen A, Legallic S, Bou J, Opolczynski G, DrouinGarraud V, Lemarchand M, Philip N, Gerard-Desplanches A, Carlier M, Philippe A, Nolen MC, Heron D, Sarda P, Lacombe D, Coizet C, Alembik Y, Layet V, Afenjar A, Hannequin D, Demily C, Petit M, Thibaut F, Frebourg T, Campion D (2007) Involvement of hyperprolinemia in cognitive and psychiatric features of the 22q11 deletion syndrome. Hum Mol Genet 16: 83-91.

Sailasuta N, Ernst T, Chang L (2008) Regional variations and the effects of age and gender on glutamate concentrations in the human brain. Magn Reson Imaging 26: 667-75.

Schneider M, Debbane M, Bassett AS, Chow EW, Fung WL, van den Bree MB, Owen M, Murphy KC, Niarchou M, Kates WR, Antshel KM, Fremont W, McDonald McGinn DM, Gur RE, Zackai EH, Vorstman J, Duijff SN, Klaassen PW, Swillen A, Gothelf D, Green T, Weizman A, Van Amelsvoort T, Evers L, Boot E, Shashi V, Hooper SR, Bearden CE, Jalbrzikowski M, Armando M, Vicari S, Murphy DG, Ousley O, Campbell LE, Simon TJ, Eliez S (2014) Psychiatric Disorders From Childhood to Adulthood in 22q11.2 Deletion Syndrome: Results From the International Consortium on Brain and Behavior in 22q11.2 Deletion Syndrome. Am J Psychiatry 171(6):627-39

Scholte E, Duijn vG, Dijkxhoorn Y, Noens I, Berckelaer-Onnes van IA (2008) Vineland Screener 0-6 jaar. PITS, Leiden,The Netherlands 
Sheehan DV, Lecrubier Y, Sheehan KH, Amorim P, Janavs J, Weiller E, Hergueta T, Baker R, Dunbar GC (1998) The Mini-International Neuropsychiatric Interview (M.I.N.I.): the development and validation of a structured diagnostic psychiatric interview for DSM-IV and ICD-10. J Clin Psychiatry 59 Suppl 20: 22-33;quiz 34-57.

Shirayama Y, Obata T, Matsuzawa D, Nonaka H, Kanazawa Y, Yoshitome E, Ikehira H, Hashimoto K, Iyo M (2010) Specific metabolites in the medial prefrontal cortex are associated with the neurocognitive deficits in schizophrenia: a preliminary study. Neuroimage 49: 2783-90.

Song J, Viggiano A, Monda M, De Luca V (2014) Peripheral glutamate levels in schizophrenia: evidence from a meta-analysis. Neuropsychobiology 70: 133-41.

Sporn A, Addington A, Reiss AL, Dean M, Gogtay N, Potocnik U, Greenstein D, Hallmayer J, Gochman P, Lenane M, Baker N, Tossell J, Rapoport JL (2004) 22q11 deletion syndrome in childhood onset schizophrenia: an update. Mol Psychiatry 9: 225-6.

StataCorp (2011) Stata Statistical Software. StataCorparation, Texas

Stone JM, Morrison PD, Pilowsky LS (2007) Glutamate and dopamine dysregulation in schizophrenia--a synthesis and selective review. J Psychopharmacol 21: 440-52.

Tomiya M, Fukushima T, Watanabe H, Fukami G, Fujisaki M, Iyo M, Hashimoto K, Mitsuhashi S, Toyo'oka $\mathrm{T}$ (2007) Alterations in serum amino acid concentrations in male and female schizophrenic patients. Clin Chim Acta 380: 186-90.

Vorstman JA, Turetsky BI, Sijmens Morcus ME, de Sain MG, Dorland B, Sprong M, Rappaport EF, Beemer FA, Emanuel BS, Kahn RS, van Engeland H, Kemner C (2009) Proline affects brain function in 22q11DS children with the low activity COMT 158 allele. Neuropsychopharmacology 34: 739-46.

Warnez S, Alessi Severini S (2014) Clozapine: a review of clinical practice guidelines and prescribing trends. BMC Psychiatry 14: 102.

Waterval WA, Scheijen JL, Ortmans Ploemen MM, Habets van der Poel CD, Bierau J (2009) Quantitative UPLC-MS/MS analysis of underivatised amino acids in body fluids is a reliable tool for the diagnosis and follow-up of patients with inborn errors of metabolism. Clin Chim Acta 407: 36-42.

Wechsler D (1997) Wechsler Adult Intelligence Scale Third Edition. The Psychological Corporation, San Antonio

Wiehahn GJ, Bosch GP, du Preez RR, Pretorius HW, Karayiorgou M, Roos JL (2004) Assessment of the frequency of the 22q11 deletion in Afrikaner schizophrenic patients. Am J Med Genet B 129B: 20-2. 
CHAPTER 7

GENERAL DISCUSSION AND CONCLUSIONS 



\section{General Discussion and Conclusions}

The overall aim of the studies described in this thesis was to increase our knowledge about adults with 22q11.2 deletion syndrome (22q11DS) with special attention to a group that functioned at a moderate to profound level of intellectual disability, most of the time after an intellectual decline, and its relation with psychopathology and biological factors.

To determine attributing factors, we conducted studies concerning intellectual function, psychiatric symptoms, neurotransmitter systems, and the length of the deletion in individuals with 22q11DS. In this general discussion, the results will be discussed in the perspective of the broader phenotype of 22q11DS and other genetic syndromes. In addition, methodological considerations (strengths and weaknesses) will be addressed, and finally some recommendations for future research will be presented.

Until today, intellectual decline in adult patients with 22q11DS has received little attention in the literature. We found in our clinical practice some indications that individuals with 22q11DS who showed a decline in cognitive functioning also suffered from severe psychopathology, especially psychosis (see Chapter 2). We noticed that, besides a decline in intellectual functioning, some of the individuals with 22q11DS had functioned at moderate to profound levels of intellectual disability from a very young age (see Chapter 2). We decided, intentionally, to also include individuals with 22q11DS and moderate to profound intellectual disability in the research described in this thesis (FSIQ below 55). These individuals were mostly institutionalised in specialised centres for intellectual disabilities. Once institutionalised, these individuals seem to disappear from scientific attention. To gain knowledge on this subgroup of individuals with 22q11DS, our first step was to describe the observed cognitive deterioration, psychopathology, and behavioural features of individuals with 22q11DS, functioning at moderate to profound levels of intellectual disability (see Chapter 3). Subsequently, we investigated the potential pathological mechanisms underlying this intellectual decline (see Chapters 4, 5, and 6) in a larger group of individuals with 22q11DS, including those who functioned at or above a mild level of intellectual disability.

\section{Psychopathological Characteristics}

The study described in Chapter 3 is the first study investigating individuals with 22q11DS focussing on adults with moderate to profound intellectual disabilities. High scores in psychopathology and behavioural problems were demonstrated. We found higher proportions of psychopathology in the "deterioration" group compared to the "premorbid low IQ" group, but equally high scores for autism spectrum disorders for (ASD) in both groups. The high proportion of psychopathology 
is comparable with what has been reported to date in the overall 22q11DS population (Fung, Butcher, Costain, Andrade, Boot, Chow,... Bassett et al., 2015). Recently the International Consortium on Brain and Behavior in 22q11.2 Deletion Syndrome presented a study, including 1402 patients with 22q11DS (Schneider, Debbane, Bassett, Chow, Fung, van den Bree,... Eliez, 2014). The patients presented in this thesis were also included in this large sample. Psychopathology in 22q11DS can be very diverse (Bassett, Chow, Husted, Weksberg, Caluseriu, Webb \& Gatzoulis et al., 2005; Schneider et al., 2014) and can be divided in 4 symptom domains: attention-executive deficits, social-cognitive deficits, anxiety-affective dysregulation, and psychosis (Baker \& Vorstman, 2012).

\section{Attention-Executive Deficits}

We scored for attention problems using the ABCL/syndrome scale and for ADHD problems using the ABCL/DSM oriented scale. Mean scores for the "intellectual decline" group were 71 (clinical range) and 67 (borderline range). In the "stable low IQ" group, these scores were 65 (borderline range) and 62 (normal range). The differences in scores between the two groups were not significant. ADHD is frequently diagnosed in children with 22q11DS, but in studies in adulthood, it is often not assessed (Baker \& Vorstman, 2012), so comparison with other studies in adults is problematic. It is typical for ADHD that the prevalence in normally developing children is higher $(2.4 \%-19.8 \%)$ than in adults $(1 \%-6 \%$; Krause, Krause, Dresel, la Fougere, \& Ackenheil, 2006), as is also the case for 22q11DS (32.1\% vs. 16\%; Schneider et al., 2014). In Prader-Willi syndrome, ADHD-related problems were reported in up to $35 \%$ of patients (Kim, Yoo, Cho, Hong, \& Kim, 2005; Wigren \& Hansen, 2005), but these results were reported in children. Sinnema et al. (Sinnema, Boer, Collin, Maaskant, van Roozendaal, Schrander Stumpel, \& Curfs , 2011) mentioned no ADHD in a cohort of 102 adults with Prader-Willi. In Smith-Magenis syndrome, ADHD is reported in several case reports, but these all concern children (Gnanavel, 2014; Poisson, Nicolas, Sanlaville, Cochat, De Leersnyder, Rigard,... Demily, 2015). Also, Fragile-X syndrome (59\%), neurofibromatosis (63\%), tuberous sclerosis (30\%-60\%), Williams syndrome (63\%), Klinefelter syndrome (24\%), and Turner syndrome (69\%) are syndromes in which ADHD criteria are met (LoCastro, D'Agati, \& Curatolo, 2011), but the studies reported also included only children. Thus, ADHD symptoms investigated in other genetic syndromes are frequent, but these studies usually concern children. Thus, studies on adults are lacking, as are studies on other syndromes. 


\section{Social-Cognitive Deficits}

In the ABCL/syndrome scale, we scored for withdrawal behaviour, and these scores were within the clinical range for both groups (75 vs. 71) and not statistically different between the two groups. On the Mini PAS-ADD, the 22q11DS patients scored high for ASD symptoms, high on the $\mathrm{N}$ (social interaction) and $\mathrm{P}$ scales (communication problems), but low on the R scale (repetitive behaviour). Also, in these three autism score domains, we saw no significant differences between the two groups. The autistic symptoms we found were very high (up to 92\%), higher than those found in other studies of children with 22q11DS (44\%-50\%; Niklasson, Rasmussen, Oskarsdottir, \& Gillberg, 2009; Vorstman, Morcus, Duijff, Klaassen, Heineman-de Boer, Beemer,... van Engeland, 2006) or adults (16\%; Schneider et al., 2014). A possible explanation for the high prevalence of ASD symptomatology in our sample could be the fact that some ASD symptoms should be seen not as part of ASD but rather as the results of a psychotic process, as is reported in schizophrenia. Already in the early 20th century, Bleuler mentioned loosening of associations, disturbances of affectivity, ambivalence, and ASD as the main symptoms of schizophrenia (the four "A's"; Fusar, Poli, \& Politi, 2008). In ASD, we see particular impairments in theory of mind (Baron Cohen, Leslie, \& Frith, 1985), central coherence (Happe \& Frith, 2006), and executive functions (Verte, Geurts, Roeyers, Oosterlaan, \& Sergeant, 2006). Research in the field of schizophrenia, however, refers to comparable restrictions (Frith \& Corcoran, 1996; John \& Hemsley, 1992; Kerns, Nuechterlein, Braver, \& Barch, 2008; Pilowsky, Yirmiya, Arbelle, \& Mozes, 2000; Uhlhaas \& Silverstein, 2005). Thus, ASD is a common feature of 22q11DS, but also of other genetic syndromes. However, our findings indicate that ASD appears to be more frequent in adults with 22q11DS functioning at a moderate to profound level of intellectual disability than in the overall 22q11DS patient population.

ASD are often seen as a continuum. Moreno-De-Luca and colleagues (MorenoDe-Luca, Myers, Challman, Moreno-De-Luca, Evans \& Ledbetter, 2013) state that developmental disorders causing autism, even with different genetic causes, should be seen as a continuum called "developmental brain dysfunction." Indeed, ASD is highly frequent in other genetic syndromes including Rett syndrome, Fragile-X syndrome, Prader-Willi syndrome, Angelman syndrome, and Kabuki syndrome (Rangasamy, D’Mello, \& Narayanan, 2013), in which epigenetic phenomena are held responsible for the genetic causes. As Bruining et al. (Bruining, de Sonneville, Swaab, de Jonge, Kas, van Engeland \& Vorstman, 2010) stated, ASD occurring in genetic syndromes differs from idiopathic ASD, with substantially lower autistic variance in syndromic ASD than in idiopathic ASD. This is seen in Klinefelter syndrome, Down's syndrome, Prader-Willi syndrome, tuberous sclerosis (Bruining, Eijkemans, Kas, Curran, Vorstman, \& Bolton, 2014), and Fragile-X syndrome (Thurman, McDuffie, Hagerman, \& Abbeduto, 2014). Also, in our sample, we typi- 
cally see profiles in which repetitive behaviour is mostly absent. This suggests that ASD in 22q11DS also differs from idiopathic ASD. ASD in these syndromes has been described in both children and adults.

\section{Anxiety-Affective Dysregulation}

We observed significantly more depressive and anxiety symptoms on the Mini PAS-ADD in the decline group. Anxiety disorders and depressive disorders are highly prevalent across the life span in 22q11DS (30\% and $11.3 \%$ respectively), and the percentage of depressive disorders increases with increasing age (Schneider et al., 2014). In one study, depressive symptomatology seemed to decline after childhood into adolescent age, but anxiety remained high (Green, Gothelf, Glaser, Debbane, Frisch, Kotler,... Eliez, 2009). Fung et al. (Fung, McEvilly, Fong, Silversides, Chow, \& Bassett 2010) reported rates of anxiety disorders at $12.5 \%$ and of depression at $\mathbf{1 7 . 5 \%}$ in an adult cohort. In Fragile-X syndrome, besides ASD, social anxiety is present in up to $70 \%$ of the patients, and it can mimic ASD (Tonnsen, Malone, Hatton, \& Roberts, 2013). In Williams syndrome, anxiety is reported in $51 \%$ to $60 \%$ of patients, although this was researched in children (Dykens, 2003). In a longitudinal study from childhood to adolescence, $62 \%$ showed a chronic, persistent anxiety (Woodruff-Borden, Kistler, Henderson, Crawford, \& Mervis, 2010). Thus, anxiety and mood disorders also occur at high rates in other genetic syndromes.

\section{Psychosis}

Psychotic disorders are often diagnosed in 22q11DS, varying from 23\% to $43 \%$ (Antshel, Aneja, Strunge, Peebles, Fremont, Stallone,... Kates, 2007; Antshel, Shprintzen, Fremont, Higgins, Faraone, \& Kates, 2010; K. D. Baker \& Skuse, 2005; Fung et al., 2010; Gothelf, Frisch, Munitz, Rockah, Laufer, Mozes,... Frydman, 1999; Green et al., 2009; Murphy, Jones, \& Owen, 1999; Pulver, Nestadt, Goldberg, Shprintzen, Lamacz, Wolyniec,... et al., 1994; Shprintzen, Goldberg, Golding Kushner, \& Marion, 1992; Tang, Yi, Calkins, Whinna, Kohler, Souders,... Gur, 2014). Schneider et al. (2014) reported, in a large 22q11DS consortium cohort of adults over age 36 , rates of $41.7 \%$ for psychotic disorders. In our relatively small sample, we found high scores of psychosis in the intellectual decline group (95\%), but not in the premorbid low group $(15 \% ; p=.002)$. Several genetic syndromes are associated with higher rates of psychotic disorders. Klinefelter's syndrome is associated with psychotic disorders (Bruining, Swaab, Kas, \& van Engeland, 2009) and DeLisi et al. (DeLisi, Maurizio, Svetina, Ardekani,Szulc, Nierenberg,... Harvey, 2005) found in a study of 11 adults that 4 of them had a psychotic disorder. Also, Prader- 
Willi syndrome is associated with psychotic disorders. The risk of developing psychotic episodes depends on the genetic subtype (Sinnema et al., 2011; Boer, Holland, Whittington, Butler, Webb, \& Clarke, 2002; Soni, Whittington, Holland, Webb, Maina, Boer, \& Clarke, 2007; Vogels, Matthijs, Legius, Devriendt, \& Fryns, 2003). For instance, Sinnema et al. (2011) found psychotic symptoms in 31 out of 97 adult patients. Out of 53, 7 were diagnosed with psychosis in the deletion subtype group, and 24 out of 44 in the maternal uniparental disomy subgroup. The findings of psychotic episodes associated with the mUPD subtype of Prader-Willi syndrome were comparable with the prevalence of psychotic disorders in 22q11DS. Thus, $22 q 11 D S$ is not the only genetic syndrome associated with psychotic disorders, and the percentages of psychotic disorders in other syndromes can also be high. Psychopathology in genetic syndromes is thus not only very common in 22q11DS but also in many other genetic syndromes.

\section{Psychosis and Cognitive Decline in 22q11DS}

The phenomena of intellectual deterioration and psychosis in genetic syndromes is documented for many syndromes. In Prader-Willi Syndrome, there is some evidence that early-onset dementia is more common and that there is an association with long histories of psychosis (Sinnema, Schrander-Stumpel, Verheij, Meeuwsen, Maaskant, \& Curfs, 2010; Sinnema, Schrander-Stumpel, Maaskant, Boer, \& Curfs, 2012; Larson, Whittington, Webb, \& Holland, 2014; Whittington, Holland, \& Webb, 2015). However, the decline in most cases often begins from the age of 40 onwards (Sinnema et al., 2012), which seemed to be later than we observed in our study (see Chapter 3). In the cohort described in Chapter 3, the mean age of the patients showing a decline was 42 years (SD \pm 7 ). In one patient (also described as case report in Chapter 2), the decline started even before the age of 40 . Cognitive decline in children with 22q11DS has been investigated intensively over recent years (Duijff, Klaassen, de Veye, Beemer, Sinnema, \& Vorstman, 2012; Duijff, Klaassen, Swanenburg de Veye, Beemer, Sinnema, \& Vorstman, 2013; Vorstman, Breetvelt, Duijff, Eliez, Schneider, Jalbrzikowski,... Bassett, 2015). Other syndromes, including the chromosome $9 q$ subtelomore deletion syndrome also known as Kleefstra syndrome, are known to be associated with early-onset cognitive decline and psychosis symptoms (Kleefstra, van Zelst-Stams, Nillesen, Cormier-Daire, Houge, Foulds, van Dooren M.... Brunner HG., 2009; Stewart \& Kleefstra, 2007; Verhoeven, Egger, Vermeulen, van de Warrenburg, \& Kleefstra, 2011). The disruption of an EHMT1associated chromatin modification seems to play an important role in cognitive processes and in the aetiology of chromosome $9 q$ subtelomere deletion syndrome (Kleefstra,Kramer, Neveling, Willemsen, Koemans, Vissers,... van Bokhoven, 2012). The EHMT1 gene related to the core phenotype of Kleefstra syndrome seems also 
be associated with ASD (Balan, Iwayama, Maekawa, Toyota, Ohnishi, Toyoshima... Yoshikawa 2014).

A recent hallmark study of the International 22q11.2 Brain Behavior Syndrome Consortium (Vorstman et al., 2015) found a cognitive decline that precedes the onset of psychotic problems in a group of 829 children with 22q11DS. The relationship between psychosis and intellectual deterioration needs further research.

\section{Measuring Length of Deletion With the Research MLPA Kit P324 Gives Extra Information About Deletion Sizes}

The typical length of the 22q11.2 deletion is about $3 \mathrm{Mb}$ and occurs in $84 \%$ to $90 \%$ of patients. Seven to fourteen percent have an atypical proximally nested deletion of a size of approximately $1.5 \mathrm{Mb}$ (Rauch, Zink, Zweier, Thiel, Koch, Rauch \& Hofbeck, 2005). There is some debate as to whether the length of deletion influences the phenotype. Until today, no clear genotype-phenotype correlation has been found (Fernandez, Nevado, Santos, Heine Suner, Martinez Glez, Garcia Minaur,... Lapunzina , 2009), and identical alterations, even within members of the same family, show high phenotypic diversity and variable expressivity or incomplete penetrance (Fernandez, Lapunzina, Pajares, Criado, Garcia-Guereta, Perez \& Delicado 2005; McDonald-McGinn, Tonnesen, Laufer-Cahana, Finucane, Driscoll, Emanuel \& Zackai, 2001). Rauch et al. (2005) found, however, that patients with minor abnormalities were associated with shorter, atypical deletions, which were not detected in patients with mental retardation. They concluded that atypical deletions are very uncommon in patients with conotruncal congenital heart defects. As described in Chapter 4, we determined the length of deletion with Multiplex ligation-dependent probe amplification (MLPA) techniques, using two different MLPA kits. The results were not indicative that the size of deletion is related to variation in IQ or the presence of psychosis.

The use of an alternative research MLPA kit gave us extra information about the deletion sizes and location of the breakpoints. Therefore, it allowed us to delineate the deletion size more accurately and learn more about which genes are deleted in patients. For two individuals, it turned out to have a shorter deletion established with the alternative P324 kit, compared to the finding with the standard P250 kit. These two patients both function at a low intellectual level. From a research point of view it is better to use both the standard MLPA kit (P250) and the research MLPA kit (P324) for measuring the length of the 22q11.2 deletion. 


\section{Neurotransmitter Systems in 22q11DS Patients Seem to be Disrupted and are related to IQ Scores}

From a psychiatric view, 22q11DS is an interesting chromosomal disorder because of the highly frequent cognitive, behavioural, and psychiatric problems (Hiroi, Takahashi, Hishimoto, Izumi, Boku, \& Hiramoto, 2013; Jonas, Montojo, \& Bearden, 2014). From a neurochemical point of view, there are a number of genes of interest that are located on the 22q11.2 location.

\section{COMT and Dopamine}

One such gene of interest is the COMT gene coding for COMT, an enzyme involved in the degradation of dopamine (DA) and norepinephrine (NE), and located at 22q11.2. Subsequently, people with 22q11DS have a reduced gene dosage for COMT. Previously, it has been demonstrated that reduced COMT expression, reduced COMT enzyme activity (Gothelf, Law, Frisch, Chen, Zarchi, Michaelovsky,... Weinberger, 2014) and disrupted dopaminergic neurotransmission occurred in 22q11DS patients (Boot, Booij, Zinkstok, Abeling, de Haan, Baas,... van Amelsvoort, 2008; van Beveren, Krab, Swagemakers, Buitendijk, Boot, van der Spek,... van Amelsvoort, 2012). Thus, COMT hemizygosity in 22q11DS may have an effect on catecholamine levels. COMT is involved in different steps in the breakdown of DA (Figure 1).

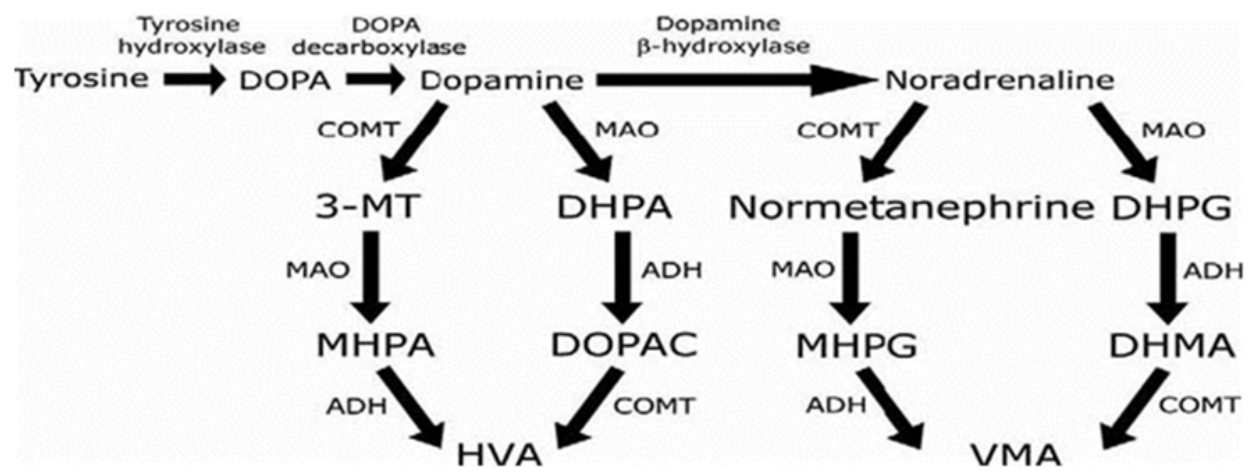

Figure 1. A schematic presentation of the different steps of the catecholamine pathway and involvement of COMT and other enzymes.

Logically, COMT hemizygosity could lead to elevated levels of DA, because the breakdown of DA is hindered due to reduced enzyme activity. This was demonstrated for 22q11DS subjects by Boot et al. (Boot et al., 2008). Aging itself is a factor that lowers dopamine functioning (Rollo, 2009). In Chapter 5, we demonstrated lower levels of homovanillic acid (HVA), a replication of earlier research by Boot et 
al. (2008), likely caused by COMT haplo-insufficiency resulting in reduced degradation of DA because of reduced enzyme activity.

\section{SEPT5 and Serotonin}

Comparing levels of neurotransmitters and their metabolites also revealed a significant difference of serotonin or 5-hydroxy-tryptamine (5-HT) in the 22q11DS subjects compared to healthy controls, with lower levels of 5-HT and HVA in 22q11DS. The reduction in 5-HT levels as described in Chapter 5 was an unexpected finding. There are no previous studies of 22q11DS patients that have addressed 5-HT. The psychiatric disorders occurring in 22q11DS are highly frequent and include, besides psychosis, mood disorders, anxiety disorders, and ASD Angkustsiri, Leckliter, Tartaglia, Beaton, Enriquez, \& Simon, 2012; Fung et al., 2010). Besides central serotonergic abnormalities, it is also assumed that central dopaminergic and noradrenergic abnormalities are thought to underlie mood disorders, anxiety disorders, and ASD (aan het Rot, Mathew, \& Charney, 2009; Drago, Crisafulli, Sidoti, \& Serretti, 2011). Also, medication used for treating these disorders often includes drugs targeting the 5-HT system (aan het Rot et al., 2009; Drago, Crisafulli, Sidoti, \& Serretti, 2011). There are at least two possible explanations for our finding of reduced 5-HT levels. One possible mechanism explaining reduced 5-HT in 22q11DS, could be related to a reduced gene dosage of SEPT5. The SEPT5 gene is located at 22q11 and codes for septin-5, a protein important for active membrane movement such as vesicle trafficking and exocytosis in nondividing cells such as platelets and neurons (Bartsch, Sandrock, Lanza, Nurden, Hainmann, Pavlova,... Zieger, 2011). Septin-5 is involved in 5-HT release in platelets (Dent, Kato, Peng, Martinez, Cattaneo, Poujol... Ware, 2002), and the majority of 5-HT in the body is transported by platelets (Anderson, Feibel, \& Cohen, 1987). Since low platelet counts are frequently observed in people with 22q11DS, (Latger-Cannard, Bensoussan, Gregoire, Marcon, Cloez, Leheup,.... Bordigoni , 2004; Saito, Ishikawa, Ito, \& Shimizu, 2004), this may indicate that the combination of reduced SEPT5 gene dosage and low platelet counts is related to the observed low 5-HT levels. Harper et al. (Harper, Hiramoto, Tanigaki, Kang, Suzuki, Trimble, \& Hiroi, 2012) and Suzuki et al. (Suzuki, Harper, Hiramoto, Sawamura, Lee, Kang,... Hiroi, 2009) suggest that SEPT5 deficiency is related to psychiatric disorders seen in 22q11DS. Another possible mechanism could be down regulation of the catalysing enzyme aromatic L-amino acid decarboxylase (AADC). AADC, also known as dopa decarboxylase (DDC), is involved in the last step before formation of DA, and it is also the catalysing enzyme involved in the last step before formation of 5-HT (Christenson, Dairman, \& Udenfriend, 1972). Down regulation of AADC owing to an assumed increased tonic DA activity might result in reduced DA synthesis over time. 
As described in Chapter 5, we found within the 22q11DS group a significant correlation between levels of 5-HT, DA, norepinephrine (NE, or noradrenaline), and vanillyl mandelic acid (VMA); the metabolite of VMA; and IQ scores. Those patients with lower IQ scores also had lower levels of the neurotransmitters we investigated. It is not clear why these neurotransmitters and their metabolites are related to IQ scores and what mechanisms underlie this relationship. All three neurotransmitters play an important role in normal brain function with regard to cognitive abilities, especially executive functioning (Barnes, Dean, Nandam, O'Connell, \& Bellgrove, 2011; Robbins \& Arnsten, 2009), learning, and cognitive flexibility (Kehagia, Murray, \& Robbins, 2010). In addition, there have been recent reports of early-onset Parkinson's disease, a progressive neurodegenerative disorder, in 22q11DS (Booij, van Amelsvoort, \& Boot, 2010; Zaleski, Bassett, Tam, Shugar, Chow, \& McPherson, 2009). It is becoming increasingly clear that, besides dopaminergic dysfunction, serotonergic abnormalities are responsible for mood and nonmotor symptoms that are frequently seen in Parkinson's disease (Butcher et al., 2013; Cole \& Siegel, 2003; Leentjens, van der Feltz Cornelis, Boenink, \& van Everdingen, 2008). In addition, the combined loss of dopaminergic and noradrenergic innervation of the limbic system is associated with cognitive and neurobehavioural problems (Delaville, Deurwaerdere, \& Benazzouz, 2011). Low 5-HT levels have been associated with low DA in the substantia nigra (Fahn, 2008; Huot, Fox, \& Brotchie, 2015) and might be related to high prevalence of psychopathology (Fernandez, 2012). Our results, described in Chapter 5, combined with the aforementioned studies suggest that a subgroup of adults with 22q11DS may be affected by a neurodegenerative process that may affect at least three neurotransmitter systems. Besides ample knowledge of their role in 22q11DS in general, the precise mechanism of the clinical deterioration as seen in 22q11DS has yet to be elucidated.

\section{PRODH and Proline}

Another gene of interest is the gene coding for proline dehydrogenase (PRODH), an enzyme responsible for the conversion of proline into glutamate. It is expected that hemizygosity of the PRODH gene, will give reduced PRODH enzyme activity and increased proline levels (Goodman, Rutberg, Lin, Pulver, \& Thomas, 2000; Magnee, Lamme, de Sain-van der Velden, Vorstman, \& Kemner, 2011; Raux, Bumsel, Hecketsweiler, van Amelsvoort, Zinkstok, Manouvrier-Hanu,... Campion, 2007). Indeed, in Chapter 6 we demonstrated for $31.3 \%$ of the 22q11DS patients a hyperprolinemia (proline 316-550 $\mu \mathrm{mol} / \mathrm{L}$ in female and 377-550 $\mu \mathrm{mol} / \mathrm{L}$ in male) as defined by Jacquet et al. (Jacquet, Demily, Houy, Hecketsweiler, Bou, Raux,... Campion, 2005). Six of the patients (9.4\%) even had severe hyperprolinemia, (proline > 550 $\mu \mathrm{mol} / \mathrm{L})$. Type 1 hyperprolinemia resulting from an inherited PRODH deficiency is a disease characterised by severe hyperprolinemia ( $>550 \mu \mathrm{mol} / \mathrm{l}$ ), seizures, intel- 
lectual disability, and psychiatric symptoms (Jacquet, Raux, Thibaut, Hecketsweiler, Houy, Demilly,... Frebourg, 2002). This finding is in accordance with earlier reports investigating proline in 22q11DS (Goodman et al., 2000; Raux et al., 2007; Vorstman, Turetsky, Sijmens-Morcus, de Sain, Dorland, Sprong,... Kemner, 2009) and is likely to be the result of hemizygosity of the PRODH. We were not able to show a relation of proline levels and psychosis or intelligence. Raux et al. (2007) reported a negative relation of proline and intelligence scores, and Jacquet et al. (2005) found that increased proline levels (plasma proline 350-550 $\mu \mathrm{mol} / \mathrm{l}$ ) could be a risk factor for schizo-affective disorders.

\section{PRODH and Glutamate}

The PRODH enzyme catalyses the conversion of proline to glutamate. Hemizygosity of PRODH can result in higher levels of proline, which we demonstrated as expected in Chapter 6 , in more than $30 \%$ of the patients. When hemizygosity hinders the formation of glutamate out of proline, it could be expected that this would lead to lower levels of glutamate. Since we did not include a control group, we were unable to demonstrate this. Our finding of increasing glutamate levels with increasing age is in contrast with findings in the normal population (Marsman, Mandl, van den Heuvel Boer, Wijnen, Klomp, Luijten \& Hilleke, 2013; Sailasuta, Ernst, \& Chang, 2008), in which an age-related decline in glutamate or no agerelated change normally exists. Therefore, a not-yet-understood mechanism could be responsible for this age-related rise in glutamate levels. Glutamate is converted from proline. Reduced PRODH activity, as is hypothesised in 22q11DS, resulted in an increase of glutamate release in PRODH-deficient mice (Paterlini, Zakharenko, Lai, Qin, Zhang, Mukai,... Gogos, 2005), which the authors explained by the activation of NMDA receptors by proline, where it acts as a co-agonist. Such a mechanism seems plausible and could explain high levels of glutamate in a subset of our 22q11DS sample. Glutamate is the principal excitatory neurotransmitter in the brain (Nedergaard, Takano, \& Hansen, 2002) and plays an important role in learning, memory (Cotman, Monaghan, \& Ganong, 1988), emotional regulation, and motivational behaviour (Mora \& Cobo, 1990).The finding that high glutamate levels are related to low IQ scores is interesting because high levels of glutamate are thought to be toxic (Lau \& Tymianski, 2010). Moreover, it is now hypothesised that aberrant glutamatergic neurotransmission via hypofunctional NMDA receptors leads to increased prefrontal glutamatergic activity in schizophrenia, possibly contributing to negative cognitive symptoms (Poels, Kegeles, Kantrowitz, Javitt, Lieberman, Abi Dargham, \& Girgis , 2014). We found that psychosis was related to intellectual deterioration and that low IQ scores were related to high peripheral levels of glutamate, so this supports a potentially aetiological role of glutamate for intellectual deterioration and psychosis. 
In other genetic disorders, neurotransmitters have also been investigated. Butler et al. (Butler, Murrell, \& Greene, 1990) conducted an amino-acid study on Prader-Willi syndrome. The focus of their study, however, was obesity, not psychiatry. They found a significantly lower level of glutamate compared to normal obese patients. More recently, a study was conducted on Prader-Willi syndrome, investigating skin picking and the influence of $\mathrm{N}$-acetylcysteïne (which is thought to act via modulation of NMDA glutamate receptors; Miller \& Angulo, 2014). All individuals improved after $\mathrm{N}$-acetylcysteïne was administered, with $71 \%$ recovering completely. Akefeld et al. (Akefeldt, Ekman, Gillberg, \& Mansson, (1998) investigated monoamines in cerebrospinal fluid in Prader-Willi syndrome and implied that there was a dysfunctional serotonergic system and possibly also a dysfunctional dopaminergic system. In that study, no relation with IQ could be established for serotonin or dopaminergic metabolites because of the small variation in IQ within the Prader-Willi syndrome group.

In Huntington's disease, dopamine has been investigated extensively. In neurochemical post-mortem studies, it turned out that in early-stage Huntington's disease, there is an increased dopamine neurotransmission with an increase of hyperkinetic movements, and in a later stage of Huntington's disease, there are dopamine deficits with hypokinetic movement as a result. The alterations in dopamine neurotransmission in turn influence the glutamate receptor modulation, which could contribute to excitotoxicity (Cepeda, Murphy, Parent, \& Levine, 2014). The dopaminergic abnormalities in Huntington's disease show some similarity with the 22q11DS subjects who have deteriorated. Boot et al. (2008) also found a higher dopamine level in 22q11DS subjects without psychiatric symptoms, whereas in our extended cohort of 22q11DS subjects (see Chapter 5), including those who had intellectually deteriorated, showed low dopamine levels. Cepeda et al. (2014) proposed that the modulatory function of dopamine is disrupted early in disease progression, which leads to secondary aberrant glutamatergic transmission and consequent excitotoxic cascades. A similar mechanism could also be responsible for the observed intellectual deterioration in 22q11DS patients.

The findings of low levels of dopamine, norepinephrine, and serotonin together with the high levels of glutamate related to IQ scores may lead to new hypotheses. A possible explanation could be that high glutamate levels interact with other neurotransmitter systems, making them vulnerable to its toxic effects with down regulation as a result. Another hypothesis could be that, initially, systems become overactive with high levels of dopamine, serotonin, and norepinephrine, which ultimately exhausts these systems, as is seen for serotonin in MDMA use (Parrot, 2013). Interactions of the neurotransmitters glutamate, dopamine, serotonin, and norepinephrine are complex, and it is not yet completely clear what the underlying mechanisms are. Neurotransmitters and their metabolites can have an inhibiting or augmenting effect on one another. It has been demonstrated, for example, that immune activation influences tryptophan degradation (serotonin is formed in this 
cascade), and these products influence glutamatergic, dopaminergic, and noradrenergic neurotransmission (Myint \& Kim, 2014).

\section{Strengths and Limitations}

\section{Limitations}

There are a number of limitations to this study. First, there is the problem of the representativeness of the participants. Though relatively unique, the group of patients is, from a methodological perspective, relatively small, especially the group studied in Chapter $3(\mathrm{n}=33)$. This group was extended with 34 individuals with 22q11DS for the studies described in Chapters 4, 5, and 6. The assessment tools used were not always tailored to individuals with moderate to profound intellectual disabilities. For instance, moderate to profound intellectual disability (IQ < 55) cannot be established accurately with Wechsler instruments. The amino acids were measured in plasma and the neurotransmitters in urine, which are indirect methods. Comparison with studies measuring directly in cerebrospinal fluid or with magnetic resonance spectroscopy is recommended.

\section{Strengths}

Most of the research on individuals with 22q11DS has been performed on children and adolescents (Schneider et al., 2014; Swillen, Devriendt, Legius, Eyskens, Dumoulin, Gewillig, Fryns, 1997; Swillen \& McDonald-McGinn, 2015; McDonaldMcGinn, 2015). The present thesis includes the first studies of adults with 22q11DS functioning at a moderate to profound level of intellectual disability. In addition to the 3322 q11DS patients with a moderate to profound level of intellectual disability, we included 34 22q11DS individuals functioning on a mild, borderline, or low-normal intellectual level. With this inclusion, a broad cognitive range of adults with 22q11DS is covered.

\section{Suggestions for Future Research}

Our research aimed at a specific group of individuals with 22q11DS, including adults functioning at a moderate to profound level of intellectual disability or demonstrating a cognitive decline during their developmental trajectory, which offers an interesting model to investigate gene, brain, and behaviour pathways and central neurotransmitter systems in the $22 \mathrm{q} 11.2$ region. This model to investigate genetic pathways and neurotransmitter systems warrants further studies. In addition to longitudinal studies aimed at the cognitive trajectories of children, adoles- 
cents, and adults with 22q11DS, more large-scale prospective studies focussed on psychopathology and neurochemistry are necessary. From a tailor-made treatment perspective, it is interesting to perform studies focussing on risk and protective factors in the environment and genotype-phenotype studies. More knowledge on psychiatric and behaviour problems will contribute to a better daily management of individuals with 22q11DS. Until now, the clinical approach that works best for 22q11DS individuals has not been sufficiently considered. 


\section{References}

aan het Rot, M., Mathew, S.J., \& Charney, D.S. (2009). Neurobiological mechanisms in major depressive disorder. CMAJ, 180(3), 305-313.

Akefeldt, A., Ekman, R., Gillberg, C., \& Mansson, J.E. (1998). Cerebrospinal fluid monoamines in PraderWilli syndrome. Biol Psychiatry, 44(12), 1321-1328.

Anderson, G.M., Feibel, F.C., \& Cohen, D.J. (1987). Determination of serotonin in whole blood, plateletrich plasma, platelet-poor plasma and plasma ultrafiltrate. Life Sci, 40(11), 1063-1070.

Angkustsiri, K., Leckliter, I., Tartaglia, N., Beaton, E.A., Enriquez, J., \& Simon, T.J. (2012). An examination of the relationship of anxiety and intelligence to adaptive functioning in children with chromosome 22q11.2 deletion syndrome. J Dev Behav Pediatr, 33(9), 713-720.

Antshel, K.M., Aneja, A., Strunge, L., Peebles, J., Fremont, W.P., Stallone, K., Abdulsabur N., Higgins A.M., Shprintzen R.J., \& Kates, W.R. (2007). Autistic spectrum disorders in velo-cardio facial syndrome (22q11.2 deletion). J Autism Dev Disord, 37(9), 1776-1786.

Antshel, K.M., Shprintzen, R., Fremont, W., Higgins, A.M., Faraone, S.V., \& Kates, W.R. (2010). Cognitive and psychiatric predictors to psychosis in velocardiofacial syndrome: a 3-year follow-up study. J Am Acad Child Adolesc Psychiatry, 49(4), 333-344.

Baker, K.D., \& Skuse, D.H. (2005). Adolescents and young adults with 22q11 deletion syndrome: psychopathology in an at-risk group. Br J Psychiatry, 186, 115-120.

Baker, K., \& Vorstman, J.A. (2012). Is there a core neuropsychiatric phenotype in 22q11.2 deletion syndrome? Curr Opin Neurol, 25(2), 131-137.

Balan S., Iwayama Y., Maekawa M., Toyota T., Ohnishi T., Toyoshima M., Shimamoto C., Esaki K., Yamada K., Iwata Y., Suzuki K., Ide M., Ota M., Fukuchi S., Tsujii M., Mori N., Shinkai Y., Yoshikawa T. (2014). Exon resequencing of H3K9 methyltransferase complex genes, EHMT1, EHTM2 and WIZ, in Japanese autism subjects. Mol Autism. Oct 6;5(1):49.

Barnes, J.J., Dean, A.J., Nandam, L.S., O'Connell, R.G., \& Bellgrove, M.A. (2011). The molecular genetics of executive function: role of monoamine system genes. Biol Psychiatry, 69(12), e127-143.

Baron Cohen, S., Leslie, A.M., \& Frith, U. (1985). Does the autistic child have a "theory of mind"? Cognition, 21(1), 37-46.

Bartsch, I., Sandrock, K., Lanza, F., Nurden, P., Hainmann, I., Pavlova, A., Greinacher A., Tacke U., Barth M., Busse A., Oldenburg J., Bommer M., Strahm B., Superti-Furga A.,\& Zieger, B. (2011). Deletion of human GP1BB and SEPT5 is associated with Bernard-Soulier syndrome, platelet secretion defect, polymicrogyria, and developmental delay. Thromb Haemost, 106(3), 475-483.

Bassett, A.S., Chow, E.W., Husted, J., Weksberg, R., Caluseriu, O., Webb, G.D., \& Gatzoulis, M.A. (2005). Clinical features of 78 adults with 22q11 Deletion Syndrome. Am J Med Genet A, 138(4), 307-313.

Boer H., Holland A., Whittington J., Butler J., Webb T., Clarke D. (2002). Psychotic illness in people with Prader Willi syndrome due to chromosome 15 maternal uniparental disomy. Lancet. 12;359(9301):135-6.

Booij, J., van Amelsvoort, T., \& Boot, E. (2010). Co-occurrence of early-onset Parkinson disease and 22q11.2 deletion syndrome: Potential role for dopamine transporter imaging. Am J Med Genet A, $152 A(11), 2937-2938$.

Boot, E., Booij, J., Zinkstok, J., Abeling, N., de Haan, L., Baas, F., Linszen, D. \& van Amelsvoort, T. (2008). Disrupted dopaminergic neurotransmission in 22q11 deletion syndrome. Neuropsychopharmacology, 33(6), 1252-1258.

Bruining, H., de Sonneville, L., Swaab, H., de Jonge, M., Kas, M., van Engeland, H., \& Vorstman, J. (2010). Dissecting the clinical heterogeneity of autism spectrum disorders through defined genotypes. PLoS One, 5(5), e10887.

Bruining, H., Eijkemans, M.J., Kas, M.J., Curran, S.R., Vorstman, J.A., \& Bolton, P.F. (2014). Behavioral signatures related to genetic disorders in autism. Molecular autism, 5(1), 11.

Bruining, H., Swaab, H., Kas, M.J.H., \& van Engeland, H. (2009). Psychiatric characteristics in a selfselected sample of boys with Kliunefelter syndrome. Pediatrics, 123(5), 865-870. 
Butcher, N.J., Kiehl, T.R., Hazrati, L.N., Chow, E.W., Rogaeva, E., Lang, A.E., \& Bassett, A.S. (2013). Association between early-onset Parkinson disease and 22q11.2 deletion syndrome: identification of a novel genetic form of Parkinson disease and its clinical implications. JAMA Neurol, 70(11), 13591366.

Butler, M.G., Murrell, J.E., \& Greene, H.L. (1990). Amino Acid Levels in Prader-Willi Syndrome and Obese Individuals. Dysmorphol Clin Genet, 4(1), 18-22.

Cepeda, C., Murphy, K.P., Parent, M., \& Levine, M.S. (2014). The role of dopamine in Huntington's disease. Prog Brain Res, 211, 235-254.

Christenson, J.G., Dairman, W., \& Udenfriend, S. (1972). On the identity of DOPA decarboxylase and 5hydroxytryptophan decarboxylase (immunological titration-aromatic L-amino acid decarboxylaseserotonin-dopamine-norepinephrine). Proc Natl Acad Sci U S A, 69(2), 343-347.

Cole, E., \& Siegel, J.A. (2003). Effective Consultation in School Psychology (Vol. 2nd rev). Toronto: Hogrefe \& Huber

Cotman, C.W., Monaghan, D.T., \& Ganong, A.H. (1988). Excitatory amino acid neurotransmission: NMDA receptors and Hebb-type synaptic plasticity. Annu Rev Neurosci, 11, 61-80.

Delaville, C., Deurwaerdere, P.D., \& Benazzouz, A. (2011). Noradrenaline and Parkinson's disease. Front Syst Neurosci, 5, 31.

DeLisi, L.E., Maurizio, A.M., Svetina, C., Ardekani, B., Szulc, K., Nierenberg, J., Leonard, J. \& Harvey, P.D. (2005). Klinefelter's syndrome (XXY) as a genetic model for psychotic disorders. Am J Med Genet B Neuropsychiatr Genet, 135B(1), 15-23.

Dent, J., Kato, K., Peng, X.R., Martinez, C., Cattaneo, M., Poujol, C., Nurden, P., Nurden, A., Trimble, W.S. \& Ware J (2002) A prototypic platelet septin and its participation in secretion. Proc Natl Acad Sci USA 99:3064-3069.

Drago, A., Crisafulli, C., Sidoti, A., \& Serretti, A. (2011). The molecular interaction between the glutamatergic, noradrenergic, dopaminergic and serotoninergic systems informs a detailed genetic perspective on depressive phenotypes. Prog Neurobiol, 94(4), 418-460.

Duijff, S.N., Klaassen, P.W., de Veye, H.F., Beemer, F.A., Sinnema, G., \& Vorstman, J.A. (2012). Cognitive development in children with 22q11.2 deletion syndrome. Br J Psychiatry, 200(6), 462-468.

Duijff, S.N., Klaassen, P.W., Swanenburg de Veye, H.F., Beemer, F.A., Sinnema, G., \& Vorstman, J.A. (2013). Cognitive and behavioral trajectories in 22q11DS from childhood into adolescence: a prospective 6year follow-up study. Res Dev Disabil., 34(9), 2937-2945.

Dykens, E.M. (2003). Anxiety, fears, and phobias in persons with Williams syndrome. Dev Neuropsychol, 23(1-2), 291-316.

Fahn, S. (2008). The history of dopamine and levodopa in the treatment of Parkinson's disease. Mov Disord, 23 Suppl 3, S497-508.

Fernandez, L., Lapunzina. P., Pajares, I.L., Criado, G.R., Garcia-Guereta, L., Perez, J., Quero, J. \& Delicado, A. (2005) Higher frequency of uncommon 1.5-2 Mb deletions found in familial cases of 22q11.2 deletion syndrome. Am J Med Genet A 136:71-75.

Fernandez, L., Nevado, J., Santos, F., Heine Suner, D., Martinez Glez, V., Garcia Minaur, S., Palomo, R., Delicado, A., Pajares, I.L., Palomares, M., Garcia Guereta, L., Valverde, E., Hawkins \& F., Lapunzina, P. (2009) A deletion and a duplication in distal 22q11.2 deletion syndrome region. Clinical implications and review. BMC Med Genet 2;10:48

Fernandez, H.H. (2012). Nonmotor complications of Parkinson disease. Cleve Clin J Med, 79 Suppl 2, S1418.

Frith, C.D., \& Corcoran, R. (1996). Exploring 'theory of mind' in people with schizophrenia. Psychol Med, 26(3), 521-530.

Fung, W.L., Butcher, N.J., Costain, G., Andrade, D.M., Boot, E., Chow, E.W., Chung, B., Cytrynbaum, C., Faghfoury, H., Fishman, L., García-Miñaúr, S., George, S., Lang, A.E., Repetto, G., Shugar, A., Silversides, C., Swillen, A., van Amelsvoort, T., McDonald-McGinn, D.M. \& Bassett, A.S. (2015). Practical guidelines for managing adults with 22q11.2 deletion syndrome. Genet Med, 17(8):599-609.

Fung, W.L., McEvilly, R., Fong, J., Silversides, C., Chow, E., \& Bassett, A. (2010). Elevated prevalence of generalized anxiety disorder in adults with 22q11.2 deletion syndrome. Am J Psychiatry, 167(8), 998. 
Fusar Poli, P., \& Politi, P. (2008). Paul Eugen Bleuler and the birth of schizophrenia (1908). Am J Psychiatry, 165(11), 1407.

Gnanavel, S. (2014). Smith-Magneis syndrome: behavioural phenotype mimics ADHD. BMJ Case Rep, 2014.

Goodman, B.K., Rutberg, J., Lin, W.W., Pulver, A.E., \& Thomas, G.H. (2000). Hyperprolinaemia in patients with deletion (22)(q11.2) syndrome. J Inherit Metab Dis, 23(8), 847-848.

Gothelf, D., Frisch, A., Munitz, H., Rockah, R., Laufer, N., Mozes, T., Hermesh H., Weizman A. \& Frydman, M. (1999). Clinical characteristics of schizophrenia associated with velo-cardio-facial syndrome. Schizophr Res, 35(2), 105-112.

Gothelf, D., Law, A.J., Frisch, A., Chen, J., Zarchi, O., Michaelovsky, E., Ren-Patterson R., Lipska B.K., Carmel M., Kolachana B., Weizman, A. \& Weinberger, D.R. (2014). Biological effects of COMT haplotypes and psychosis risk in 22q11.2 deletion syndrome. Biol Psychiatry, 75(5), 406-413.

Green, T., Gothelf, D., Glaser, B., Debbane, M., Frisch, A., Kotler, M., Weizman, A. \& Eliez, S. (2009). Psychiatric disorders and intellectual functioning throughout development in velocardiofacial (22q11.2 deletion) syndrome. J Am Acad Child Adolesc Psychiatry, 48(11), 1060-1068.

Happe, F., \& Frith, U. (2006). The weak coherence account: detail-focused cognitive style in autism spectrum disorders. J Autism Dev Disord, 36(1), 5-25.

Harper, K.M., Hiramoto, T., Tanigaki, K., Kang, G., Suzuki, G., Trimble, W., \& Hiroi, N. (2012). Alterations of social interaction through genetic and environmental manipulation of the 22q11.2 gene Sept 5 in the mouse brain. Hum Mol Genet, 21(15), 3489-3499.

Hiroi, N., Takahashi, T., Hishimoto, A., Izumi, T., Boku, S., \& Hiramoto, T. (2013). Copy number variation at 22q11.2: from rare variants to common mechanisms of developmental neuropsychiatric disorders. Mol Psychiatry, 18(11), 1153-1165.

Huot P., Fox S.H., Brotchie J.M. (2015). Monoamine reuptake inhibitors in Parkinson's disease. Parkinsons Dis, 60942,.

Jacquet, H., Demily, C., Houy, E., Hecketsweiler, B., Bou, J., Raux, G., Lerond J., Allio G., Haouzir S., Tillaux A., Bellegou C., Fouldrin G., Delamillieure P., Ménard J.F., Dollfus S., D'Amato T., Petit M., Thibaut F. \& Campion, D. (2005). Hyperprolinemia is a risk factor for schizoaffective disorder. Mol Psychiatry, 10(5), 479-485.

Jacquet, H., Raux, G., Thibaut, F., Hecketsweiler, B., Houy, E., Demilly, C., Haouzir S., Allio G., Fouldrin G., Drouin V., Bou J., Petit M., Campion D. \& Frebourg, T. (2002). PRODH mutations and hyperprolinemia in a subset of schizophrenic patients. Hum Mol Genet, 11(19), 2243-2249.

John, C.H., \& Hemsley, D.R. (1992). Gestalt perception in schizophrenia. Eur Arch Psychiatry Clin Neurosci, 241(4), 215-221.

Jonas, R.K., Montojo, C.A., \& Bearden, C.E. (2014). The 22q11.2 deletion syndrome as a window into complex neuropsychiatric disorders over the lifespan. Biol Psychiatry, 75(5), 351-360.

Kehagia, A.A., Murray, G.K., \& Robbins, T.W. (2010). Learning and cognitive flexibility: frontostriatal function and monoaminergic modulation. Curr Opin Neurobiol, 20(2), 199-204.

Kerns, J.G., Nuechterlein, K.H., Braver, T.S., \& Barch, D.M. (2008). Executive functioning component mechanisms and schizophrenia. Biol Psychiatry, 64(1), 26-33.

Kim, J.W., Yoo, H.J., Cho, S.C., Hong, K.E., \& Kim, B.N. (2005). Behavioral characteristics of Prader-Willi syndrome in Korea: comparison with children with mental retardation and normal controls. J Child Neurol, 20(2), 134-138.

Kleefstra, T., van Zelst-Stams, W.A., Nillesen, W.M., Cormier-Daire, V., Houge, G., Foulds, N., van Dooren, M., Willemsen, M.H., Pfundt, R., Turner, A., Wilson, M., McGaughran, J., Rauch, A., Zenker, M., Adam, M.P., Innes, M., Davies, C., López, A.G., Casalone, R., Weber, A., Brueton, L.A., Navarro, A.D., Bralo, M.P., Venselaar, H., Stegmann, S.P., Yntema, H.G., van Bokhoven, H., Brunner, H.G. (2009). Further clinical and molecular delineation of the 9q subtelomeric deletion syndrome supports a major contribution of EHMT1 haploinsufficiency to the core phenotype. J Med Genet. 46(9):598-606. 
Kleefstra, T., Kramer, J.M., Neveling, K., Willemsen, M.H., Koemans, T.S., Vissers, L.E., Wissink-Lindhout, W., Fenckova, M., van den Akker, W.M., Kasri, N.N., Nillesen, W.M., Prescott, T., Clark, R.D., Devriendt, K., van Reeuwijk, J., de Brouwer, A.P., Gilissen, C., Zhou, H., Brunner, H.G., Veltman, J.A., Schenck, A., van Bokhoven, H. (2012). Disruption of an EHMT1-associated chromatin-modification module causes intellectual disability. Am J Hum Genet. 13;91(1):73-82.

Krause, J., Krause, K.H., Dresel, S.H., la Fougere, C., \& Ackenheil, M. (2006). ADHD in adolescence and adulthood, with a special focus on the dopamine transporter and nicotine. Dialogues Clin Neurosci, $8(1), 29-36$.

Larson F.V., Whittington J., Webb T., Holland A.J. (2014). A longitudinal follow-up study of people with Prader-Willi syndrome with psychosis and those at increased risk of developing psychosis due to genetic subtype. Psychol Med. 44(11):2431-5.

Latger-Cannard, V., Bensoussan, D., Gregoire, M.J., Marcon, F., Cloez, J.L., Leheup, B., Jonveaux, P., Lecompte, T. \& Bordigoni, P. (2004). Frequency of thrombocytopenia and large platelets correlates neither with conotruncal cardiac anomalies nor immunological features in the chromosome 22q11.2 deletion syndrome. Eur J Pediatr, 163(6), 327-328.

Lau, A., \& Tymianski, M. (2010). Glutamate receptors, neurotoxicity and neurodegeneration. Pflugers Arch, 460(2), 525-542.

Leentjens, A.F., van der Feltz Cornelis, C.M., Boenink, A.D., \& van Everdingen, J.J. (2008). Richtlijn 'consultatieve psychiatrie' van de nederlandse vereniging voor psychiatrie voor consulten in de eerste lijn en in de ziekenhuissetting. Ned Tijdschr Geneeskd, 152(35), 1914-1917.

Lo-Castro, A., D'Agati, E., \& Curatolo, P. (2011). ADHD and genetic syndromes. Brain Dev, 33(6), 456461.

Magnee, M.J., Lamme, V.A., de Sain-van der Velden, M.G., Vorstman, J.A., \& Kemner, C. (2011). Proline and COMT status affect visual connectivity in children with 22q11.2 deletion syndrome. PLoS One, 6(10), e25882.

Marsman, A., Mandl, R.C., van den Heuvel, M.P., Boer, V.O., Wijnen, J.P., Klomp, D.W., Luijten, P.R. \& Hilleke, E.H. (2013). Glutamate changes in healthy young adulthood. Eur Neuropsychopharmacol, 23(11), 1484-1490.

McDonald-McGinn, D.M., Tonnesen, M.K., Laufer-Cahana, A., Finucane, B., Driscoll, D.A., Emanuel, B.S., Zackai, E.H. (2001) Phenotype of the 22q11.2 deletion in individuals identified through an affected relative: cast a wide FISHing net! Genet Med 3:23-29.

Miller, J.L., \& Angulo, M. (2014). An open-label pilot study of N-acetylcysteine for skin-picking in PraderWilli syndrome. Am J Med Genet A, 164a(2), 421-424.

Mora, F., \& Cobo, M. (1990). The neurobiological basis of prefrontal cortex self-stimulation: a review and an integrative hypothesis. Prog Brain Res, 85, 419-431.

Moreno-De-Luca, A., Myers, S.M., Challman, T.D., Moreno-De-Luca, D., Evans, D.W., Ledbetter, D.H.(2013) Developmental brain dysfunction: revival and expansion of old concepts based on new genetic evidence. Lancet Neurol 12(4):406-14.

Murphy, K.C., Jones, L.A., \& Owen, M.J. (1999). High rates of schizophrenia in adults with velo-cardiofacial syndrome. Arch Gen Psychiatry, 56(10), 940-945.

Myint, A.M., \& Kim, Y.K. (2014). Network beyond IDO in psychiatric disorders: revisiting neurodegeneration hypothesis. Prog Neuropsychopharmacol Biol Psychiatry, 48, 304-313.

Nedergaard, M., Takano, T., \& Hansen, A.J. (2002). Beyond the role of glutamate as a neurotransmitter. Nat Rev Neurosci, 3(9), 748-755.

Niklasson, L., Rasmussen, P., Oskarsdottir, S., \& Gillberg, C. (2009). Autism, ADHD, mental retardation and behavior problems in 100 individuals with 22q11 deletion syndrome. Res Dev Disabil., 30(4), 763-773.

Parrot, A.C. (2013). MDMA, serotonergic neurotoxicity, and the diverse functional deficits of recreational 'Ecstasy' users. Neurosci Biobehav Rev, 37(8):1466-84.

Paterlini, M., Zakharenko, S.S., Lai, W.S., Qin, J., Zhang, H., Mukai, J., Westphal, K.G., Olivier, B., Sulzer, D., Pavlidis, P., Siegelbaum, S.A., Karayiorgou, M. \& Gogos, J.A. (2005). Transcriptional and behavioral interaction between 22q11.2 orthologs modulates schizophrenia-related phenotypes in mice. Nat Neurosci, 8(11), 1586-1594. 
Pilowsky, T., Yirmiya, N., Arbelle, S., \& Mozes, T. (2000). Theory of mind abilities of children with schizophrenia, children with autism, and normally developing children. Schizophr Res, 42(2), 145-155.

Poels, E.M., Kegeles, L.S., Kantrowitz, J.T., Javitt, D.C., Lieberman, J.A., Abi Dargham, A., \& Girgis, R.R. (2014). Glutamatergic abnormalities in schizophrenia: a review of proton MRS findings. Schizophr Res, 152(2-3), 325-332.

Poisson, A., Nicolas, A., Sanlaville, D., Cochat, P., De Leersnyder, H., Rigard, C., Franco, P., des Portes, V., Edery, P.\& Demily, C. (2015). Le syndrome de Smith-Magenis, une association unique de troubles du comportement et du cycle veille/sommeil. Arch Pediatr, 22(6), 638-645.

Pulver, A. E., Nestadt, G., Goldberg, R., Shprintzen, R. J., Lamacz, M., Wolyniec, P.S., Morrow, B., Karayiorgou, M., Antonarakis, S.E. \& Housman, D. (1994). Psychotic illness in patients diagnosed with velocardio-facial syndrome and their relatives. J Nerv Ment Dis, 182(8), 476-478.

Rangasamy, S., D'Mello, S.R. \& Narayanan, V. (2013). Epigenetics, autism spectrum, and neurodevelopmental disorders. Neurotherapeutics, 10(4), 742-756.

Rauch A., Zink S., Zweier C., Thiel C.T., Koch A., Rauch R., Lascorz J., Huffmeier U., Weyand M., Singer H. \& Hofbeck M. (2005) Systematic assessment of atypical deletions reveals genotype-phenotype correlation in 22q11.2. J Med Genet 42:871-876.

Raux, G., Bumsel, E., Hecketsweiler, B., van Amelsvoort, T., Zinkstok, J., Manouvrier-Hanu, S., Fantini, C., Brévière, G.M., Di Rosa, G., Pustorino, G., Vogels, A., Swillen, A., Legallic, S., Bou, J., Opolczynski, G., Drouin-Garraud, V., Lemarchand, M., Philip, N., Gérard-Desplanches, A., Carlier, M., Philippe, A., Nolen, M.C., Heron, D., Sarda, P., Lacombe, D., Coizet, C., Alembik, Y., Layet, V., Afenjar, A., Hannequin, D., Demily, C., Petit, M., Thibaut, F., Frebourg, T.\& Campion, D. (2007). Involvement of hyperprolinemia in cognitive and psychiatric features of the 22q11 deletion syndrome. Hum Mol Genet, 16(1), 83-91.

Robbins, T.W., \& Arnsten, A.F. (2009). The neuropsychopharmacology of fronto-executive function: monoaminergic modulation. Annu Rev Neurosci, 32, 267-287.

Rollo, C.D. (2009). Dopamine and aging: intersecting facets. Neurochem Res, 34(4), 601-629.

Sailasuta, N., Ernst, T., \& Chang, L. (2008). Regional variations and the effects of age and gender on glutamate concentrations in the human brain. Magn Reson Imaging, 26(5), 667-675.

Saito, M., Ishikawa, T., Ito, Y., \& Shimizu, H. (2004). Hematological abnormalities in a patient with a 22q11.2 deletion. Brain Dev, 26(5), 342-344.

Schneider, M., Debbane, M., Bassett, A.S., Chow, E.W., Fung, W.L., van den Bree, M., Owen, M., Murphy, K.C., Niarchou, M., Kates, W.R., Antshel, K.M., Fremont, W., McDonald-McGinn, D.M., Gur, R.E., Zackai, E.H., Vorstman, J., Duijff, S.N., Klaassen, P.W., Swillen, A., Gothelf, D., Green, T., Weizman, A., Van Amelsvoort, T., Evers, L., Boot, E., Shashi, V., Hooper, S.R., Bearden, C.E., Jalbrzikowski, M., Armando, M., Vicari, S., Murphy, D.G., Ousley, O., Campbell, L.E., Simon, T.J., Eliez, S.; International Consortium on Brain and Behavior in 22q11.2 Deletion Syndrome. (2014). Psychiatric disorders from childhood to adulthood in 22q11.2 deletion syndrome: results from the International Consortium on Brain and Behavior in 22q11.2 Deletion Syndrome. Am J Psychiatry, 171(6), 627-639.

Shprintzen, R.J., Goldberg, R., Golding Kushner, K.J., \& Marion, R.W. (1992). Late-onset psychosis in the velo-cardio-facial syndrome. Am J Med Genet, 42(1), 141-142.

Sinnema M., Schrander-Stumpel C.T., Verheij H.E., Meeuwsen M., Maaskant M.A., Curfs L.M. (2010). Dementia in a woman with Prader-Willi syndrome. Eur J Med Genet. 53(3):145-8.

Sinnema, M., Boer, H., Collin, P., Maaskant, M.A., van Roozendaal, K.E., Schrander Stumpel, C.T., \& Curfs, L.M. (2011). Psychiatric illness in a cohort of adults with Prader-Willi syndrome. Res Dev Disabil, 32(5), 1729-1735.

Sinnema, M., Schrander Stumpel, C.T., Maaskant, M.A., Boer, H., \& Curfs, L.M. (2012). Aging in PraderWilli syndrome: twelve persons over the age of 50 years. Am J Med Genet A, 158a(6), 1326-1336.

Soni S., Whittington J., Holland A.J., Webb T., Maina E., Boer H., Clarke D. (2007). The course and outcome of psychiatric illness in people with Prader-Willi syndrome: implications for management and treatment. J Intellect Disabil Res.51(Pt 1):32-42.

Stewart D.R., Kleefstra T. (2007).The chromosome 9q subtelomere deletion syndrome. Am J Med Genet C Semin Med Genet. 15;145C(4):383-92. 
Suzuki, G., Harper, K. M., Hiramoto, T., Sawamura, T., Lee, M., Kang, G., Tanigaki, K., Buell, M., Geyer, M.A., Trimble, W.S., Agatsuma, S. \& Hiroi, N. (2009). Sept5 deficiency exerts pleiotropic influence on affective behaviors and cognitive functions in mice. Hum Mol Genet, 18(9), 1652-1660.

Swillen A., Devriendt K., Legius E., Eyskens B., Dumoulin M., Gewillig M., Fryns J.P. (1997). Intelligence and psychosocial adjustment in velocardiofacial syndrome: a study of 37 children and adolescents with VCFS. J Med Genet. 34(6):453-8.

Swillen A, McDonald-McGinn D. (2015) Developmental trajectories in 22q11.2 deletion. Am J Med Genet C Semin Med Genet.169(2):172-81.

Tang, S.X., Yi, J.J., Calkins, M.E., Whinna, D.A., Kohler, C.G., Souders, M.C., McDonald-McGinn, D.M., Zackai, E.H., Emanuel, B.S., Gur, R.C.\& Gur, R.E. (2014). Psychiatric disorders in 22q11.2 deletion syndrome are prevalent but undertreated. Psychological medicine, 44(6), 1267-1277.

Thurman, A.J., McDuffie, A., Hagerman, R., \& Abbeduto, L. (2014). Psychiatric symptoms in boys with fragile X syndrome: a comparison with nonsyndromic autism spectrum disorder. Res Dev Disabil, 35(5), 1072-1086.

Tonnsen, B.L., Malone, P.S., Hatton, D.D., \& Roberts, J.E. (2013). Early negative affect predicts anxiety, not autism, in preschool boys with fragile X syndrome. J Abnorm Child Psychol, 41(2), 267-280.

Uhlhaas, P.J., \& Silverstein, S.M. (2005). Perceptual organization in schizophrenia spectrum disorders: empirical research and theoretical implications. Psychol Bull, 131(4), 618-632.

van Beveren, N.J., Krab, L.C., Swagemakers, S., Buitendijk, G.H., Boot, E., van der Spek, P., Elgersma, Y.,\& van Amelsvoort, T.A. (2012). Functional gene-expression analysis shows involvement of schizophrenia-relevant pathways in patients with 22q11 deletion syndrome. PLoS One, 7(3), e33473.

Verhoeven, W.M., Egger, J., Vermeulen, K., van de Warrenburg, B.P. \& Kleefstra T. (2011). Kleefstra syndrome in three adult patients: further delineation of the behavioral and neurological phenotype shows aspects of a neurodegenerative course. Am J Med Genet A. 155A(10):2409-15.

Verte, S., Geurts, H.M., Roeyers, H., Oosterlaan, J., \& Sergeant, J.A. (2006). Executive functioning in children with an Autism Spectrum Disorder: can we differentiate within the spectrum? J Autism Dev Disord, 36(3), 351-372.

Vogels A., Matthijs G., Legius E., Devriendt K., Fryns J.P. (2003) Chromosome 15 maternal uniparental disomy and psychosis in Prader-Willi syndrome. J Med Genet, 40(1):72-3.

Vorstman, J.A., Breetvelt, E.J., Duijff, S.N., Eliez, S., Schneider, M., Jalbrzikowski, M., Armando, M., Vicari, S., Shashi, V., Hooper, S.R., Chow, E.W., Fung, W.L., Butcher, N.J., Young, D.A., McDonald-McGinn, D.M., Vogels, A., van Amelsvoort, T., Gothelf, D., Weinberger, R., Weizman, A., Klaassen, P.W., Koops, S., Kates, W.R., Antshel, K.M., Simon, T.J., Ousley, O.Y., Swillen, A., Gur, R.E., Bearden, C.E., Kahn, R.S., Bassett, A.S.; International Consortium on Brain and Behavior in 22q11.2 Deletion Syndrome. (2015). Cognitive Decline Preceding the Onset of Psychosis in Patients With 22q11.2 Deletion Syndrome. JAMA Psychiatry. 72(4):377-85.

Vorstman, J.A., Morcus, M.E., Duijff, S.N., Klaassen, P.W., Heineman-de Boer, J.A., Beemer, F.A., Swaab, H., Kahn, R.S. \& van Engeland, H. (2006). The 22q11.2 deletion in children: high rate of autistic disorders and early onset of psychotic symptoms. J Am Acad Child Adolesc Psychiatry, 45(9), 1104-1113.

Vorstman, J.A., Turetsky, B.I., Sijmens-Morcus, M.E., de Sain, M.G., Dorland, B., Sprong, M., Rappaport, E.F., Beemer, F.A., Emanuel, B.S., Kahn, R.S., van Engeland H \& Kemner, C. (2009). Proline affects brain function in 22q11DS children with the low activity COMT 158 allele. Neuropsychopharmacology. 34(3):739-46.

Wigren, M., \& Hansen, S. (2005). ADHD symptoms and insistence on sameness in Prader-Willi syndrome. J Intellect Disabil Res, 49(Pt 6), 449-456.

Whittington J.E., Holland A.J., Webb T. (2015) Ageing in people with Prader-Willi syndrome: mortality in the UK population cohort and morbidity in an older sample of adults. Psychol Med, 45(3):615-21.

Woodruff-Borden, J., Kistler, D. J., Henderson, D.R., Crawford, N.A., \& Mervis, C.B. (2010). Longitudinal course of anxiety in children and adolescents with Williams syndrome. Am J Med Genet C Semin Med Genet, 154C(2), 277-290.

Zaleski, C., Bassett, A.S., Tam, K., Shugar, A.L., Chow, E.W., \& McPherson, E. (2009). The co-occurrence of early onset Parkinson disease and 22q11.2 deletion syndrome. Am J Med Genet A, 149A(3), 525-528. 

SUMMARY 



\section{Summary}

The aim of this doctoral dissertation is to contribute to a better understanding and improvement of our knowledge about the 22q11.2 deletion syndrome (22q11DS). We investigated a specific subgroup of this syndrome for which information about phenotype and pathways was lacking.

\section{Chapter 1}

In this introductory chapter, we provide information on the history, genetic background, and physical and psychiatric characteristics of 22q11DS. Furthermore, we discuss associated cognitive problems and introduce the rationale and methods employed in this thesis. The overall goal of this thesis is to offer more knowledge on the phenomenon of intellectual decline in 22q11DS patients and which factors can contribute to it.

\section{Chapter 2}

This chapter consists of two case studies. The first article describes a clinical case which was actually the inspiration of the studies performed and described in this thesis. The patient described presents a congenital palatal defect and other typical 22q11DS symptoms, autistic features, and an overall deteriorating process. The second article in this chapter describes a case series in which we report seven patients who all function at a level of moderate to profound intellectual disability, as a result of an intellectual decline or because they have always functioned at that level.

\section{Chapter 3}

In this chapter, we describe the behavioural and psychiatric characteristics of 33 adults with 22q11DS and a Full-Scale IQ (FSIQ) below 55. Participants were divided into two groups: one group with FSIQ $\leq 55$, including people who previously functioned at a significantly higher intellectual level $(n=21)$, and one group with FSIQ $\leq 55$, including people who had always functioned at this level $(n=12)$. High scores on psychopathology subscales were found for both subgroups. Patients with intellectual decline showed higher rates of comorbid psychopathology, particularly psychosis. Furthermore, psychosis and intellectual decline were positively correlated. This is the first report addressing adult patients with 22q11DS and moderate to severe intellectual deterioration. Overall, we found high levels of psychopathol- 
ogy, with higher scores of psychopathology in the intellectual decline group. Lifetime psychosis seemed to be related to deterioration.

\section{Chapter 4}

In this chapter, we investigated whether the length of the deletion was related to observed intellectual level and psychotic symptomatology during life. We used two different MLPA kits and compared the results using the two different methods.

\section{Chapter 5}

Here, we analysed peripheral levels of serotonergic, dopaminergic, and noradrenergic markers in 67 adults with 22q11DS. Levels of serotonin and the catecholamine metabolite homovanillic acid were significantly lower in the 22q11DS subjects compared to healthy controls. Within the 22q11DS group, levels of dopamine, homovanillic acid, norepinephrine, vanillyl mandelic acid, and serotonin positively correlated with FSIQ scores. Our results suggest that cognitive deficits in 22q11DS are associated with abnormal function of several neurotransmitters.

\section{Chapter 6}

The relation between plasma proline, glutamate, and glutamine and age, intelligence, and psychosis in 64 adults with 22q11DS was investigated in this chapter. Hyperprolinaemia was found in $31.3 \%$ of subjects with 22 q11DS. A relation between glutamine, glutamate, proline, and presence of psychosis was not observed. Regression analysis revealed a positive relation between plasma glutamate and age, a positive relation between glutamate and antipsychotic drugs, a relation between glutamine and gender, a positive relation between glutamine and moodstabilising drugs, and a negative relation between the glutamine-glutamate ratio and age. The group with relatively lower IQ had higher glutamate levels compared to the group with relatively higher IQ. Our results suggest that 22q11DS is accompanied by abnormalities in glutamatergic metabolism. Future longitudinal studies are needed to further investigate the glutamatergic system in 22q11DS and how this affects the development of cognitive problems and psychopathology. 


\section{Chapter 7}

The overall goal of the studies described in this thesis was to provide more knowledge on the phenomenon of intellectual decline in 22q11DS and the factors that can contribute to it. We conclude that psychopathology is common in 22q11DS patients who function at a moderate to severe level of intellectual disability, and that psychosis is related to intellectual decline. Furthermore, we have demonstrated abnormal functioning of neurotransmitters and amino acids, and this is especially related to intellectual function. These findings are placed in a broader perspective and are compared with earlier findings in the literature. We discuss further potential practical implications. We also identify the strengths and limitations of this thesis. Finally, we provide directions for future research. 

SAMENVATTING 



\section{Nederlandse samenvatting}

Het doel van dit proefschrift is om bij te dragen tot een beter begrip en verbetering van onze kennis over het 22q11.2 deletie syndroom (22q11DS). We onderzochten een specifieke subgroep van dit syndroom waarvan informatie rondom het fenotype en de pathologische mechanismen ontbreekt.

\section{Hoofdstuk 1}

In dit inleidende hoofdstuk geven we informatie over het 22q11DS. Aan bod komen de geschiedenis, de genetische achtergrond, fysieke en psychische kenmerken en de bijbehorende cognitieve problemen. De rationale en de methodes die we in dit proefschrift gehanteerd hebben worden besproken. De algemene doelstelling van dit proefschrift is om meer kennis op te doen rondom het fenomeen intellectuele achteruitgang bij het 22q11DS en welke factoren hieraan kunnen bijdragen.

\section{Hoofdstuk 2}

Dit hoofdstuk bestaat uit twee case studies. Het eerste artikel beschrijft een casus, welke in feite de inspiratie was van de onderzoeken beschreven in dit proefschrift. De beschreven patiënt was bekend met een aangeboren gehemelteafwijking (verspleten verhemelte) en andere typische 22q11DS kenmerken, autistische kenmerken en een algemene cognitieve achteruitgang. Het tweede deel in dit hoofdstuk beschrijft een reeks patiënten die allen functioneren op een laag niveau (matig tot zeer ernstig verstandelijke beperkt) ten gevolge van een achteruitgang, of omdat zij altijd op dat lage niveau gefunctioneerd hebben.

\section{Hoofdstuk 3}

In dit hoofdstuk beschrijven we gedrags- en psychiatrische kenmerken van 33 volwassenen met het 22q11DS en een totaal IQ onder 55. De deelnemers werden verdeeld in twee groepen: een groep met een IQ $\leq 55$, waarvan de mensen voorheen op een beduidend hoger intellectueel niveau functioneerden $(n=21)$ en één groep met een IQ $\leq 55$, waarvan de mensen altijd al op dit niveau hadden gefunctioneerd $(n=12)$. We vonden hoge scores op psychopathologie sub-schalen voor beide subgroepen. 22q11DS patiënten met een verstandelijke achteruitgang vertoonden veel co-morbide psychopathologie, met name psychoses. Psychose en het intellectuele verval waren positief met elkaar gecorreleerd. Dit is het eerst verschenen onderzoek dat volwassen patiënten met het 22q11DS en een matige tot 
ernstige verstandelijke beperking beschrijft. In het algemeen zagen we dat veel patiënten psychopathologie vertoonden waarbij patiënten uit de intellectuele achteruitgang groep meer psychopathologie lieten zien. Of patiënten gedurende hun leven psychotisch waren geweest leek samen te hangen met de geobserveerde achteruitgang.

\section{Hoofdstuk 4}

In dit hoofdstuk onderzochten we of de lengte van de deletie was gerelateerd aan het intellectuele niveau en psychotische symptomatologie gedurende het leven. Twee verschillende MLPA kits werden gebruikt en de gevonden resultaten met behulp van deze van deze twee verschillende methoden vergeleken.

\section{Hoofdstuk 5}

Hier analyseerden we perifere spiegels van serotonerge, dopaminerge en noradrenerge markers bij 67 volwassenen met het 22q11DS. De spiegels van serotonine en de catecholamine metaboliet homovanillinezuur waren significant lager in de 22q11DS proefpersonen vergeleken met gezonde controles. Binnen de 22q11DS groep, waren de spiegels van dopamine, homovanillinezuur, norepinefrine, vanillyl amandelzuur en serotonine positief gecorreleerd met het totale IQ. Deze resultaten suggereren dat cognitieve gebreken bij het 22q11DS geassocieerd zijn met abnormale functie van verscheidene neurotransmitters.

\section{Hoofdstuk 6}

Het onderzoek naar de relatie tussen plasma spiegels van proline, glutamaat en glutamine en leeftijd, intelligentie en psychose bij 64 volwassenen met het 22q11DS wordt in dit hoofdstuk gepresenteerd. Hyperprolinemie werd gevonden bij 31,3\% van de proefpersonen met het 22q11DS. Een relatie tussen glutamine, glutamaat, proline, en de aanwezigheid van psychose werd niet aangetoond . Regressie-analyse liet een positieve relatie zien tussen de plasma spiegels van glutamaat en leeftijd, een positieve relatie van glutamaat met antipsychotica, een relatie van glutamine en geslacht, en een positieve relatie tussen glutamine en stemming stabilisatoren, en een negatieve relatie van de verhouding glutamine/glutamaat en leeftijd. De groep met een relatief lager IQ hadden hogere niveaus glutamaat in vergelijking met de groep met een relatief hogere IQ. Onze resultaten suggereren dat 22q11DS gepaard gaat met afwijkingen in het glutamaterge metabolisme. Het is van belang in de nabije toekomst op basis van longitudinale studies het glutama- 
terge systeem bij 22q11DS patiënten en de invloed hiervan op de ontwikkeling van cognitieve problemen en psychopathologie verder te onderzoeken.

\section{Hoofdstuk 7}

Het algemene doel van de in dit proefschrift beschreven onderzoeken was om meer kennis te vergaren rondom het fenomeen intellectuele achteruitgang bij het 22q11DS en welke factoren hieraan kunnen bijdragen. We concludeerden dat psychopathologie vaak voor komt bij mensen met 22q11DS, die op een laag intellectueel niveau functioneerden en dat psychose gerelateerd is aan intellectuele achteruitgang. Bovendien constateerden we een abnormale werking van neurotransmitters en aminozuren. Deze bevindingen werden in een breder perspectief geplaatst en vergeleken met eerdere bevindingen uit de literatuur. Tot slot komen sterke en zwakke punten en van dit proefschrift aan de orde met aansluitend enkele suggesties voor toekomstig onderzoek. 

Valorisation 



\section{Addendum Valorisation}

I met Philip* in a facility for people with intellectually disabilities. At that moment, he was a man in his late forties and he functioned at a severely disabled level. I learned that he formerly had lived for years in a psychiatric indoor clinic because of a treatment-resistant psychosis. Also, it became clear to me that during his childhood, he suffered from a cleft palate (which was corrected surgically). When studying his medical records, I saw that during adolescence, he functioned at an intellectual level (IQ) of 80, and when I assessed him, he nearly reached an IQ of 20. Because of several symptoms, we thought it would be wise to do a genetic check-up, and he turned out to have a deletion on 22q11.2. The intellectual deterioration that he suffered was dramatic and, in the literature, never described. When discussing this with colleagues, who also worked with patients with an ID, I learned that they recognized this phenomenon. This was the beginning of the research leading up to this thesis.

We decided to focus on the 22q11.2 deletion syndrome (22q11DS) patients with a moderate-to-severe intellectual disability (IQ below 55). In the 22q11DS literature, it was said that these patients were rare. Within a year, we included in the Netherlands 33 patients with an IQ below 55. During this time, we came in contact with parents and family members of these 22q11DS patients, and many of them told us that nobody could tell them about what to expect in adulthood, how to treat and cope with the problems they suffered.

$22 q 11 D S$ is the most common microdeletion syndrome and occurs in about 1:2000 people (Shprintzen, 2008) and, recently, Grati et al. (2015) reported an incidence of 1:992 in a cohort of over 9500 pregnancies. Based on the first figure $(1: 2000)$ it is seen as a rare disorder (a disorder affecting fewer than 1 in 2000 (http://www.eurordis.org/about-rare-diseases), but the findings of Grati et al. (2015) suggest that 1:2000 is an underestimation and it no longer should be seen as a rare disorder. There has been a lot of research about several topics in this syndrome, and the majority of it is done in children, adolescents and young adults. Our knowledge is focused on these ages, but how symptoms evolve in adulthood is less known. The phenomenon deterioration in 22q11DS is neglected in literature and therefore not known by laypeople, and even by many professionals. The findings of the research described in this thesis will be very valuable for parents and professionals, especially concerning what to expect during life (prognosis).

Based on the number of births in the Netherlands in 2012 (173.000 newborns in 2012, source: http://www.nationaalkompas.nl/bevolking/geboorte/huidig), there would be an annual rate of about 80-90 newborns with this syndrome. Based on the Dutch inhabitants (16,8 miljon), and the 1:2000 assumption, there would live 
over 8000 patients with the 22q11 deletion syndrome in the Netherlands. With the latest findings of Grati et al. (2015), these numbers could be doubled. Of all 22q11DS patients, about one third will suffer from psychosis, especially schizophrenia. Those who suffer from chronic psychotic symptoms (most of the time, this will be diagnosed with the term "schizophrenia") are the ones who are (probably very) vulnerable to a deterioration process. This is accompanied by personal suffering and often with a lot of desperation in the family, but also for professionals. Naturally, this also expresses the costs needed for the care of such patients.

Knowledge of the phenomenon deterioration and its psychopathological mechanisms can give us clues for possible treatment options. If new strategies are found, they can prevent a lot of suffering in patients and their families. Another aspect is that aforementioned knowledge can give clues for the treatment of other psychiatric disorders. If strategies (pharmaceutical or other strategies) are helpful in 22q11DS patients, it is in our opinion useful to investigate these strategies in other psychiatric disorders; for instance, schizophrenia or anxiety and mood disorders (both occur commonly in 22q11DS).

The reported research in this thesis are first steps towards a better understanding of people alive today with 22q11DS and designing appropriate healthcare for people suffering from this condition.

*This case is anonymized

\section{References}

Grati, F. R., Molina Gomes, D., Ferreira, J. C., Dupont, C., Alesi, V., Gouas, L., . . Vialard, F. (2015). Prevalence of recurrent pathogenic microdeletions and microduplications in over 9,500 pregnancies. Prenatal diagnosis. 35(8):801-9.

Shprintzen, R. J. (2008). Velo-cardio-facial syndrome: 30 Years of study. Dev Disabil Res Rev, 14(1), 3-10. 
Dankwoord 



\section{Dankwoord}

De uitspraak dat 'het doen van een promotieonderzoek iets is wat je niet alleen doet' geldt zeker voor mij. Ik ben daarom aan velen dank verschuldigd. Het is lastig om iedereen te noemen, dus bij voorbaat mijn excuses aan diegene die ik in dit dankwoord vergeet. Graag wil ik in het algemeen iedereen bedanken voor de complimenten, aanmoedigingen, adviezen en allerlei andere manieren van ondersteuning. Uiteraard zijn er wel een paar mensen die ik in het bijzonder wil bedanken.

Allereerst ben ik veel dank verschuldigd aan de deelnemers van dit onderzoek, hun familieleden, vertegenwoordigers, begeleiders en betrokken deskundigen. Zonder jullie had dit onderzoek nooit plaats kunnen vinden.

In het bijzonder dank ik mijn promotoren: professor Curfs en professor van Amelsvoort. Beste Leopold, dank voor het vertrouwen dat je altijd in mij hebt gehouden en de peptalks die nodig waren om weer aan de gang te gaan. Je was vanaf het begin enthousiast toen ik bij je langs kwam om de promotiemogelijkheden te bekijken en bracht me in contact met de internationale wetenschap met betrekking tot 'behavioural phenotype's '(SSBP). Sindsdien bezoek ik jaarlijks deze internationale congressen. Therese, zonder jou was het onderzoek in zijn huidige vorm nooit definitief van start gegaan. In eerste instantie als copromotor, maar nadat je je verdiende hoogleraarsstoel kreeg, als tweede promotor. Je hebt me geënthousiasmeerd aangaande het 22q11-onderzoek en veel richting aan het onderzoek gegeven. Ook je niet aflatende, supersnelle reacties op weer een versie die ik bij je indiende, maakte dat ik door kon gaan (waarbij ook je correcties op mijn Engels erg welkom waren). Met name je sublieme kennis op het gebied van 22q11 was voor mij onmisbaar.

De leden van de beoordelingscommissie, professor Connie Stumpel, professor Rudolph Ponds, professor Ann Swillen en dr. Jacob Vorstman wil ik bedanken voor het beoordelen van dit proefschrift en voor de bereidheid om te opponeren. Ook de overige leden van de corona, dr. Maarten Bak en professor Jacques Scheres, wil ik danken voor hun bereidheid om te opponeren.

Het protocol dat de basis van dit onderzoek vormde (juli 2009), werd begeleid door een studiegroep waar Jaap, Jörgen, Bert, Jean-Pierre, Irene, Jim en Connie onderdeel van waren. De groep werd ondersteund door Bert en Erik. Joep stond als hoofd van klinische genetica garant. Allen hartelijk dank hiervoor. In het begin van mijn promotietraject heb ik veel hulp gehad van mede-promovendi, waarbij ik met name Nicky en Margje wil bedanken.

Ook de verdere leden van mijn begeleidingsteam en de mede-auteurs van de verschenen artikelen, ben ik zeer erkentelijk voor hun hulp. Bij dit promotieonderzoek heb ik veel zaken aangesneden waarbij mijn kennis evidente hiaten kende. Jullie hebben me geholpen om deze gaten te dichten. Jaap, je hebt me enorm goed geholpen met de logistiek van het praktische gedeelte en de ontvangst van mij en het materiaal. Je analyses van de aminozuren waren al beroemd en ik kon 
gelukkig voortborduren op deze kennis. Helaas (voor mij) heb je op een zeker moment tijdens mijn promotietraject besloten om de overstap naar Leiden te maken. Desalniettemin kon ik steeds rekenen op je steun en waardevolle reacties op de neurotransmitterartikelen. Nico, gezeteld in Amsterdam, ik heb gebruik mogen maken van je uitgebreide metabole expertise en je analyses aangaande dopamine, serotonine en hun metabolieten; waarvoor veel dank. Veel dank ben ik ook verontschuldigd aan Math en Marjan, die me bij verschillende trajecten door het statistische -voor mij ondoordringbare- woud geholpen hebben. John, we kennen elkaar al jaren. We hebben elkaar leren kennen aan het begin van mijn geneeskundestudie, toen ik stage op de afdeling genetica liep. Het was dan ook een groot genoegen om weer met jou samen te werken aan een tweetal artikelen en gebruik te maken van je moleculair genetische expertise. Erik, jouw onderzoek was als het ware een onderlegger voor dat van mij. Dat heeft mij erg geholpen en ook je bijdragen waren van hoog niveau en zeer nuttig. Verder wil ik Michiel, Christine, Erik, Mariet, Nieke, Fabiana, Mariken en Harm danken voor hun bijdragen aan de verschenen artikelen. Jullie zienswijzen waren heel belangrijk. Jörgen, bedankt dat je me alle hulp geboden hebt die ik met betrekking tot het metabole lab nodig had. De algehele afdeling genetica wil ik bedanken voor de goede ontvangst. In het bijzonder wil ik professor Smeets, Bert, bedanken voor de verschillende keren dat je meedacht hoe je een bijdrage kon leveren. Het zit nog in de pen om een keer een DNA-artikel te schrijven, dus wellicht komt het toch nog tot een samenwerking.

Verder is het erg inspirerend om in Nederland deel te nemen aan het 22q11onderzoek. Vanuit Utrecht worden met name de kinderen in kaart gebracht en het contact met onder andere Jacob, Sasja en Petra heb ik altijd heel prettig gevonden. Dank jullie wel.

Ook aan Koraal Groep - de organisatie waar ik als psychiater werkzaam ben ben ik veel dank verschuldigd. Chrik Diemel heeft destijds de mogelijkheden voor een promotietraject geplaveid en zijn opvolgers, Hank van Geffen en Radboud Quik, hebben mij hier altijd in gesteund. Heel veel dank daarvoor. Ook wil ik Ben bedanken voor de geboden ondersteuning.

Mijn collegae bij het MFCG - mijn team - Gerlie, Nathalie, Marco, Sebastiaan en Ley wil ik ook graag bedanken. Veel dank dat jullie er waren en zijn als fijne collega's. Arno, jij hebt me vaak goed geholpen op momenten dat ik je expertise nodig had. Het feit dat jij ook aan het promoveren bent, maakte dat ik me niet zo alleen voelde. Ook dank aan mijn collegae van de vakgroep psychiatrie: Inge, Jacques, Maurice, Ramses, Therese, Marien en Mauk. Philippe, dank voor je gezelschap tijdens onze jaarlijkse SSBP-trips en wellicht pak je je oude promotie-aspiraties nog een keer op.

Mijn paranimfen, Hugo en Martin, hartelijk dank dat jullie direct toegezegd hebben om me te steunen. Ook dank ik mijn familie, die soms met verbazing moesten aanhoren waar ik mee bezig was. Dank jullie wel. Jammer dat pap en Toon dit niet met ons kunnen delen. 
Last but not least, ben ik uiteraard het thuisfront heel erg veel dank verontschuldigd. Lieve Leanne, je hebt nogal wat gemopper van mij moeten aanhoren, maar klagen deed je daarover nooit. Ik weet dat je af en toe gedacht moet hebben 'waar is hij toch mee bezig', maar je hebt het me nooit verweten. Tim, Jules en Jop, jullie hebben - als ik weer iets moest afmaken - jullie vader soms moeten missen. Maar dat hoop ik snel goed te kunnen maken. Ik vind het erg fijn dat Leanne en Jules zorg hebben gedragen voor de omslag, dank jullie wel. 

Curriculum Vitae 



\section{Curriculum Vitae}

Rens Evers werd geboren op 25 maart 1961 in het Brabantse Budel in een arbeidersgezin. Na de lagere school volgde hij de MAVO in Budel en na een korte periode op de laboratoriumschool gezeten te hebben start hij in 1979 de opleiding tot Zverpleegkundige bij stichting Daelzicht, welke hij in 1982 afrond. Daarna werkt hij als Z-verpleegkundige binnen de stichting Daelzicht te Heel. In 1985 besluit hij om verder te studeren aan de sociale academie te Eindhoven (richting inrichtingswerk) welke opleiding in 1989 afgerond wordt. Het studeren bevalt goed, maar de richting wordt gewijzigd in geneeskunde, welke opleiding in 1989 gestart wordt aan de universiteit in Maastricht. In 1995 wordt het basisartsendiploma gehaald. Tot die tijd werkte hij nog part time binnen stichting Daelzicht als Z-verpleegkundige. Vanuit de ervaring in het werken met verstandelijk gehandicapten is zijn eerste plan om klinische genetica als specialisatie te gaan doen, maar na het coschap psychiatrie weet hij dat het psychiatrie moet worden. Na eerst anderhalf jaar als AGNIO in de verslavingszorg gewerkt te hebben mag hij in 1997 de opleiding binnen het destijdse Welterhof te Heerlen gaan doen onder leiding van Peter van Harten en later Joost à Campo. Het laatste gedeelte van de opleiding wordt ingevuld bij de RIAGG te Roermond (tegenwoordig MetGGZ) onder psychiater Leo Vanmolkot. In die periode ontstaan er al contacten om het verleden met het heden te laten samensmelten en op uitnodiging van Hank van Geffen van st. Anna (tegenwoordig onderdeel van de Koraalgroep) zet hij het MFCG mee op. Na de afronding van zijn opleiding psychiatrie (2001) gaat hij aan de slag als psychiater deels bij het MFCG en deels als (sociaal) psychiater bij de RIAGG in Roermond (o.a. bij het autismeteam en de bemoeizorg). In 2007 maakt hij helemaal de overstap naar het MFCG. Samen met Leopold Curfs werden mogelijkheden voor het doen van onderzoek naar het 22q11 deletie syndroom onderzocht wat onder meer leidde tot de 2 artikelen in het introductiehoofdstuk. Het onderzoek naar het 22q11 deletie syndroom kwam echt in een stroomversnelling nadat Rens in contact kwam met Therese van Amelsvoort, in eerste instantie als co-promotor , maar later als mede promotor. Dit proefschrift is mede daarvan het resultaat.

Rens is getrouwd met Leanne en samen hebben ze drie zoons: Tim (19 jaar), Jules (17 jaar) en Jop (9 jaar). 



\section{List of publications}

\section{Journal articles}

Evers L.J., Schrander-Stumpel C.T., Engelen J.J., Mulder H., Borghgraef M., Fryns J.P. (1993). Terminal deletion of long arm of chromosome 4: patient report and literature review. Genet Couns, 4, 139-145.

Evers L.J., Schrander-Stumpel C.T., Engelen J.J., Hoorntje T.M., Pulles Heintzberger C.F., Schrander J.J., Albrechts J.C., Peters J., Fryns J.P. (1996). Deletion of the long arm of chromosome 6: two new patients and literature review. Clin Genet, 50:138-144.

Evers L.J.M., Steyaert J.G.P.L.E., (1996). Het velocardiofaciaal (Shprintzen-) syndroom; een element in de ontrafeling van de pathogenese van schizofrenie? Ned Tijdschr Geneeskd, 140:1702-3.

Evers L.J., Vermaak M.P., Engelen J.J., Curfs L.M. (2006). The velocardiofacial syndrome in older age: dementia and autistic features. Genet Couns, 17, 333-340.

Evers L.J., De Die-Smulders C.E., Smeets E.E., Clerkx M.G., Curfs L.M. (2009). The velo-cardio-facial syndrome: the spectrum of psychiatric problems and cognitive deterioration at adult age. Genet Couns, 20, 307-315.

Evers L.J., van Amelsvoort T.A., Candel M.J., Boer H., Engelen J.J., Curfs L.M. (2014). Psychopathology in adults with 22q11 deletion syndrome and moderate and severe intellectual disability. J Intellect Disabil Res, 58, 915-925.

Evers L.J., Curfs L.M., Bakker J.A., Boot E., da Silva Alves F., Abeling N., Bierau J., Drukker M., van Amelsvoort T.A. (2014). Serotonergic, noradrenergic and dopaminergic markers are related to cognitive function in adults with $22 \mathrm{q} 11$ deletion syndrome. Int J Neuropsychopharmacol, 17, 1159-1165.

Schneider, M., Debbane, M., Bassett, A. S., Chow, E. W., Fung, W. L., van den Bree, M., Owen, M., Murphy, K. C., Niarchou, M., Kates, W. R., Antshel, K. M., Fremont, W., McDonald-McGinn, D. M., Gur, R. E., Zackai, E. H., Vorstman, J., Duijff, S. N., Klaassen, P. W., Swillen, A., Gothelf, D., Green, T., Weizman, A., Van Amelsvoort, T., Evers, L., Boot, E., Shashi, V., Hooper, S. R., Bearden, C. E., Jalbrzikowski, M., Armando, M., Vicari, S., Murphy, D. G., Ousley, O., Campbell, L. E., Simon, T. J., Eliez, S. (2014). Psychiatric disorders from childhood to adulthood in 22q11.2 deletion syndrome: results from the International Consortium on Brain and Behavior in 22q11.2 Deletion Syndrome. Am J Psychiatry. 171, 627-639.

Evers, L.J.M., van Amelsvoort, A.M.J., Bakker, J.A., de Koning, M.B., Drukker, M., Curfs, L.M.G. (2015). Glutamatergic markers, age, intellectual functioning and psychosis in 22q11 deletion syndrome. Psychopharmacology, 232(18), 331925.

Evers, R, van Amelsvoort, T. Reactie op 'Minocycline bij schizofrenie: een beknopt overzicht' (letter to the editor). Tijdschr Psychiatr, 56 (2014) 8, 561 - 562 


\section{Book chapters}

Rens Evers. (2004) Psychiatrische zorg aan mensen met een verstandelijke handicap. Vademecum zorg voor verstandelijk gehandicapten: 1500-1 - 1500-12. 


\subsection{6}

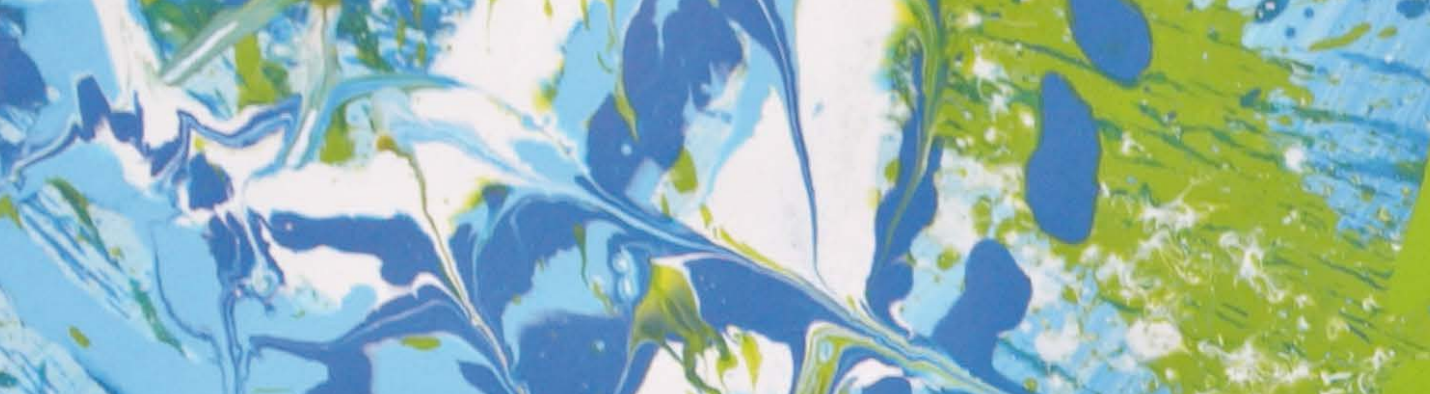

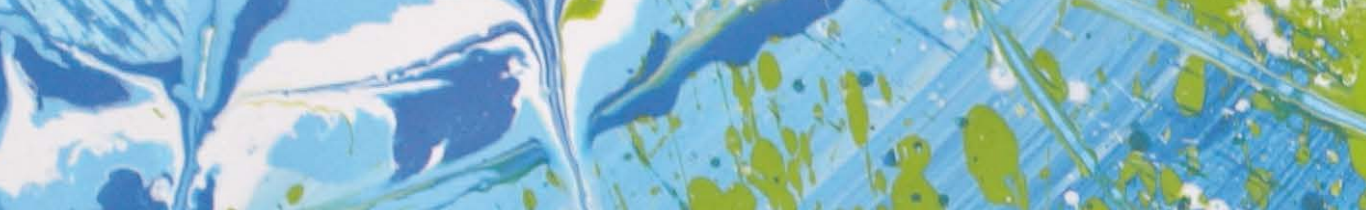

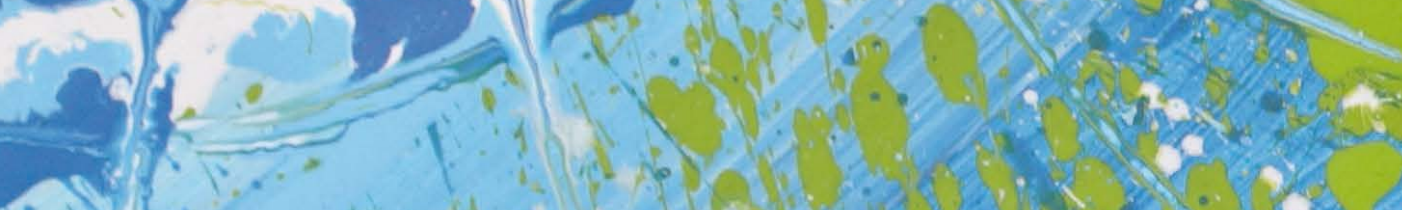

toy $+1,2$ $\therefore$ $\frac{1}{16}$

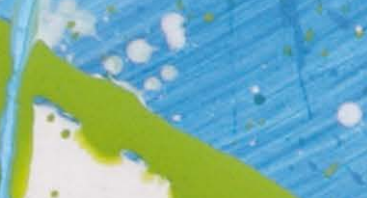

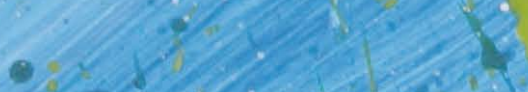
8 $-4)^{2}$
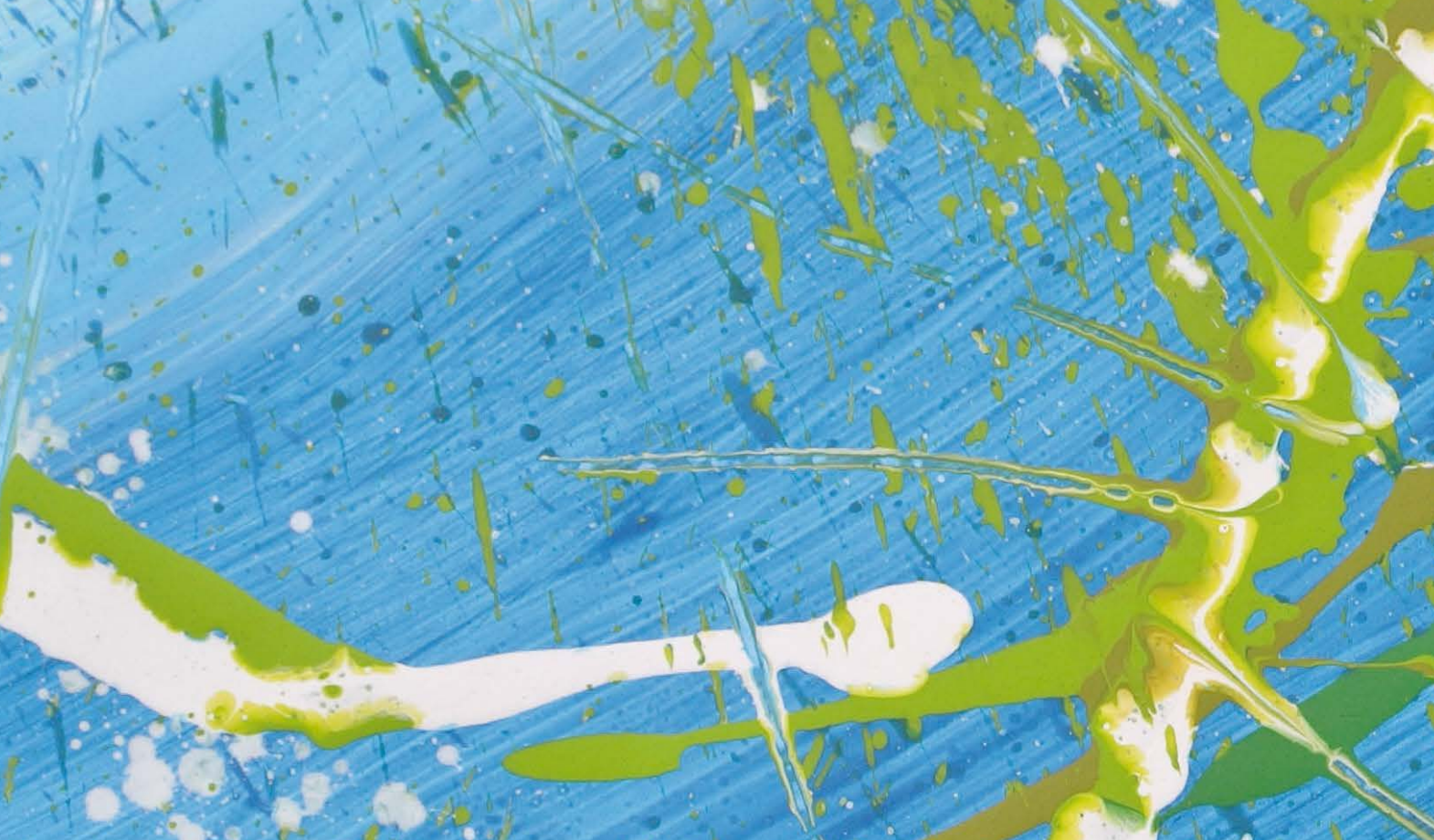
10.90 $\div$ i.

1. -2

$x+5$ ?

(.).

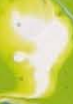

82

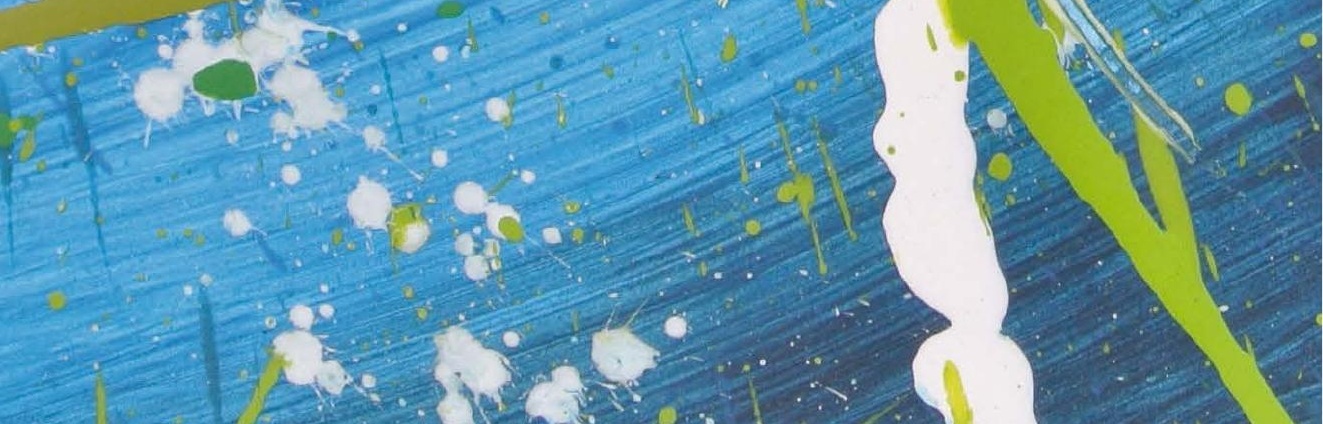

